\title{
Kasai: The Forgotten Province of DRC Gender Assessment
}

October-November 2017

Iulia Andreea Toma, Gender Adviser, Humanitarian Support Personnel

OXFAM

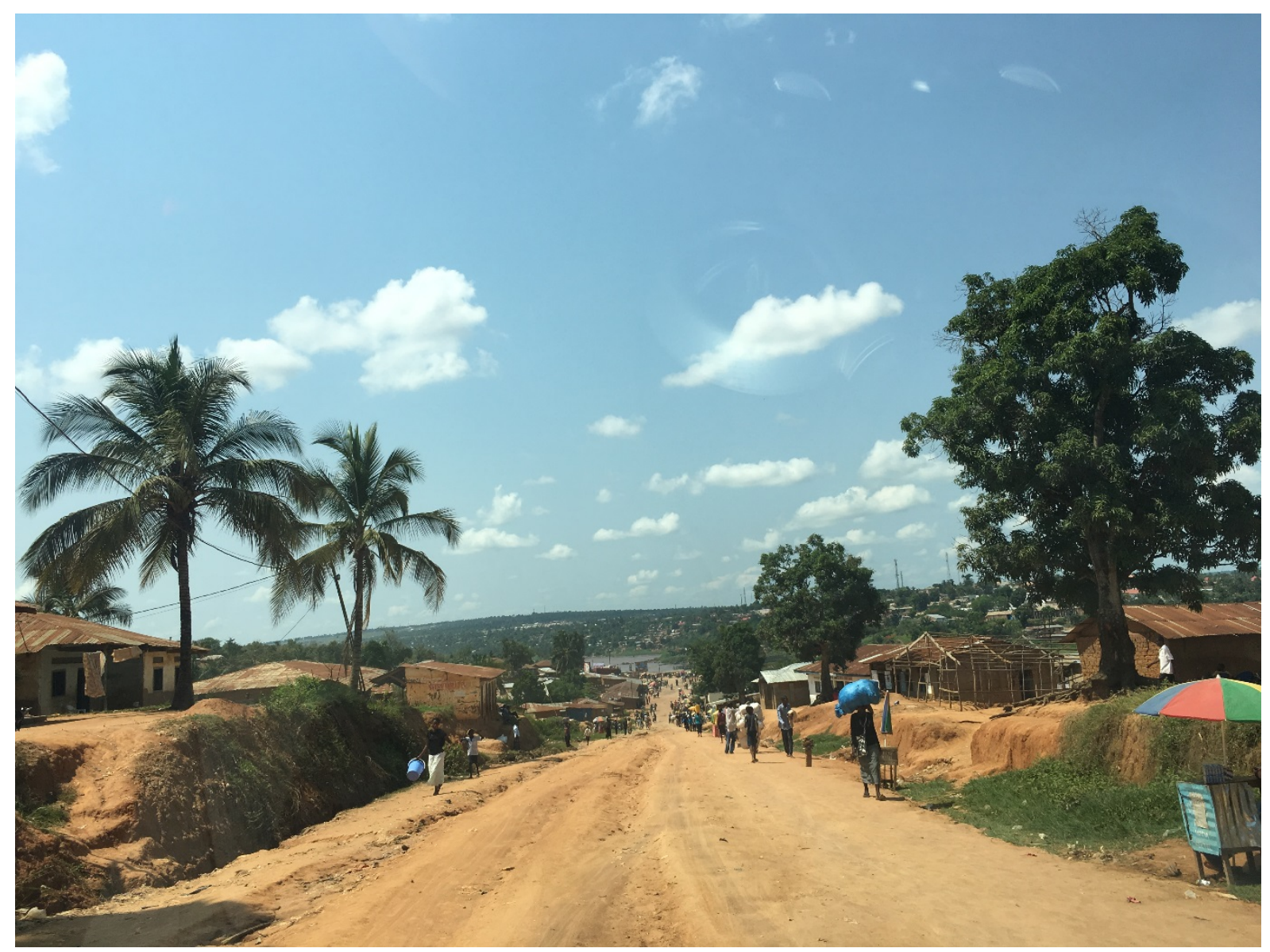

View from a hill in Tshikapa. Photo: Iulia Toma 


\section{Oxfam Research Reports}

Oxfam Research Reports are written to share research results, to contribute to public debate and to invite feedback on development and humanitarian policy and practice. They do not necessarily reflect Oxfam policy positions. The views expressed are those of the author and not necessarily those of Oxfam.

For more information, or to comment on this report, email lulia Andreea Toma (iulia.toma(doxfam.org).

(C) Oxfam International February 2018

This publication is copyright but the text may be used free of charge for the purposes of advocacy, campaigning, education, and research, provided that the source is acknowledged in full. The copyright holder requests that all such use be registered with them for impact assessment purposes.

For copying in any other circumstances, or for re-use in other publications, or for translation or adaptation, permission must be secured and a fee may be charged.

Email policyandpractice@oxfam.org.uk.

The information in this publication is correct at the time of going to press.

Published by Oxfam GB for Oxfam International under ISBN 978-1-78748-166-4 in February 2018. DOl: 10.21201/2017.1657

\section{OXFAM}

Oxfam is an international confederation of 20 organizations networked together in more than 90 countries, as part of a global movement for change, to build a future free from the injustice of poverty. Please write to any of the agencies for further information, or visit www.oxfam.org. 


\section{Contents}

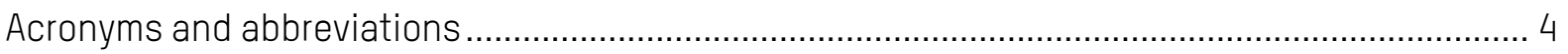

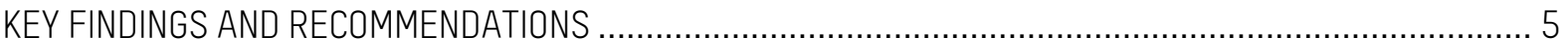

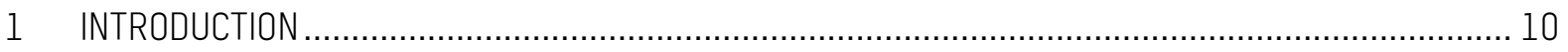

Democratic Republic of Congo: country profile and gender inequality ....................................... 10

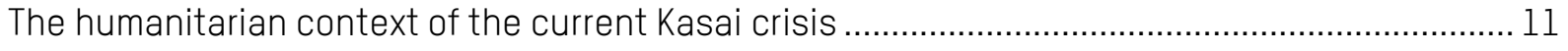

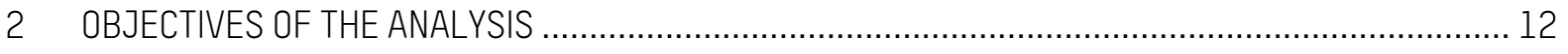

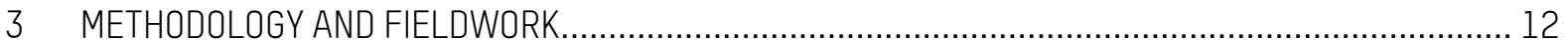

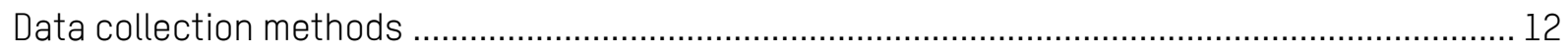

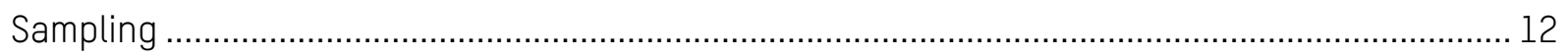

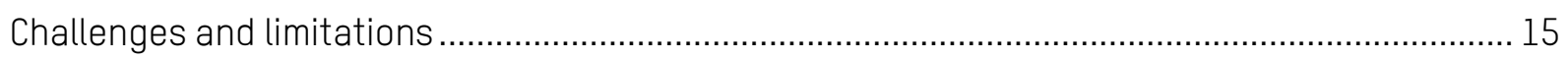

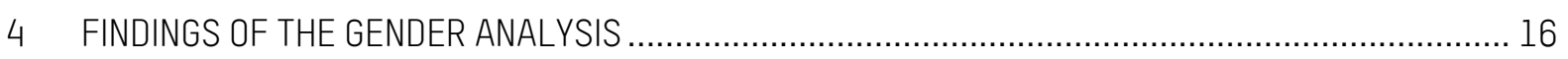

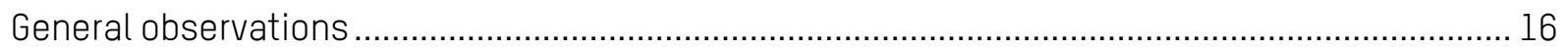

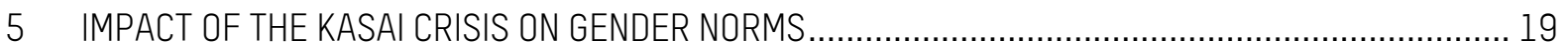

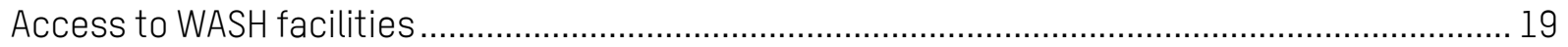

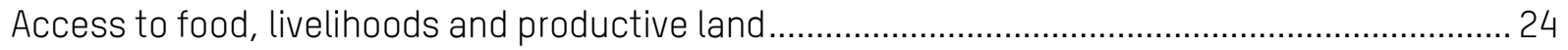

Access to healthcare, including sexual and reproductive healthcare .......................................... 26

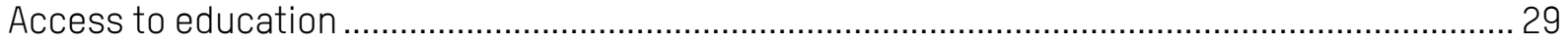

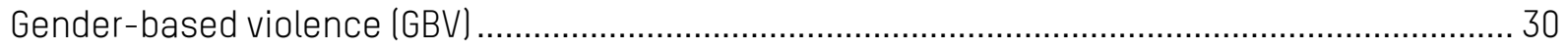

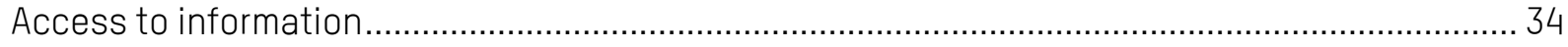

Patterns of power and household decision making, including control over assets and resources

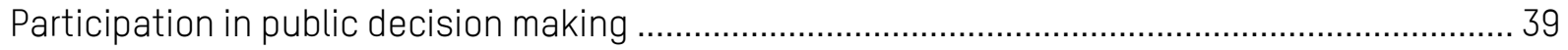

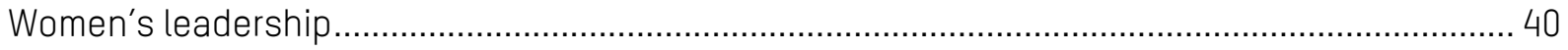

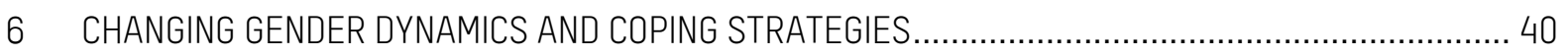

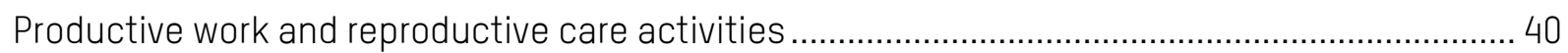

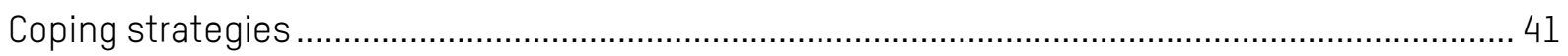

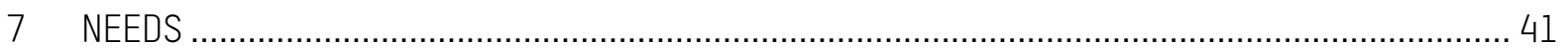

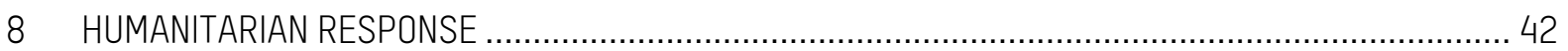

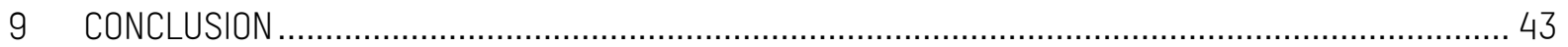

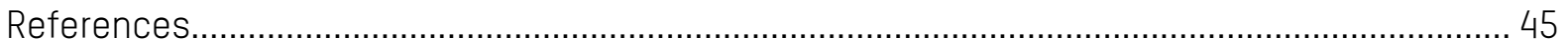

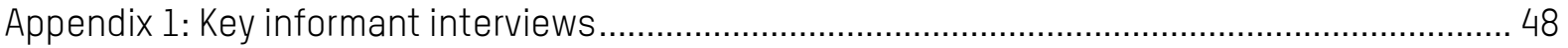

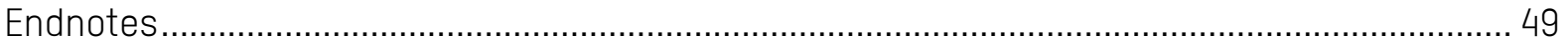




\section{Acronyms and abbreviations}

\begin{tabular}{ll} 
CSO & Civil society organization \\
DPS & Division Provinciale de la Santé (Provincial Health Department) \\
DRC & Democratic Republic of Congo \\
EFSL & Emergency food security and livelihoods \\
FGD & Focus group discussion \\
GBV & Gender-based violence \\
GVBIMS & Gender-Based Violence Information Management System \\
IASC & Inter-Agency Standing Committee \\
IDP & Internally displaced person \\
KII & Key informant interview \\
MEAL & Monitoring, evaluation, accountability and learning \\
NFI & Non-food item \\
NGO & Non-governmental organization \\
OCHA & UN Office for the Coordination of Humanitarian Affairs \\
OHCHR & Office of the UN High Commissioner for Human Rights \\
SEA & Sexual exploitation and abuse \\
SGBV & Sexual and gender-based violence \\
UNHCR & United Nations High Commissioner for Refugees \\
UNICEF & United Nations Children's Fund \\
WASH & Water, sanitation and hygiene \\
WFP & World Food Programme \\
\hline
\end{tabular}




\section{EXECUTIVE SUMMARY}

The Democratic Republic of Congo is currently gripped by national political deadlock and is also plagued by localized armed conflicts, both old and new. In the central region of Kasai, one of the five poorest in DRC, the conflict between government forces and the Kamwina Nsapo militia escalated dramatically in the first quarter of 2017 and has caused a serious humanitarian crisis extending over five provinces. The crisis has led to major food insecurity and has exacerbated the existing vulnerabilities of the local population.

Despite progress in public policy making, gender inequalities persist in various aspects of life in DRC, with women playing a limited role in public life and having limited access to services and opportunities. This is especially true in Kasai province, where the humanitarian crisis is entrenching existing inequalities in gender norms. In this context, Oxfam conducted a gender analysis in October-November 2017 in order to identify the impacts that the conflict is having on women, girls, boys and men in the province and their coping mechanisms, and to inform its own humanitarian programmes and those of its partners and other organizations, as well as the wider humanitarian response.

The analysis was undertaken in five health zones designated by the Division Provinciale de la Santé (DPS Provincial Health Department) in and around the towns of Tshikapa and Kamonia. Researchers collected information by means of a mobile survey of 449 households, 60 focus group discussions (FGDs) and 35 key informant interviews (KIIs).

\section{KEY FINDINGS AND RECOMMENDATIONS Findings}

\section{Access to water, sanitation and hygiene (WASH) facilities}

- There is limited access to potable water and to water in general. There are few water sources available, and not all of these are maintained regularly.

- The majority of households are using inadequate water and sanitation facilities.

- Communities are selling water to generate revenue.

- Women and girls are responsible for hygiene, waste disposal, fetching water and other household chores related to WASH (gathering wood, washing clothes, preparing food).

- $\quad$ Both women and men feel unsafe using WASH facilities, due to the distance of these from their houses. Inter-community tensions caused by the conflict have led to very high levels of fear among the population.

- Most women and girls use reusable sanitary cloths for menstruation and for the majority disposal is inadequate.

\section{Access to food, livelihoods and productive land}

- Agriculture is the main subsistence sector and the bulk of agricultural work is done by women, with men involved more in diamond extraction and related activities.

- $\quad$ Neither host communities nor internally displaced persons (IDPs) have access to land now due to insecurity, and both populations express the need for tools and seeds.

- Men are in charge of livestock management, with women mostly responsible for poultry management.

- There are high rates of malnutrition, caused by lack of access to land, the loss of livestock, lack of income and the increased cost of living.

- $\quad$ Children, pregnant and breastfeeding women and elderly women are the most vulnerable groups.

- Food aid is insufficient.

- Polygamy is a widespread practice in Kasai, and polygamous households face a disproportionate degree of vulnerability.

\section{Access to healthcare, including sexual and reproductive healthcare}

- The main health issues identified since the start of the crisis are malnutrition and diarrhoea, followed by injuries caused by violence, including sexual violence.

- For victims of sexual violence, stigmatization and cost are serious impediments to accessing health services. 
- Generally, cost, distance and the availability of health services are the main obstacles to accessing health services, including for pregnant women.

- Most of the population primarily use local practitioners and traditional medicine to treat health problems.

- People are suffering significant psychosocial effects as a result of the crisis.

\section{Access to education}

- Access to education is limited, especially for girls, and the rate of illiteracy in the region is around $60 \%$ on average.

- The majority of village schools have been destroyed, and there has been a fall in the number of children attending school since the crisis began.

- Before the crisis, cost was the main obstacle to children attending school; with the crisis have come added risks of insecurity as children must travel long distances to school.

- There are very few female teachers, which was also the case before the crisis.

- There are many cases of early marriage and many child mothers; this was the case both before and after the crisis.

\section{Gender-based violence (GBV)}

- There are numerous security risks, including many checkpoints on roads and aggressive behaviour by both armed groups and the military. This makes the population feel at risk.

- There is limited understanding of what domestic violence means.

- Women and girls are most at risk of rape, harassment and extortion; men and boys are at risk of extortion and physical violence, with also some cases of harassment.

- There is a perceived overall increase in cases of GBV with new perpetrators, both armed groups and the military.

- Girls are at risk of early and forced marriage.

\section{Access to information}

- There is a lack of available information on GBV and health services, especially in some villages and especially for women.

\section{Patterns of power and household decision making, including control over assets and resources}

- Women in the areas studied are marginalized and men mostly make decisions in the household, though there is some shared decision making.

- Since the crisis began, women have taken economic charge of the family and a large number of the women in the areas studied have started petty trading; in households where this is the case, women are more involved in decision making.

\section{Participation in public decision making}

- Women in the study areas do not play a leading role in community decision making, and the vast majority of community leaders are men.

- Similarly, local government roles are male-dominated.

- The crisis has affected some women's groups due to displacement.

\section{Women's leadership}

- There are many women's groups, both formal (such as small traders' associations) and informal (savings groups), as well as religious groups.

- Women's groups are successful but are women-only, and have yet to move into male-dominated spaces.

\section{Productive work/reproductive care activities}

- Men and boys who were formerly involved in activities related to diamond extraction are now unemployed.

- Women have largely taken over economic responsibility for the family while also retaining their reproductive care responsibilities, with help from girls. 
- Men have largely retained their traditional role as head of household, though some decisions are shared or women are silently making decisions.

\section{Coping strategies}

- People travel and work in the fields in groups and try to avoid contact with armed groups and the military.

- Some people are pooling resources in order to access healthcare.

- In general, it is difficult for the community to adopt positive or sustainable coping strategies.

- Negative coping strategies include begging, reducing food intake and selling livestock for ready cash, as well as early marriage, prostitution and theft.

\section{RECOMMENDATIONS (in the immediate, medium and long terms)}

\begin{tabular}{|c|c|}
\hline Donors & $\begin{array}{l}\text { - Allocate financial resources for gender mainstreaming into all humanitarian } \\
\text { programmes, including prevention of GBV and sexual exploitation and abuse } \\
\text { (SEA) and gendered response interventions. } \\
\text { - } \quad \text { Allocate more funding for the response overall, but particularly for } \\
\text { emergency food security and livelihoods (EFSL). }\end{array}$ \\
\hline INGOs & $\begin{array}{l}\text { - } \begin{array}{l}\text { Ensure a coordinated approach between the government, the UN system } \\
\text { - }\end{array} \text { Strengthecal, national and international NGOs to address food and water needs. } \\
\text { gender issues, GBV and women's empowerment. } \\
\text { - } \quad \text { Provide capacity building by relevant UN agencies for local NGOs and for the } \\
\text { government on gender mainstreaming, gender-focused actions and GBV } \\
\text { considerations. } \\
\text { - } \quad \text { Prioritize gender-responsive actions, prevention of GBV and promotion of } \\
\text { women's leadership. } \\
\text { - Support more women's rights organizations and women's groups as agents } \\
\text { of change in communities and as leaders in establishing mechanisms for } \\
\text { women's protection, participation and leadership, including province-wide } \\
\text { sensitization on women's rights. } \\
\text { Focus on both short- and long-term needs to improve people's resilience } \\
\text { and reduce dependency on aid. }\end{array}$ \\
\hline INGOs and NGOs & $\begin{array}{l}\text { - Integrate gender considerations and prevention of GBV and SEA into all } \\
\text { - } \quad \text { Implement initiatives that increase women's voice and participation in any } \\
\text { humanitarian programming, through training and capacity building targeted } \\
\text { at women, sensitization for men and boys, building on existing women's } \\
\text { groups, etc. } \\
\text { - } \quad \text { Extend targeting to host communities, to women and to female- and child- } \\
\text { headed households. } \\
\text { - Introduce information, sensitization and awareness-raising initiatives on } \\
\text { - } \quad \text { Sumen's and girls' rights. } \\
\text { Support and scale up women's mutual aid groups. }\end{array}$ \\
\hline WASH sector & $\begin{array}{l}\text { - } \quad \text { Engage women, girls, men and boys separately in the design of latrines and } \\
\text { bathing spaces, including locations and distance from dwellings. } \\
\text { - } \quad \text { ensure that the design of latrines includes safety measures such as locks } \\
\text { on doors and sufficient distance for privacy. } \\
\text { - } \quad \text { Ensure that both women and men participate in the identification of safe } \\
\text { and accessible sites for water pumps and sanitation facilities. } \\
\text { - } \quad \text { Train women and men in the use and maintenance of sanitation facilities. } \\
\quad \text { Distribute female dignity kits to women and girls (these can include } \\
\text { - } \quad \text { Invonstrual cloths, underwear, soap, flashlights). } \\
\text { relieve the burden on women and girls, and involve them in household } \\
\text { activities by means of sensitization and by creating programmes targeted } \\
\text { specifically at boys and men. } \\
\text { Increase the number of female community health volunteers and encourage } \\
\text { equal male/female membership of all committees and the active } \\
\text { participation of women. Ensure that committee meetings are held at }\end{array}$ \\
\hline
\end{tabular}




\begin{tabular}{|c|c|}
\hline & $\begin{array}{l}\text { convenient times and locations and that targeted support is provided to } \\
\text { women, while engaging men in order to sensitize them on women's needs. } \\
\text { - Ensure women's active participation and leadership in water committees in } \\
\text { particular and monitor their participation continuously. } \\
\text { Distribute non-food items (NFIs) including jerrycans, clothes and kitchen } \\
\text { utensils to all households, especially IDPs and host family households. }\end{array}$ \\
\hline $\begin{array}{l}\text { Emergency food } \\
\text { security and } \\
\text { livelihoods (EFSL) }\end{array}$ & 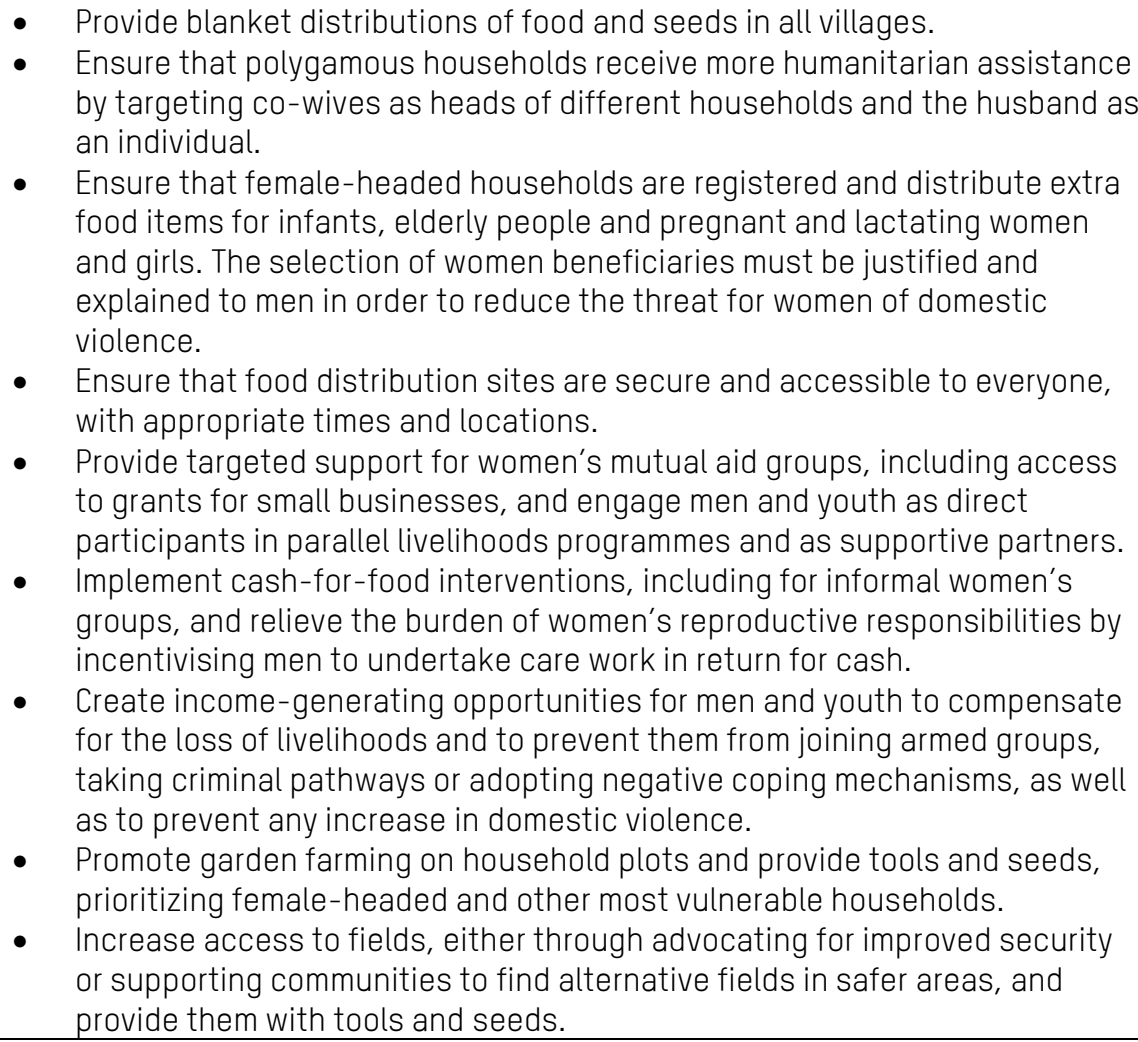 \\
\hline Education $^{1}$ & $\begin{array}{l}\text { - Improve existing schools in terms of infrastructure and by providing food } \\
\text { distributions at school, school furniture and kits to students containing } \\
\text { backpacks, books, pens and stationery. } \\
\text { - } \quad \text { Create and build emergency primary and secondary schools in villages } \\
\text { where schools have been burned or destroyed and include WASH facilities } \\
\text { for boys and girls, proportionate to their numbers. } \\
\text { - } \quad \text { Enhance school enrolment rates for girls by providing cash for education } \\
\text { and other targeted interventions. } \\
\text { - } \quad \text { Increase the number of trained female teachers in schools. } \\
\text { - } \quad \text { Offpert the provision of literacy courses for women and girls. } \\
\text { - } \quad \text { Child protection actors should offer empowerment programmes to help girls } \\
\text { avoid early marriage, by informing them of their basic rights and providing } \\
\text { educational programmes on health and sex education. } \\
\text { - Child protection actors should also support young girls who have already } \\
\text { married, providing them with a chance to complete or continue their } \\
\text { education. } \\
\text { Educate families to challenge stereotypes and attitudes that result in early } \\
\text { marriage, emphasizing the contribution that educated girls can make to } \\
\text { their families. } \\
\text { Raise awareness among religious and community leaders of the negative } \\
\text { impacts of early marriage and polygamous relationships. }\end{array}$ \\
\hline Health $^{2}$ & $\begin{array}{l}\text { - Ensure free access to primary health services for the most vulnerable } \\
\text { people, including IDPs and female-headed and single-parent households, } \\
\text { and provide information in local languages to women and men about the } \\
\text { health services available and their locations. } \\
\text { - Train traditional midwives. }\end{array}$ \\
\hline
\end{tabular}




\begin{tabular}{|c|c|}
\hline & $\begin{array}{l}\text { - Regularly distribute dignity kits to girls and women, and distribute health } \\
\text { kits containing medicines to treat preventable life-threatening diseases to } \\
\text { households that are unable to access healthcare. } \\
\text { - Improve the sexual and reproductive health of girls and women by providing } \\
\text { access to gynaecological treatment, and educate women, men, girls and } \\
\text { boys on preventing pregnancy and culturally acceptable methods of } \\
\text { contraception. }\end{array}$ \\
\hline Protection & $\begin{array}{l}\text { - Ensure sensitization for all three ethnic groups in the region - Luba, } \\
\text { Tchokwe and Pende - on peaceful cohabitation. }\end{array}$ \\
\hline GBV & $\begin{array}{l}\text { - Advocate for free access to services, provide survivors of GBV with } \\
\text { information about the intervention services that are available and direct } \\
\text { them to appropriate services. } \\
\text { - Scale up existing GBV prevention and response structures, including } \\
\text { psychosocial support, legal assistance and safe shelter for GBV survivors, } \\
\text { as well as training for health and community-based service providers to } \\
\text { listen and provide emotional support. } \\
\text { - Ensure that GBV interventions are mainstreamed throughout humanitarian } \\
\text { actions. } \\
\text { - } \quad \text { Protection actors should strengthen referral systems to support women, } \\
\text { girls, boys and men who have been affected by GBV or who require } \\
\text { psychosocial support, and ensure collaboration with other sectors to } \\
\text { strengthen GBV prevention and risk mitigation across sectors, in alignment } \\
\text { with the } 2015 \text { IASC Guidelines on GBV. } \\
\text { - } \quad \text { Provide training on GBV/SEA to all humanitarian staff. } \\
\text { - Ensure the sensitization of communities on GBV and SEA, using local } \\
\text { languages. } \\
\text { - Adopt strategies for targeting, recruiting and organizing men and boys as } \\
\text { champions for combating GBV and promoting women's rights. } \\
\text { - Advocate for better law enforcement in relation to polygamy and early } \\
\text { marriage. } \\
\text { Educate the community on constitutional rather than customary law. }\end{array}$ \\
\hline All & $\begin{array}{l}\text { - Ensure capacity building on gender equality and women's rights by } \\
\text { - Engaging with women, men, girls and boys. } \\
\text { - Ensure that spaces are created for women's leadership and representation } \\
\text { at the community level. } \\
\text { - Ensure that attention is paid to not overloading women, as they are already } \\
\text { involved in both productive and care work, by engaging men and boys or } \\
\text { providing cash for care work. } \\
\text { - Ensure the development of capacity on women's rights. }\end{array}$ \\
\hline
\end{tabular}




\section{$1 \quad$ INTRODUCTION}

\section{Democratic Republic of Congo: country profile and gender inequality}

Following decades of conflict, there are now 13.1 million people in DRC facing unprecedented levels of vulnerability, including 4.1 million internally displaced persons (IDPS) and 1.9 million children suffering from acute malnutrition. ${ }^{4}$ As a result of the violence currently affecting several of the country's provinces, large swathes of the civilian population are in need of urgent humanitarian and protection assistance. The various conflicts have resulted in a loss of access to goods, services and livelihoods, a situation exacerbated by the lack of pre-existing socio-economic infrastructure in the affected areas.

Over the past two years the country has suffered the effects of national political deadlock and an increased number of localized armed conflicts. The delay of presidential and parliamentary elections initially planned for November 2016 and the failure to implement the December 2016 New Year's Eve agreement have worsened political and economic instability, and there is no clear plan in prospect for new elections.

Despite progress in public policy making, gender inequalities persist in various aspects of life in DRC. The country's 2006 constitution upholds the principle of equality between men and women and states that discrimination against women should be addressed in civil, political, economic, social and cultural domains (Article 145). Women's access to property and land rights is often inhibited by local customs of patrilineal inheritance, as well as by a lack of legislation that would guarantee their right to own and inherit property. As a result, women are often unable to secure inheritance rights or even take part in negotiations about inheritance. Women are also socially vulnerable due to the absence of good governance and the weak rule of law. DRC was ranked 46th out of 54 countries in the Ibrahim Index of African Governance (IIAG) in $2017^{6}$ Women's representation in positions of leadership and decision making is very low, with women holding only $8.9 \%$ of parliamentary seats in $2016 .{ }^{7}$

The national Demographic and Health Survey most recently conducted in 2013-14 found that $72 \%$ of women nationwide had been paid for work done in the 12 months prior to the study, compared with $81 \%$ of men. ${ }^{8}$ Women's economic participation is mostly in the agricultural and informal sectors, and women earn less on average than men: in 2011, women had an estimated gross annual income of US\$599 compared with US\$761 for men. ${ }^{9}$ Women are therefore more affected by poverty, with an estimated $61.2 \%$ of female-headed households living under the poverty line compared with $54.3 \%$ for male-headed households. ${ }^{10}$

With regard to education, the rate of illiteracy for women is $50 \%$ higher than for men, especially in rural areas. ${ }^{11}$ Schooling rates are very low for all children but especially so for girls, with nine girls in primary, six girls in secondary and four girls in tertiary education for every 10 boys. ${ }^{12}$ While primary education should be free according to Congolese law, parents generally have to pay to send their children to school; fees vary depending on the school and province, and there is no clear average. ${ }^{13}$

When it comes to health and reproductive rights, in 2015 only $20 \%$ of married women aged between 15 and 49 used a contraceptive method (modern or non-modern), and the maternal mortality rate in the country is $48 \%$ higher than the average for sub-Saharan Africa. ${ }^{14}$

Sexual and gender-based violence (SGBV) is rampant in DRC. UNICEF has reported that, in 2016, $9 \%$ of women aged 15-49 had been sexually abused and, according to the Gender-Based Violence Information Management System (GVBIMS), there were 15,500 cases of violence reported in $2016,69 \%$ of which were rapes. ${ }^{15}$ Female victims of SGBV also have to deal with social stigma, with between $6 \%$ and $29 \%$ of victims being banished from their homes or communities. ${ }^{16}$ Boys and men have also suffered sexual abuse, with estimates of sexual violence against them in the east of the country ranging from $10 \%$ to $30 \%$ of the male population. ${ }^{17}$ Reporting of such violence is expected to be lower due to gender stereotypes and the culture of masculinity in the country.

Since August 2016 fighting between government forces and the Kamwina Nsapo militia in the central region of Kasai has added to the country's ongoing insecurity and humanitarian crisis, and there has been renewed and continued fighting in the east. In recognition of the severity of the crisis, DRC has been categorized a Level 3 emergency by the international relief community, to ensure that an aid response is galvanized. This status will last for an initial six months from October 2017 to March 2018 and is focused on the situation in the greater Kasai region, as well as in Tanganyika and South Kivu provinces. 


\section{The humanitarian context of the current Kasai crisis}

Grand Kasai Is made up of five provinces - Kasai, Central Kasai, Eastern Kasai, Sunkuru and Lomami - following the 2015 division of Western Kasai and Eastern Kasai provinces. Historically, the region had not experienced any of the humanitarian crises or conflicts that had engulfed other parts of the country. However, even before the current conflict, Kasai faced enormous levels of humanitarian need stemming from years of chronic poverty and underdevelopment.

The current conflict started in August 2016 and was political in origin, stemming from disagreements over traditional authority between a local chief from Central Kasai, Kamwina Nsapu, and the government. The region of Kasai had always been a stronghold of political opposition and this has added to the complexity of this conflict, which escalated dramatically in the first quarter of 2017 and spread from Central Kasai to affect the entire region, including Kasai province.

There has been a sharp increase in insecurity, with populations fleeing attacks by armed groups. Civilians have suffered infringements of human rights and international humanitarian law from all sides. From April 2017, the crisis in Kasai province in particular took on a more pronounced ethnic dimension, with members of the Luba people (accused of being supporters of the Kamwina Nsapu militial coming into conflict with Tchokwe and Pende communities (associated with the government). The country team of the Office of the UN High Commissioner for Human Rights (OHCHR) has confirmed that in early 2017 individuals from the Tshokwe and Pende ethnic groups created a militia, the Bana Mura, which committed serious and large-scale human rights abuses against the Luba. This militia was allegedly armed and supported in its operations by local traditional leaders and security officials. ${ }^{18}$

Despite a significant reduction in the fighting in Kasai region since June 2017, the conflict has caused an explosion of large-scale displacement. An estimated 1.3 million people were internally displaced in May 2017 though, following a series of targeting exercises, the number of IDPs had fallen to 762,000 by October. ${ }^{19}$ Kasai province, where the violence reached the provincial capital Tshikapa in January 2017, has the highest number of IDPs, at 333,906 people. Unlike in many other emergencies of this scale, people forced from their homes are being hosted by poor local communities, rather than in large camps, which adds to the difficulty of responding to the crisis. Very few IDPs are being hosted in churches or are taking shelter in abandoned buildings: a total of 17 such sites have been identified in Tshikapa, with the numbers of people in each ranging from 50 to 300 . This situation puts added pressure on dilapidated local infrastructure, with poor host communities having to cope with new demands on water, food and shelter. In addition, many IDPs have not reached the town itself and have spent several months in the bush, invisible and unreachable by humanitarian assistance until October 2017, when access improved.

Oxfam's initial needs assessment, conducted in Tshikapa in May 2017, noted that access to most local areas was still very limited, with checkpoints manned by armed actors creating problems such as extortion and harassment of the local population and contributing to restricted movement. Exorbitant and illegal taxes imposed by both the security forces and militiamen have also led to a sharp increase in prices in local markets, in an area where prices were already higher than the national average due to the region's diamond extraction industry. The checkpoints have also affected access to fields, extraction sites and supply routes and have led to a significant reduction in the supply of food and in artisanal activities related to diamond mining. The area's largely agricultural and subsistence-based economy has been severely affected as no agricultural production has been possible, leading to food shortages. ${ }^{20}$

Gender issues that exist nationally are likely to be magnified in the Kasai region as it is one of the least developed and poorest regions in the country, with a population that is already vulnerable. Data from the Demographic and Health Survey conducted in 2014 show that the incidence of child marriages, sexual violence and intimate partner violence in Kasai is already higher than the national average. ${ }^{21}$ The conflict has exacerbated these vulnerabilities, leading to greater health risks and increased food insecurity; as in other crises, these affect men, women, boys and girls differently. In this context, Oxfam hoped that a gender analysis would provide a clearer picture of the different needs of different groups and of the humanitarian assistance required to accurately respond to these needs. 


\section{OBJECTIVES OF THE ANALYSIS}

The aim of the gender analysis was to identify the impacts of the conflict in Kasai province on women, girls, boys and men in the affected areas, and the coping mechanisms they have adopted. It is hoped that this analysis will inform the humanitarian programmes of Oxfam, its partners and other organizations, as well as the wider humanitarian response.

The specific objectives of the analysis were to:

- identify gender norms, attitudes and beliefs that drive risks and vulnerabilities

- identify the root causes of vulnerability for women, girls, men and boys

- identify the existing context and opportunities for increasing the voice, leadership and meaningful participation of women and girls

- identify how host communities and IDPs interact to support social, economic and political inclusion in society from a gender perspective

- assess the types and prevalence of GBV

- assess the extent to which the current humanitarian response is preventing and mitigating risks

- assess the capacities of duty bearers - government, international organizations, UN agencies, I/NGOs and grassroots civil society organizations (CSOs) - in responding to the needs of affected women, girls, boys and men in the province.

\section{METHODOLOGY AND FIELDWORK}

\section{Data collection methods}

The assessment used mixed data collection methods and included both primary and secondary data. The secondary data comprised a desk review which provided an understanding of the current situation and a preliminary analysis of existing gender gaps. The primary data were both quantitative and qualitative, and were collected using four techniques: a household survey utilizing the SurveyCTO mobile data collection platform, focus group discussions (FGDs), key informant interviews (KIIs) and direct observation. The analysis was carried out in Kasai province, using the towns of Tshikapa and Kamonia as bases, and was split across five health zones, as designated nationally by the Division Provinciale de la Santé (DPS - Provincial Health Department). These were Tshikapa, Kalonda West, Kanzala, Kamonia and Kamwesha, including surrounding villages ( 24 in total) and IDP sites (17). The survey, FGDs and observation notes were collected over a period of six days (23-28 0ctober 2017), with a team of 20 enumerators ( 10 women and 10 men) working as community liaison in the five health zones selected. The enumerators were assisted throughout the exercise by the Oxfam Monitoring, Evaluation, Accountability and Learning (MEAL) team and Gender Adviser. For the household survey, the enumerators used SurveyCTO data collection handsets, and for the FGDs they conducted and observation notes they made pre-set guidelines were followed. The Klls were conducted by the Gender Adviser over a period of six weeks in Tshikapa. All the survey tools, FGD guidelines and KII questions were developed in French and were reviewed by Oxfam staff in the UK and in Tshikapa, including local staff, and were double-checked for appropriateness by representatives of seven local NGOs familiar with the context.

\section{Sampling}

The 20 enumerators, using SurveyCT0 mobile data collection, interviewed 449 households across the five health zones. Those interviewed were $51 \%$ male, $49 \%$ female; $63 \%$ Luba, $16 \%$ Tchokwe and $12 \%$ Pende; and $43 \%$ local community and $30 \%$ IDP (with the other 27\% represented in Figure 4), which roughly reflected the demographics of the local communities in and around Tshikapa. Generally, it was difficult to ascertain accurate numbers of affected people or to gather reliable statistics on the demographics of Kasai province. The most accurate statistics collected during the analysis came from the DPS, which put the total population of the province at 4,567,845, comprising 2,238,244 men and 2,329,601 women. The DPS had no accurate demographic statistics on the three ethnic groups but estimated roughly that the Luba represented over $60 \%$ of the population, with the remaining $40 \%$ split between the Tchokwe and Pende. The affected population in the province, as estimated by the DPS, totalled 2,009,852, with 984,827 men and 1,025,024 women. In Tshikapa, the DPS estimated that 91,411 women and 87,827 men were affected ${ }^{22}$. Statistics from UNCHR put the total IDP population in Tshikapa at 61,395, including 33,416 women and 27,979 men; IDPs are drawn from all three ethnic groups but there are no clear figures on the percentage split. Figures 1-4 and Table 1 below set out the demographics of the study area in more detail. 


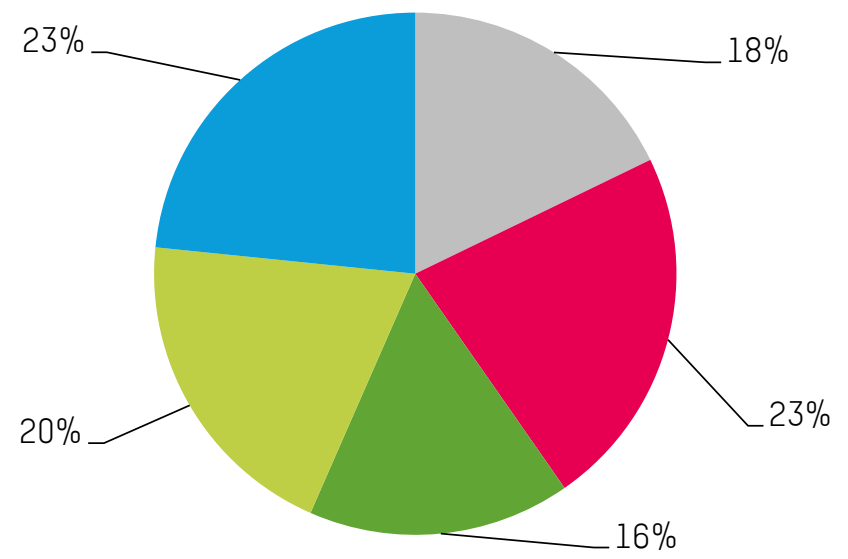

Kalonda West

Kamonia

Kamwesha

Kanzala

- Tshikapa

Figure 1: Distribution of households surveyed, by health zone

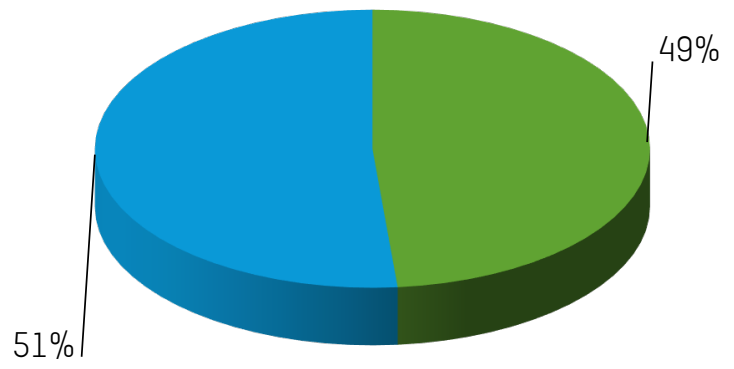

- Female

Male

Figure 2: Sex of respondents (total in all locations)

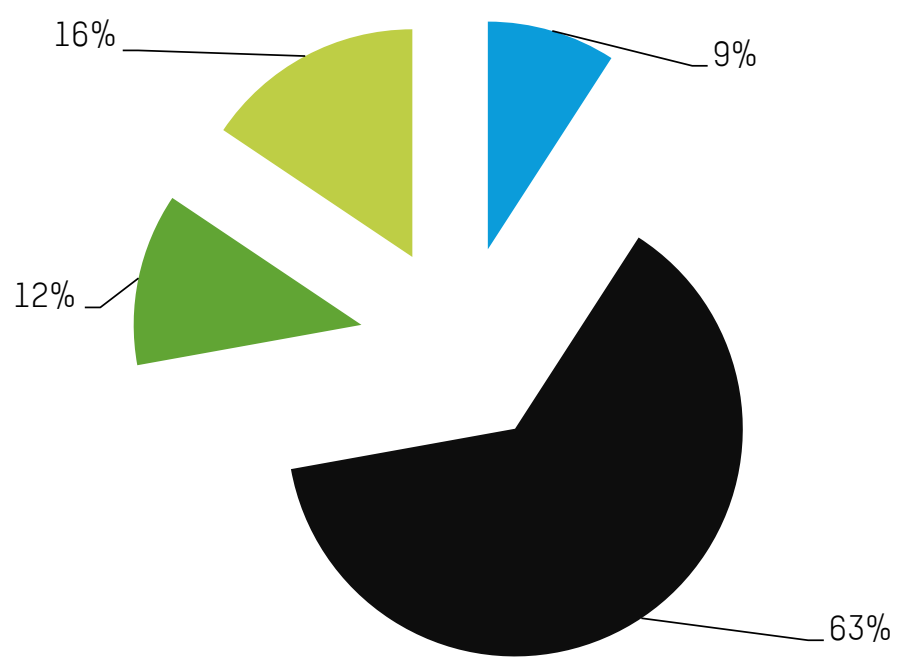

- Other

- Luba

- Pende

Tschokwe

Figure 3: Main language of respondents (total in all locations) ${ }^{23}$ 


\begin{tabular}{|l|l|l|l|l|l|l|l|l|}
\hline $\begin{array}{l}\text { Households } \\
\text { Icategories } \\
\text { by sex and } \\
\text { age) }\end{array}$ & 18 & $18-24$ & $25-34$ & $35-44$ & $45-64$ & $\begin{array}{l}65 \text { and } \\
\text { above }\end{array}$ & $\begin{array}{l}\text { Do not } \\
\text { know } \\
\text { their } \\
\text { age }\end{array}$ & Total \\
\hline Women & 0 & 49 & 56 & 53 & 50 & 6 & 4 & 218 \\
\hline Men & 0 & 19 & 42 & 52 & 94 & 24 & 0 & 231 \\
\hline Total & 0 & 68 & 98 & 105 & 144 & 30 & 4 & 449 \\
\hline
\end{tabular}

Table 1: Households surveyed, disaggregated by sex and age

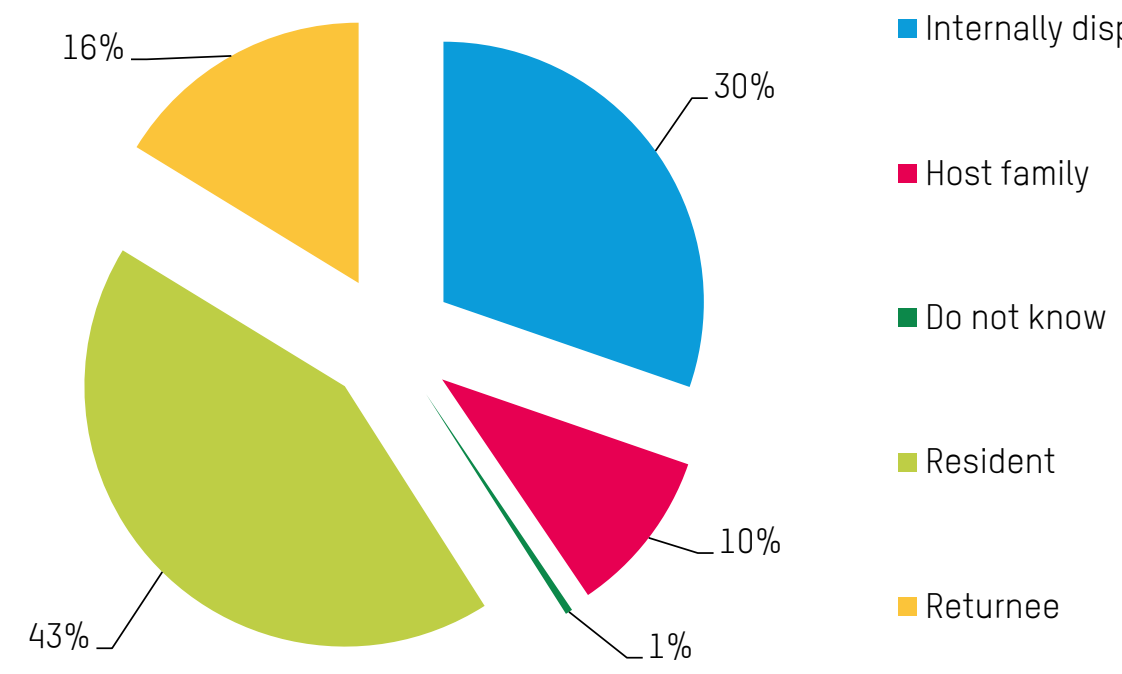

Figure 4: Household categories (in all locations)

The survey found that $31 \%$ of households were headed by women (Figure 5). Information gathered during data collection indicated that many women had been widowed due to the fighting and that others had been rejected by their husbands on account of their ethnic background; in reality, numbers of female-headed households are likely to be higher. The Division de Genre, Enfant et Famille (Ministry of Gender, Family Affairs and Children) puts the overall percentage much higher at $60.1 \%$, though the accuracy of this figure is unclear.

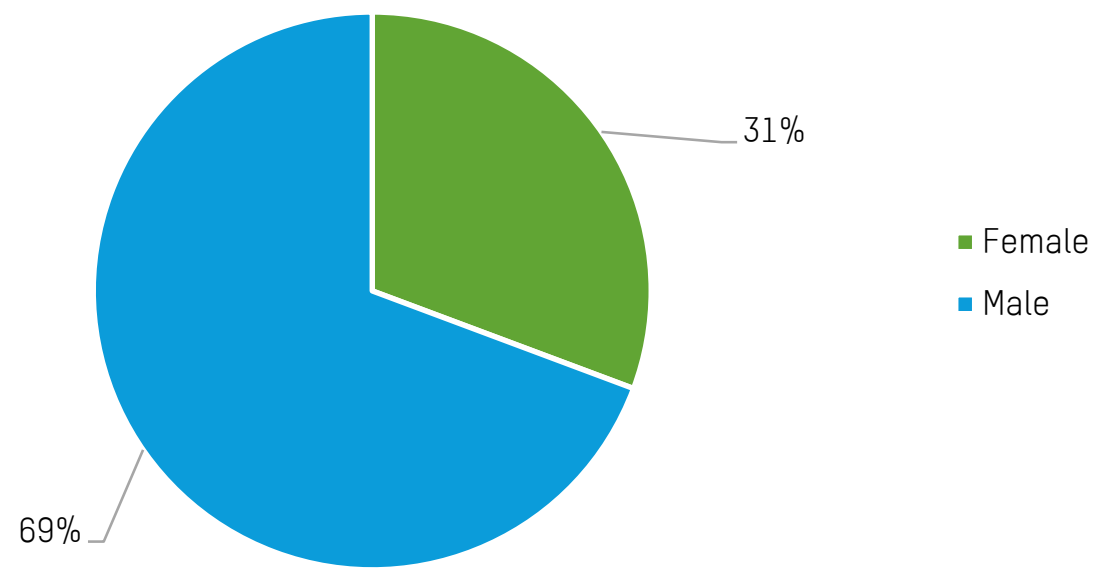

Figure 5: Sex of head of household (all locations) 
The FGDs also covered all five health zones, and participants were divided according to their age and IDP/host community status. There were 12 different types of FGD, with one of each type being conducted in each of the five areas, making a total of 60 group discussions:

- adult women IDPs and adult women from the host community

- IDP girls aged $15-19$ and girls aged 15-19 from the host community

- IDP girls aged 10-14 and girls aged 10-14 from the host community

- adult men IDPs and adult men from the host community

- IDP boys aged $15-19$ and boys aged 15-19 from the host community

- IDP boys aged 10-14 and boys aged 10-14 from the host community.

The three different ethnic groups were also represented in the FGDs, in an attempt to reflect their local distribution and also their separation from one another across communities in Kasai. It was assumed that participants in each FGD were exclusively from the ethnic group associated with that area, giving percentages similar to those for the mobile data, with $60 \%$ of FGDs being conducted in areas associated with the Luba, $28 \%$ in areas associated with the Tchowke and $12 \%$ in areas associated with the Pende.

A total of $35 \mathrm{Klls}$ were conducted, with interviewees including representatives of local and international NGOs, UN agencies and the DRC government, along with local leaders and members of women's groups la full list of key informants is given in Appendix 1), all conducted in Tshikapa. Lastly, direct observations made by the enumerators in the five health zones were compiled and factored into the analysis.

\section{Challenges and limitations}

Various challenges were encountered in the collection of data, particularly from the FGDs. Firstly, due to logistical issues, FGDs were not recorded. Secondly, the enumerators' lack of experience with qualitative data collection, as well as their general lack of experience and language barriers between French and the three local languages, meant that the quality of the notes was limited, with very few testimonies and data that were largely general. Some of the potential difficulties arising from the enumerators' lack of experience in conducting FGDs were identified during training, and so the FGDs were made more participatory and some key concepts were translated prior to the collection of data to ease facilitation.

Thirdly, the enumerators pointed out that they were encountering difficulties in controlling group size with many FGDs going out of the 9-12 people range. In addition, due to the local context and people's expectations of aid due to the presence of a foreign NGO, visits from the Gender Adviser during the FGDs attracted very large crowds, and prolonging such visits would have compromised the data further.

It is also worth mentioning that a number of FGD participants requested that some sort of compensation be provided for their participation, and some expressed disappointment at the fact that they had been asked questions many times before, with no concrete aid resulting from their answers.

For the FGDs with youth and children, parental authorization was requested and obtained and, apart from the enumerators, no other adults were present. There were no enumerators available who had already been trained in facilitating FGDs for youth or in specialized interview techniques for children and youth prior to selection for this study. There was also limited time available (three days) for training enumerators on all the techniques used in the study, due to budget constraints. As a result, the data collected for this demographic were limited.

Given the limited information collected using FGDs generally and those with youth and children in particular, questions similar to those asked in the FGDs were put in KIls with local actors in order to understand the local context and the main issues for each group. Additional secondary data were also collected during the study to assist with this and with the triangulation of data.

A limitation of the household survey was the way in which data were collected, allowing for multiple options for various questions and giving respondents the option to choose their first two or three preferred answers. This resulted in repetition of answers to some questions, which made the analysis harder and confused results. Some of these answers are explained further below.

A major limitation of the study was the non-inclusion in the mobile data collection and the FGDs of questions relating to polygamy. This surfaced only in the first KIls as a practice that was widespread and widely accepted in the province, despite being forbidden by the country's constitutional law. All subsequent Klls then included 
questions on polygamy in order to better understand the issue and how to take account of it in the analysis, despite the shortcomings of a lack of triangulation and a narrow information base.

Lastly, because Kasai is a new province, and despite support from the local government, it was difficult to gather province-wide statistics on a variety of issues. Sometimes only pockets of data were available, whose accuracy was unclear, and this limited the scope of the study.

\section{$4 \quad$ FINDINGS OF THE GENDER ANALYSIS}

\section{General observations}

The conflict in Kasai along ethnic lines and the ongoing, sporadic insecurity have engendered a culture of fear and a loss of trust between the different ethnic groups; this extends to inter-ethnic marriages, some of which have been terminated as a result. A school director mentioned when interviewed that he had even noticed tribal tensions amongst pupils in primary schools. The population remains in a state of fear despite the fact that security incidents have subsided in frequency and, at least in the towns, activities have returned to normal. However, most respondents - women, men, boys and girls - said that the presence of the military did not reassure them.

The fact that IDPs are dispersed within host communities caused problems in identifying and profiling the most affected populations. However, all the participants in FGDs raised largely similar issues and needs, with few differences between IDPs and members of host communities. Some $60 \%$ of respondents to the household mobile data survey had hosted a member of their own extended family or an IDP since the start of the crisis.

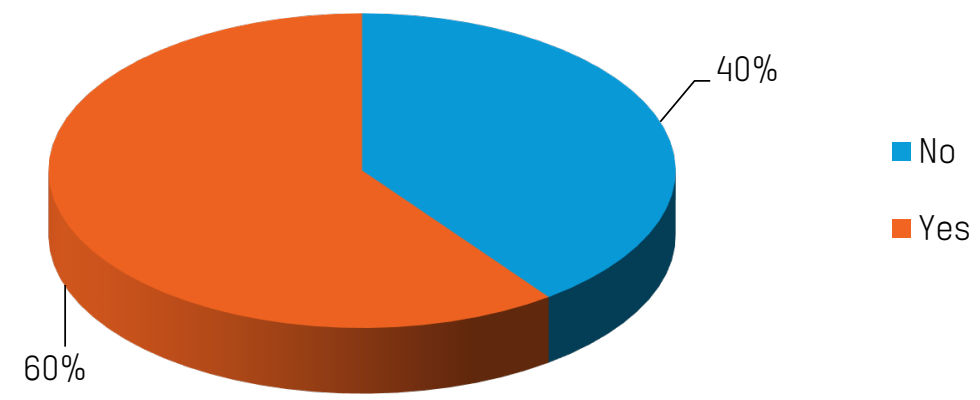

Figure 6: Hosting other family members or displaced persons since the conflict began

Both communities see themselves as extremely vulnerable, regardless of their situation, which has created tensions in some villages where food distributions have targeted only certain households. All of this, coupled with the limited humanitarian response relative to the needs of the region, has created a situation where any targeted response requires substantial sensitization of the community in order for them to understand why some have been given aid and others have not. This is especially important to avoid stoking inter-ethnic tensions as well as tensions between host communities and IDPS.

In the survey, when respondents were asked which category of people were most affected by the crisis, the answers were mostly teenage boys and girls, though answers disaggregated by sex showed that men's responses were more varied (Figures 7, 7a and 7b). As mentioned above, one challenge was that the way information was collected allowed for multiple answers to questions, with two or sometimes three options possible. For example, in Figure $7,41 \%$ of respondents thought that both teenage girls and teenage boys were the most affected, 6\% thought that it was teenage boys and adult men, while $8 \%$ answered adult women, adult men and pregnant or breastfeeding mothers. This information was corroborated by the FGDs, which indicated vulnerability for most groups. Teenage girl and boy participants and adult male and female participants all said that everything had changed and they felt insecure, with risks involved in many of their normal activities, and that they were now unable to do many of the things they were able to do before the crisis. 


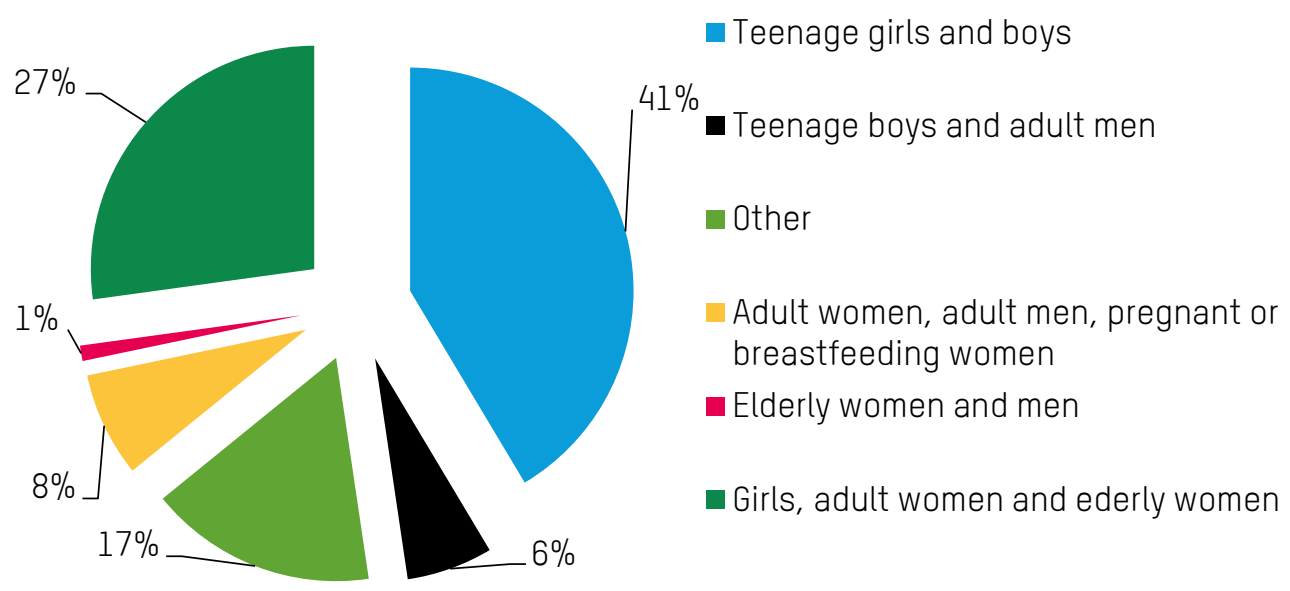

Figure 7: Categories of people in the community perceived as most affected by the crisis (all respondents)

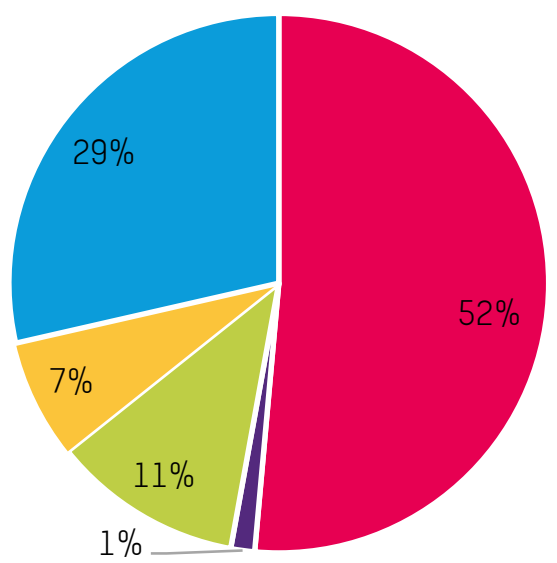

- Teenage girls and boys

- Teenage boys and elderly men

- Other

Adult women and men, pregnant and breasfeeding women

- Girls, adult women and elderly women

Figure 7a: Categories of people in the community perceived as most affected by the crisis (women)

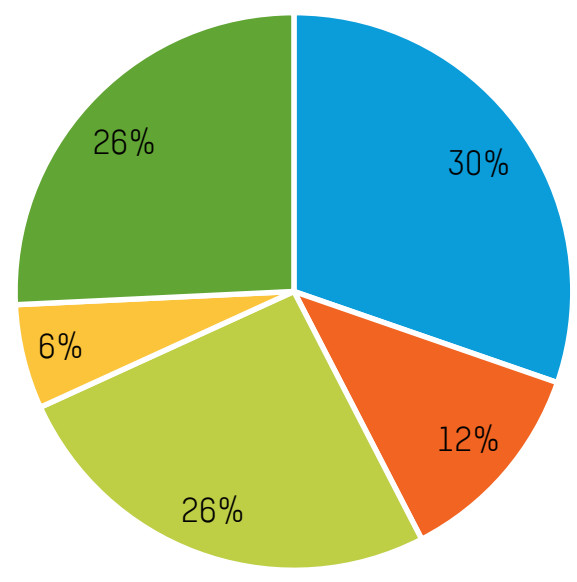

- Teenage girls and boys

- Teenage boys and elderly men

- Other

- Adult women and men, pregnant and breasfeeding women

- Girls, adult women and elderly women

Figure 7b: Categories of people in the community perceived as most affected by the crisis (men)

The main reason given by respondents for their vulnerability was the lack of security, followed by loss of the head of household and restrictions on freedom of movement (Figure 8). Given the different categories of people identified as being vulnerable, information from the FGDs suggests that reasons such as the lack of security and restrictions on movement would most likely apply to all categories, while no head of household would apply to adult and elderly women, girls and boys. 


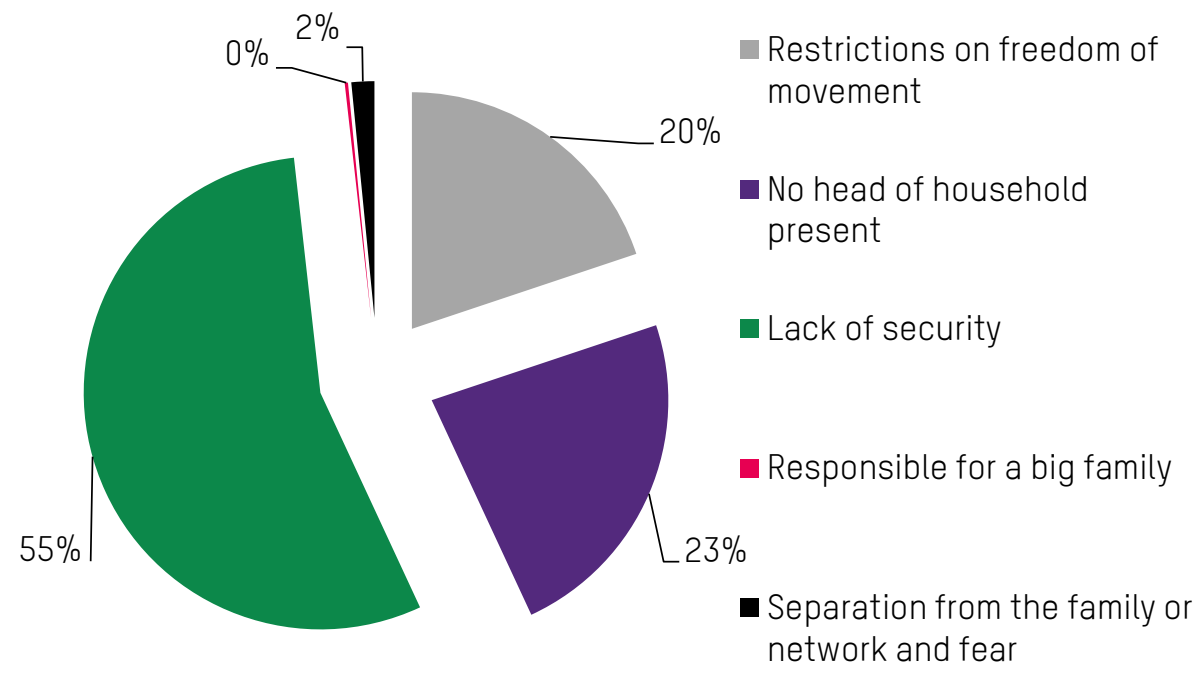

Figure 8: Reasons for vulnerability caused by the conflict

The main reasons given by IDPs for fleeing were the conflict and the destruction of their homes, with slightly different fears expressed by female IDPs compared with male IDPs; Figures 9, 9a and $9 \mathrm{~b}$ indicate that women IDPS fled for slightly different reasons than men. More women (33\%) than men (27\%) feared violence towards a family member and more women (10\%) than men (2\%) were worried about restrictions on freedom of movement.

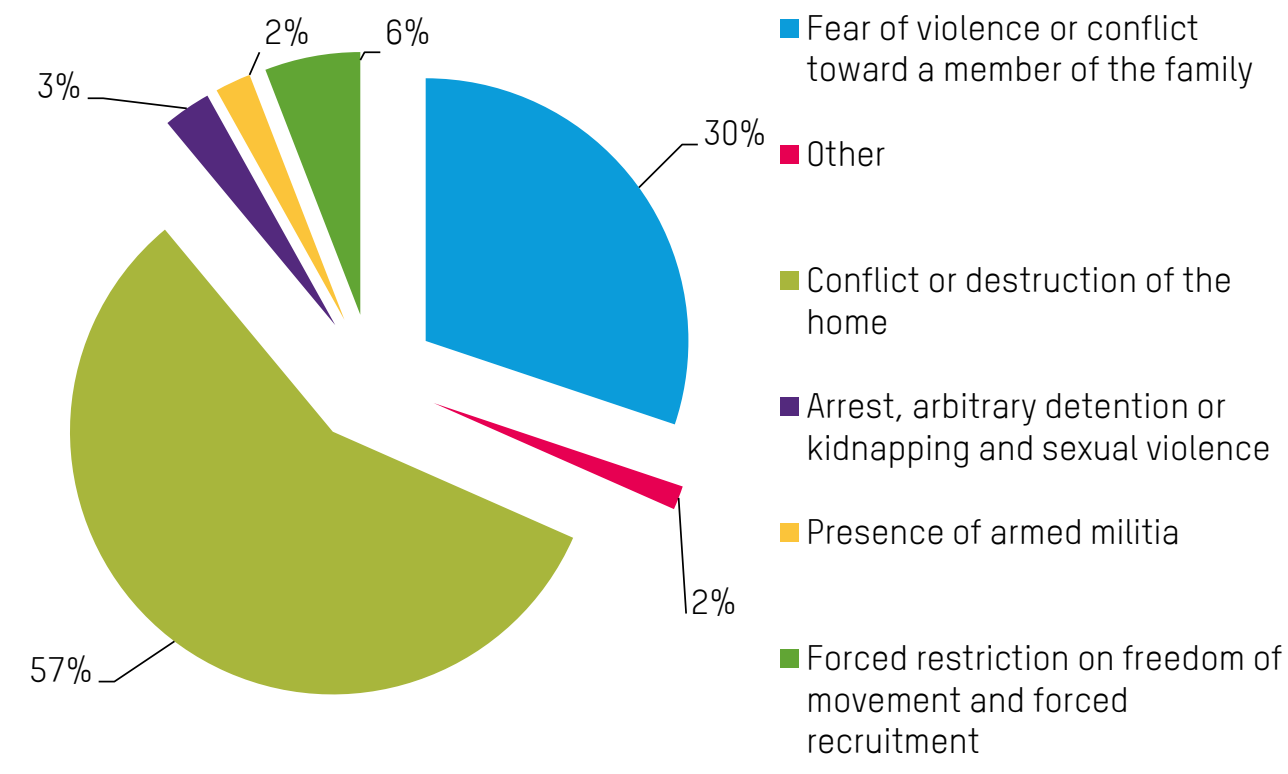

Figure 9: Main reasons for IDPs leaving their homes (all respondents) 


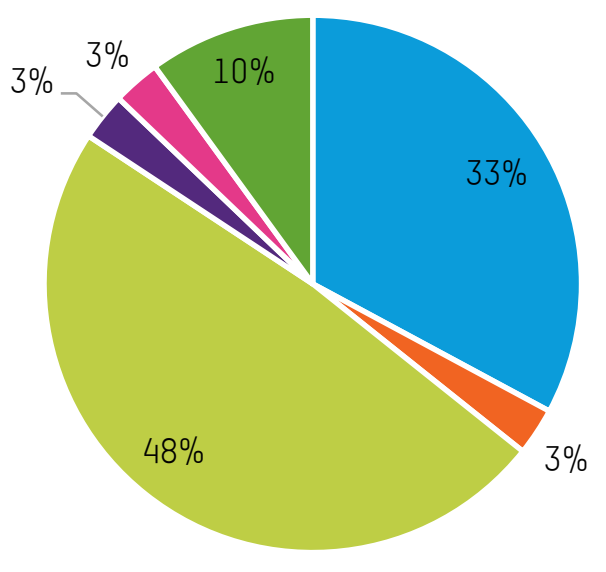

- Fear of violence towards members of the family and conflict

- Other

- Conflict and destruction of the home

- Arrest, detention or kidnapping and sexual violence

- Presence of armed militia

- Restriction on freedom of movement and forced recruitment

Figure 9a: Main reasons for IDPs leaving their homes (women)

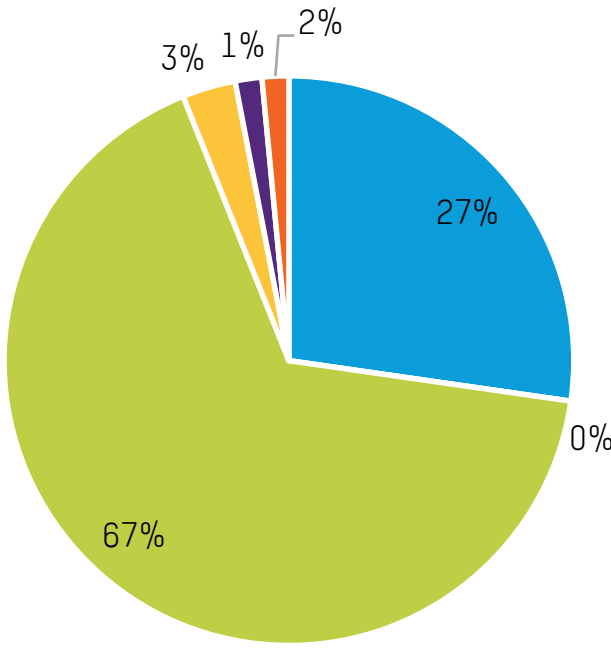

- Fear of violence towards members of the family and conflict

- Other

- Conflict and destruction of the home

- Arrest, detention or kidnapping and sexual violence

- Presence of armed militia

- Restriction on freedom of movement and forced recruitment

Figure 9b: Main reasons for IDPs leaving their homes (men)

\section{IMPACT OF THE KASAI CRISIS ON GENDER NORMS}

\section{Access to WASH facilities}

The observation notes indicated that in the areas studied for this analysis people have limited access to potable water and to water generally. There are few water sources present, and not all of these are maintained regularly. Water sources are located mostly on private property and their management and maintenance are in the hands of the land-owner, at a cost to the community. As a result, communities have used the sale of water as a revenuegenerating activity. As everywhere in DRC, women and girls are the ones responsible for hygiene, waste disposal, fetching water and all other household chores related to WASH (Figures 10, 11 and 12). 


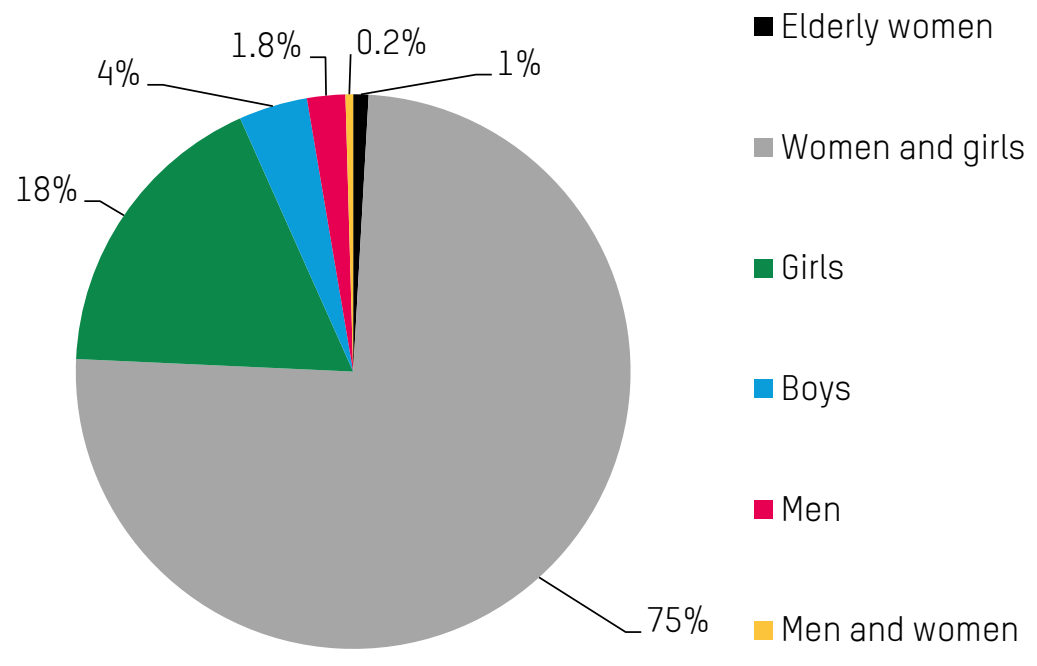

Figure 10: Person in the household responsible for fetching water

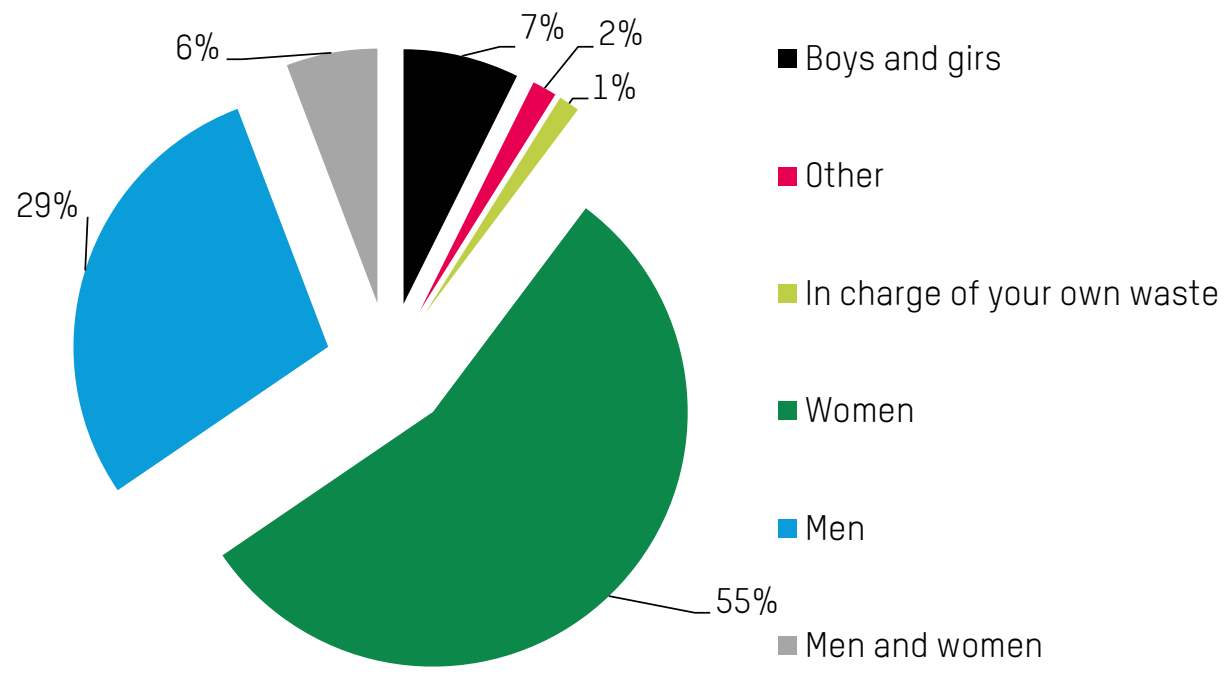

Figure 11: Person responsible for the disposal of waste

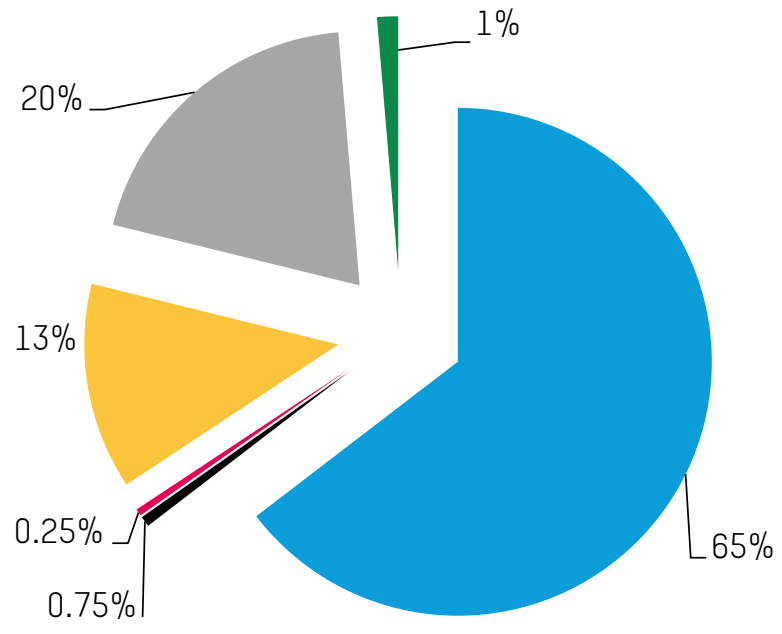

- Wives / women

- Girls

- Boys

Men / husbands

- Shared (husband and wife)

- Another woman within the household

Figure 12: Person in the family responsible for hygiene 
Almost half of respondents (49\%) said they had to walk between 30 minutes and one hour to make a return journey from home to the closest water source (Figure 13).

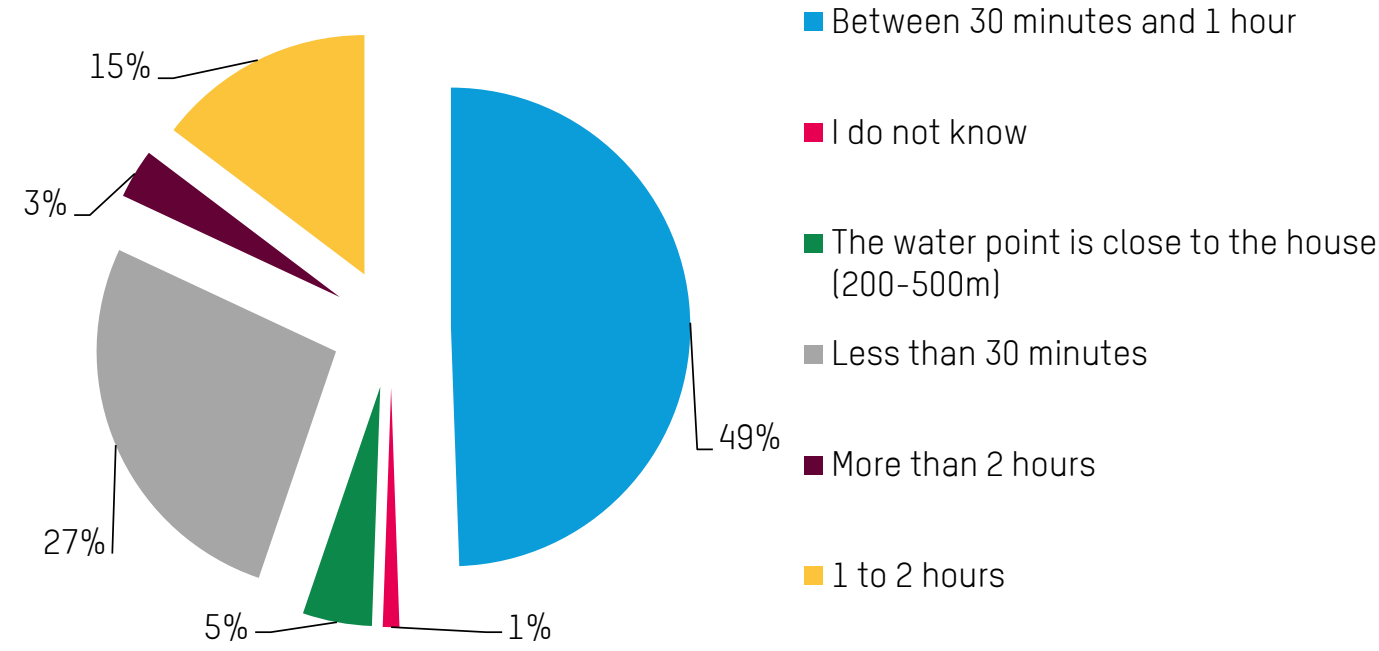

\section{Figure 13: Distance and length of time to fetch water and return home}

In relation to household chores, especially WASH activities (though not exclusively), it was evident from FGD responses on the typical day in the life of a woman, man, boy and girl that women and girls work longer hours than men and boys. Women and girls are also responsible for gathering wood, washing clothes, preparing food and other household chores. Some boys aged 10-14 said that they helped their families with collecting firewood or sometimes with fetching water or sweeping the plot in front of the house, and some IDP men said that they helped more in the household by being carers for the children, but most of the burden of household work falls on women and girls. This was true both before and after the crisis, with the only difference being the added insecurity.

As seen in Figure 14,64\% of all respondents said that they did not feel safe at water sources, and $71 \%$ said that they also did not feel safe going to the toilet (Figure 16). The results were identical for responses disaggregated for men and women, indicating that it is likely men fear for their own safety but also for that of women. For $57 \%$ of those who did not feel safe using water sources, the reasons given were the distance from their homes and intercommunity tensions. For $80 \%$ of those who did not feel safe going to the toilet, the main reason was the lack of locks and privacy (toilets are usually located outside, and are not constructed with durable materials or sufficient coverl. It is important to note that both men and women had similar concerns and gave similar answers, which would indicate that community tensions and the fear factor caused by these tensions and the potential for conflict are very high, and that as a result everyone feels at risk.

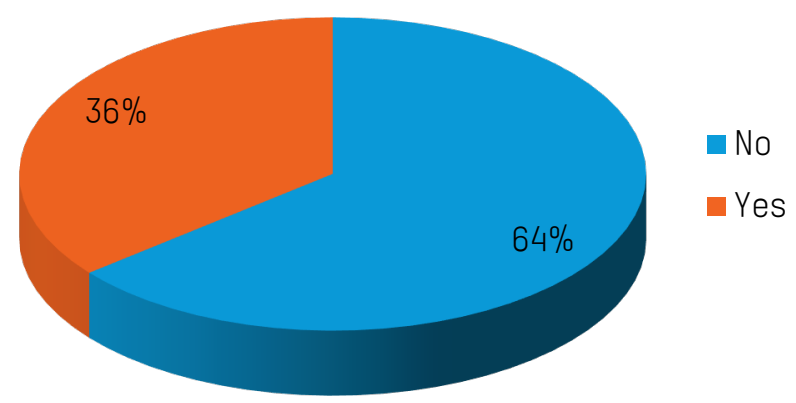

Figure 14: Do you feel safe at the water point? 


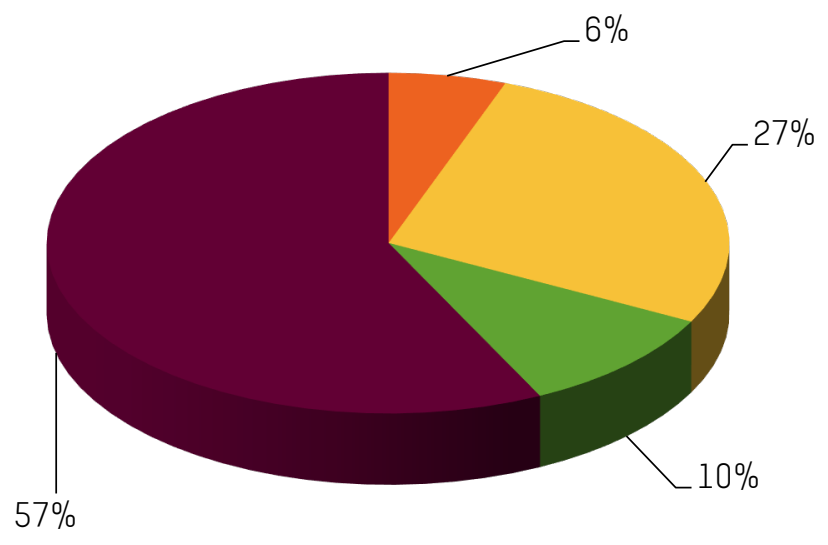

Other

- Conflicts with other communities using the same water point

Insecurity on the way to the water point

- Too far away from home and conflicts with communities using the same water point

Figure 15: Reasons why you do not feel safe at the water point

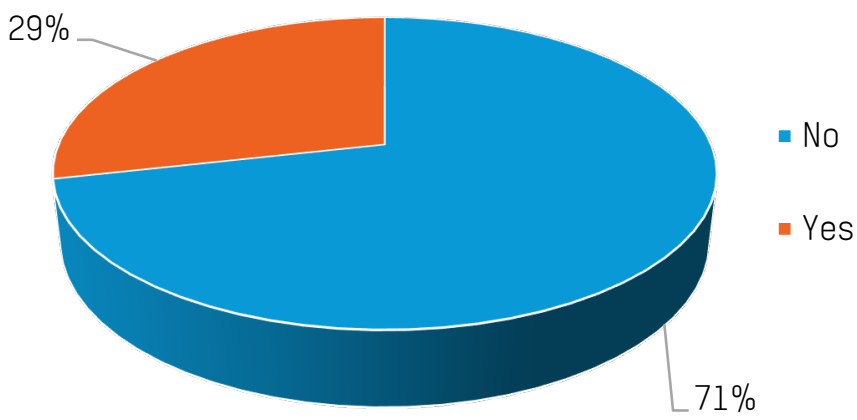

Figure 16: Do you feel safe while going to the toilet?

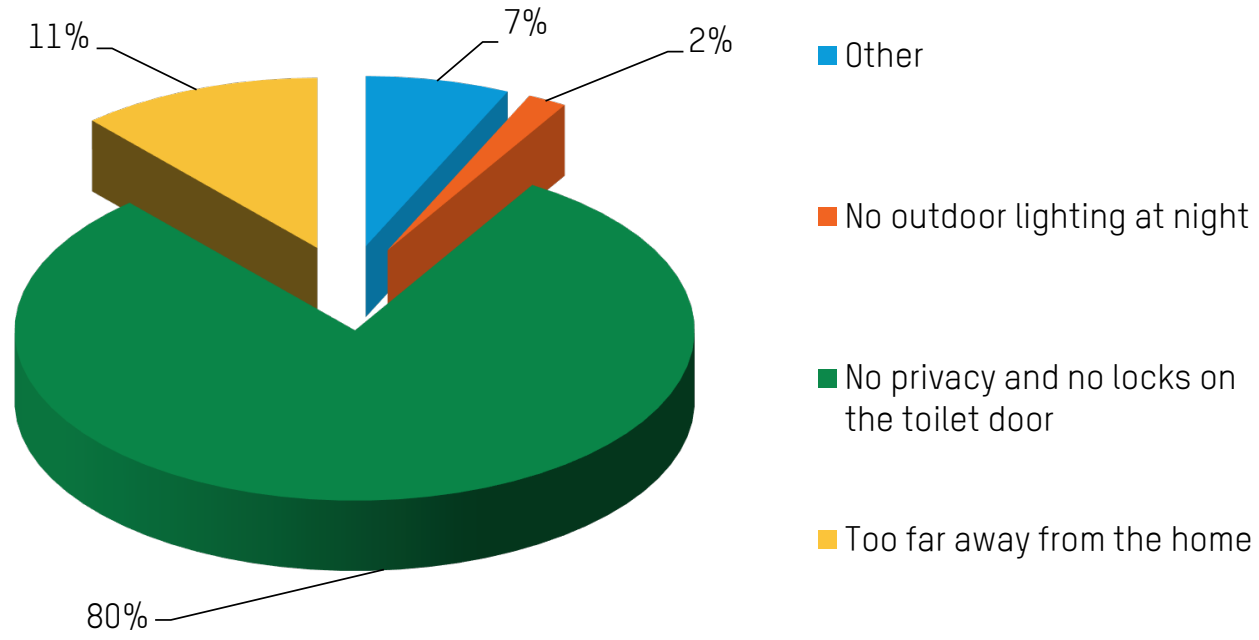

Figure 17: Reasons why you do not feel safe going to the toilet

The majority of households are using inadequate water and sanitation facilities. Only $55 \%$ of respondents said that they had their own toilet, and $78 \%$ of households responded that they were currently sharing a toilet with other households. As expected, the lack of toilet facilities also means that there are very few separate facilities for men and women, with $83 \%$ of respondents reporting that they used communal facilities.

With regards to menstrual hygiene, most women and girls (51\%) said that they used cloths that they washed and reused, with $63 \%$ of respondents using some form of homemade menstrual hygiene item. Only $18 \%$ of respondents 
said that they could afford to purchase disposable sanitary pads, though another $12 \%$ were able to obtain them from other sources (Figures 18 19). This was corroborated by participants in the FGDs, who added that they washed themselves several times a day to ensure hygiene.

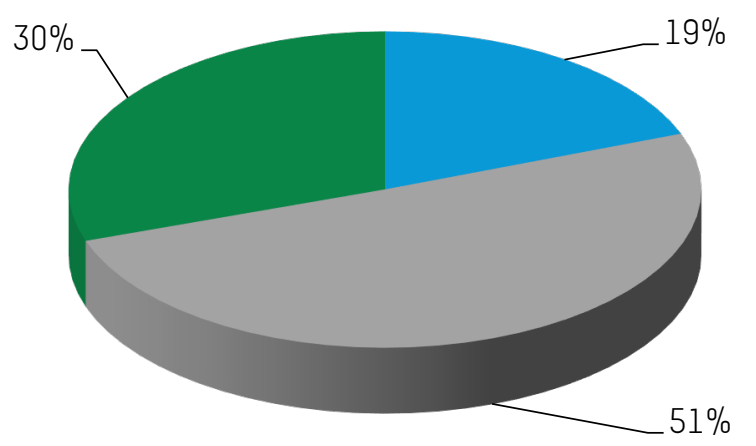

\author{
- Other \\ Reusable cloths \\ - Disposable sanitary pads
}

Figure 18: What do you use for your menstrual hygiene?

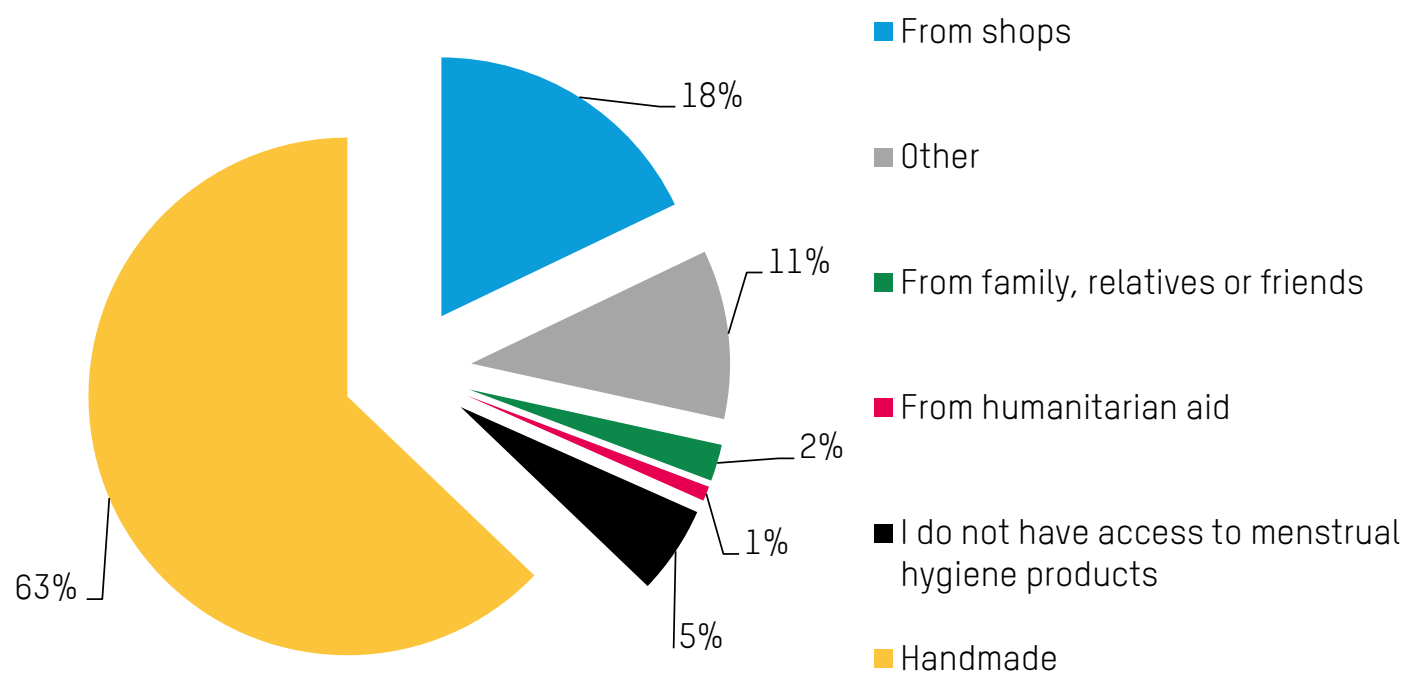

Figure 19: How do you have access to menstrual hygiene products?

The $11 \%$ who responded 'Other' to this question were either using unhygienic products, asked a neighbour for items or no longer needed menstrual hygiene products. When it comes to disposal of these products, the majority do not dispose of them correctly (Figure 20).

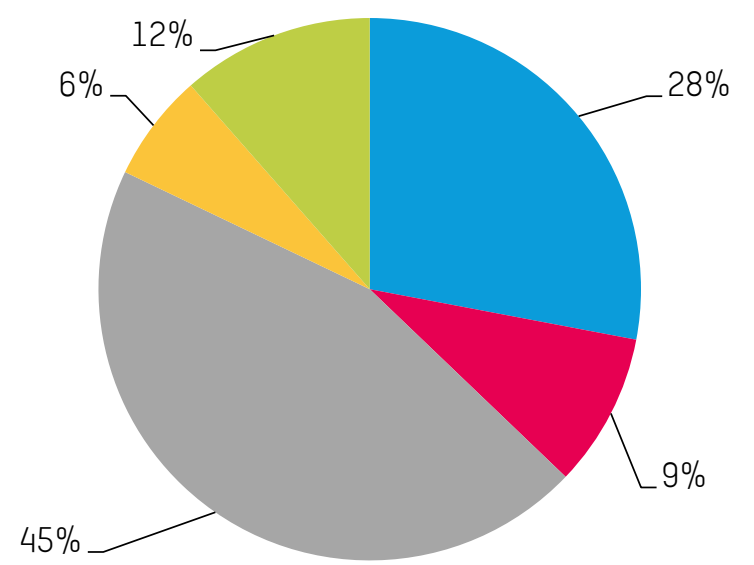

- In the latrines

- In the bins

I throw them away

I burn them

I bury them

Figure 20: How do you dispose of menstrual hygiene products 


\section{Access to food, livelihoods and productive land}

In both the villages and the towns falling under the scope of this study, agriculture is the main subsistence sector and the bulk of agricultural work is done by women, with men involved more in activities relating to diamond extraction (Figures 21 and 22), especially so for the IDPs - figure 21 . With answers disaggregated by gender, $56 \%$ of women said that they were involved in agriculture and $24 \%$ of men said that they were involved in diamond extraction, making agriculture, which is dominated by women, the main source of livelihoods.
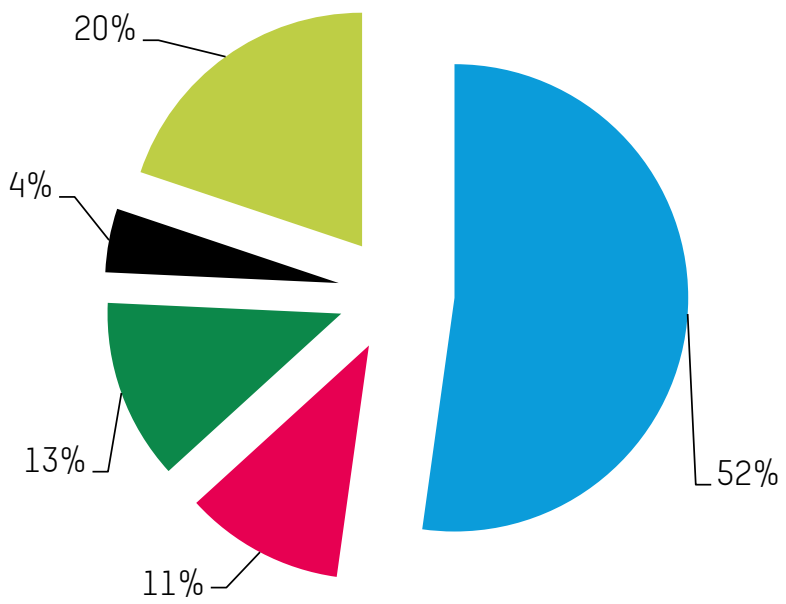

Agriculture

- Other

- Small shop

- Domestic chores

Diamond extraction

Figure 21: Main activity before the crisis (all IDP respondents)

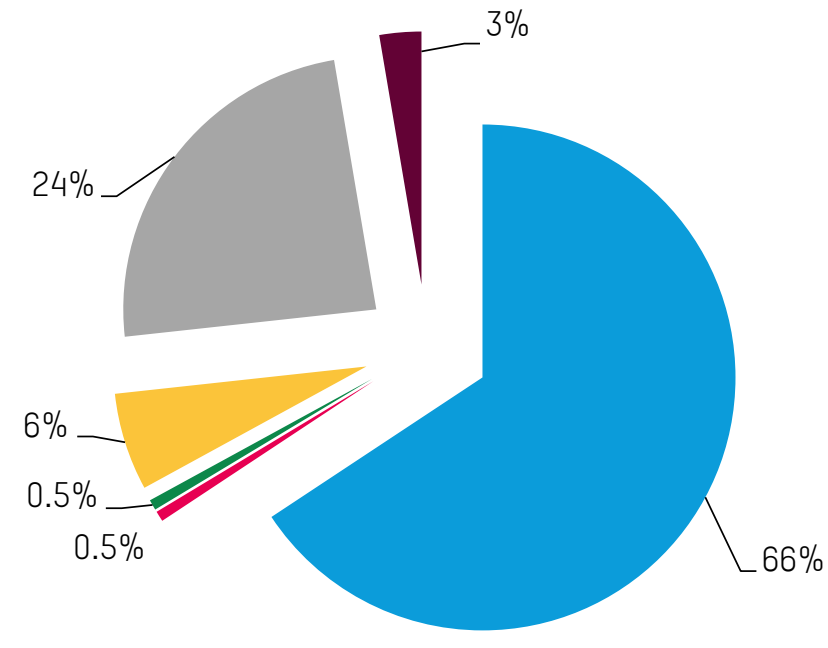

Wives

- Girls

Boys

Men / husbands

Shared

- Another woman within the household

Figure 22: Person in the household responsible for agricultural work

In the current context, many IDPs are unable to continue with their previous livelihood activities due to the crisis. This was the case for $60 \%$ of women and $62 \%$ of men, with the main reasons given being a lack of access to land and a lack of tools. The $23 \%$ who responded 'Other' were either working for the government, had jobs such as driver, mechanic or preacher, or were involved in livestock management (Figure 23). 


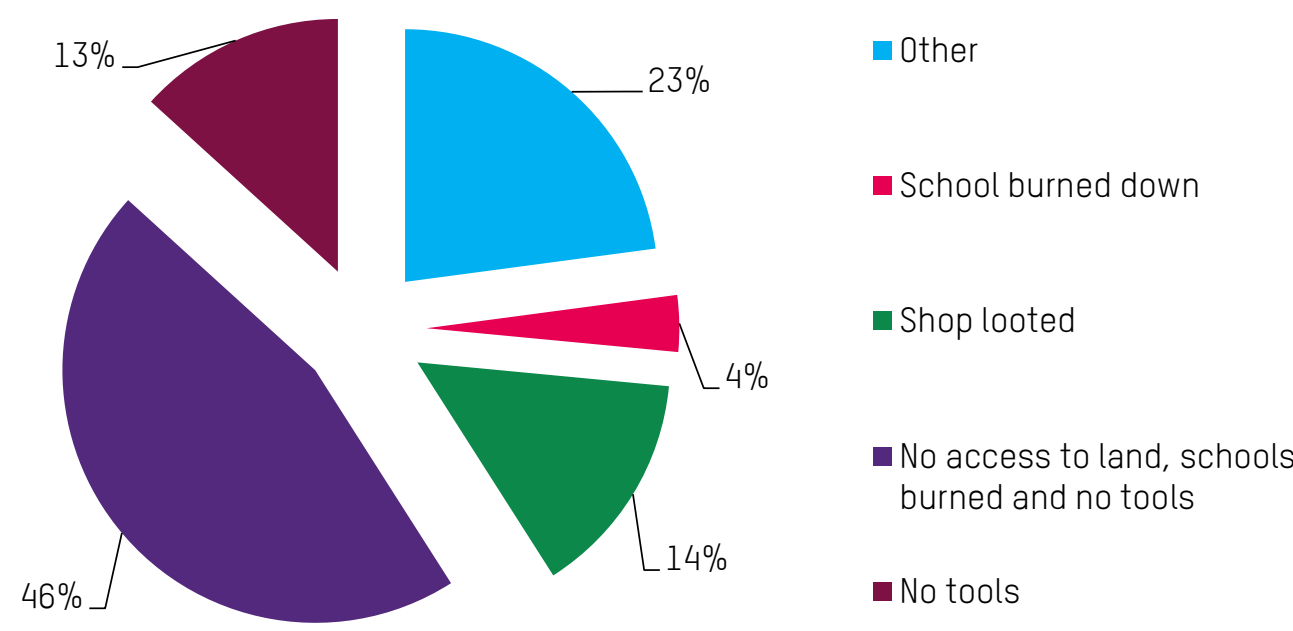

\section{Figure 23: Reasons for not carrying out the same activity today (all respondents)}

The FGDs indicated that the same concerns existed in host communities, with participants expressing the need for tools and seeds. Overall, the biggest concern for the majority of participants was that they no longer had access to their fields; this same answer was given by men, women, boys and girls. This lack of access means that people are unable to produce food crops for direct consumption or cash crops to generate household income, thus negatively affecting their nutritional status and food security. This supports the earlier finding of the UN Office for the Coordination of Humanitarian Affairs (OCHA) that most families in Kasai have now missed two consecutive planting seasons, which has led to the region being categorized as food-insecure. ${ }^{24}$

Information gathered from the FGDs indicated that men are in charge of livestock management, while women are mostly responsible for poultry management. This division of labour supports and is reinforced by customary household roles. The loss of livestock was a key finding from the FGDs, with participants reporting that animals had been stolen by armed groups or had been sold in order to raise ready cash for survival. Livestock is often a crucial form of capital, and the loss of animals has deprived affected communities, and especially men, of crucial economic assets and a potential coping mechanism, which in turn increases their vulnerability and that of their households.

The primary data collected corroborate previous estimates of high rates of malnutrition in the affected communities. The World Food Programme (WFP), for example, has reported that nine out of 10 people are foodinsecure in the worst-affected communities and that one in two is severely food-insecure. ${ }^{25}$ In many FGDs, youth and male participants said that they went for days without eating and that mangoes were the only food source, either for their own consumption or for sale. This was also noted in the enumerators' observations and in the KIls. Villagers participating in an FGD for girls aged 15-19 gave this as an example of the extremely rough coping mechanisms they have had to resort to: 'Having two mangoes a day is a return to primitive living'. ${ }^{26}$

The findings also indicate that the coping abilities of communities vary according to location, with larger towns Tshikapa and Kamonia - being better able to provide inhabitants with resources and products, as shown by the presence of small, medium and large markets. The surrounding villages, however, host only small markets offering few and basic products, and provide extremely limited options in terms of livelihoods. Of all the 449 survey respondents, $65 \%$ said that they did not have a source of income in their family. With the town locations removed from the analysis, $72 \%$ of respondents from villages had no source of income. When the answers of host communities and IDPs were separated, $75 \%$ of IDP respondents said that they had no income. These groups thus find themselves in a much more difficult situation compared with people in towns. Respondents also noted that the cost of living had increased since the crisis began.

The loss of livestock, the reduction of income-generating activities, the increase in the cost of living and the lack of access to agricultural activities have resulted in the population becoming extremely food-insecure. It is clear from the analysis of all data gathered that pregnant and breastfeeding women, elderly people, orphaned children, disabled people and widows/female-headed households in particular are very vulnerable. Just over half (51\%) of the survey respondents said they had at least one person in three very vulnerable categories (pregnant women, breastfeeding women or women with a chronic illness) in their family at the time of the mobile data collection. This would indicate that approximately half of families are food-insecure, although the details of chronic disease were 
not investigated. Responses on the way that families prioritize food intake paint a bleak picture, showing children and other women in the household to be the most vulnerable, with under 3\% of households prioritizing each of these groups, followed by $22 \%$ of households prioritizing wives, ${ }^{27} 23 \%$ sharing between husband and wife and $49 \%$ of households prioritizing men (Figure 24).

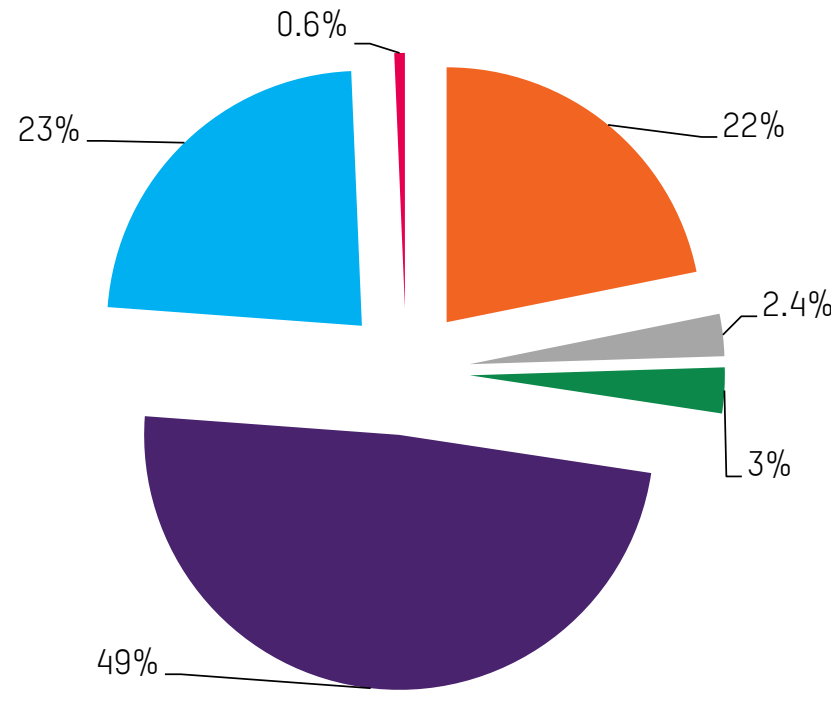

Women / wives

घirls

Boys

Men / husbands

- Shared

Another women in the household

Figure 24: Family member prioritized within the household with regard to food distribution

Further, while polygamous households were not accounted for either in the FGDs or the mobile data collection, and while most NGO representatives interviewed said that they ensured that women were targeted when delivering food, it seems quite likely that polygamous households are facing a disproportionate degree of vulnerability and that humanitarian assistance may be insufficient. Overall, the information collected through the KIls pointed to a shortage of aid, resulting in some households being overlooked. Although no secondary sources were found relating specifically to polygamy in Kasai province, again the KIls offered additional insights. Both male and female interviewees noted that polygamy was extremely widespread in the region, being practised by as many as $80 \%$ of all households; according to one male key informant, 'in villages all men have at least two wives' with the average polygamous household being one with three wives. One female key informant said that men did not support all their wives equally and that, more often than not, they supported only the last wife. ${ }^{28}$ Three female key informants claimed that polygamy was a source of unhappiness for women and one male interviewee said that 'men in Kasai use polygamy so that they can use the women as production units'. ${ }^{29}$ This information suggests that, since aid is insufficient generally, polygamous households need to be specifically targeted.

\section{Access to healthcare, including sexual and reproductive healthcare}

The main health issues identified in the study areas since the crisis began were malnutrition and diarrhoea, with $59 \%$ of all respondents mentioning both of these. They were followed by wounds caused by violence, including sexual violence (Figure 25). Children, pregnant women and breastfeeding mothers are those most likely to suffer from malnutrition, given the food prioritization described above. Women and girls are also more likely to be victims of sexual violence given their responsibilities for WASH and agricultural tasks, which increase their risks while going to the fields or to fetch water. The information collected during the study confirmed this. For example, one female FGD participant said, 'There are threats everywhere'; ${ }^{30}$ another female pointed out, 'Women and girls are the most exposed due to the distance, there are many risks because of the distance'; ${ }^{31}$ and a girl aged $15-19$ said in an FGD, 'Everything is limited because of the destruction and the fear of being raped on the way.' ${ }^{32}$ Further details on the security risks associated with these activities are discussed in the section below on GBV. 


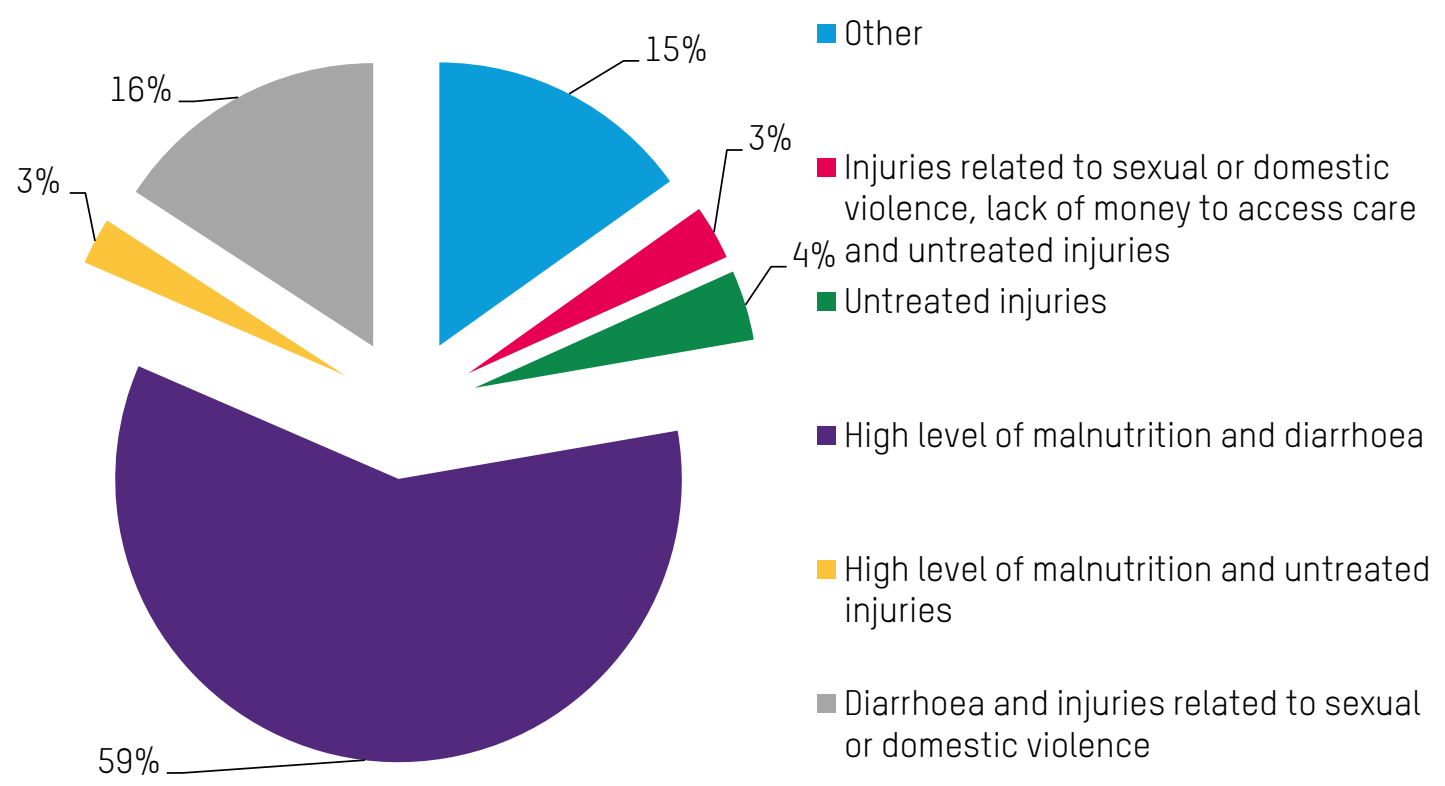

Figure 25: Main health issues since the conflict began

For victims of sexual violence, respondents to the survey mentioned stigmatization and cost as the main impediments to accessing health services, with strikingly similar answers for both men and women, indicating that men are also aware of the stigma associated with sexual violence (Figures 26 and 27). This information was supported by the findings of the FGDs and the KIIs, especially with regard to cost.

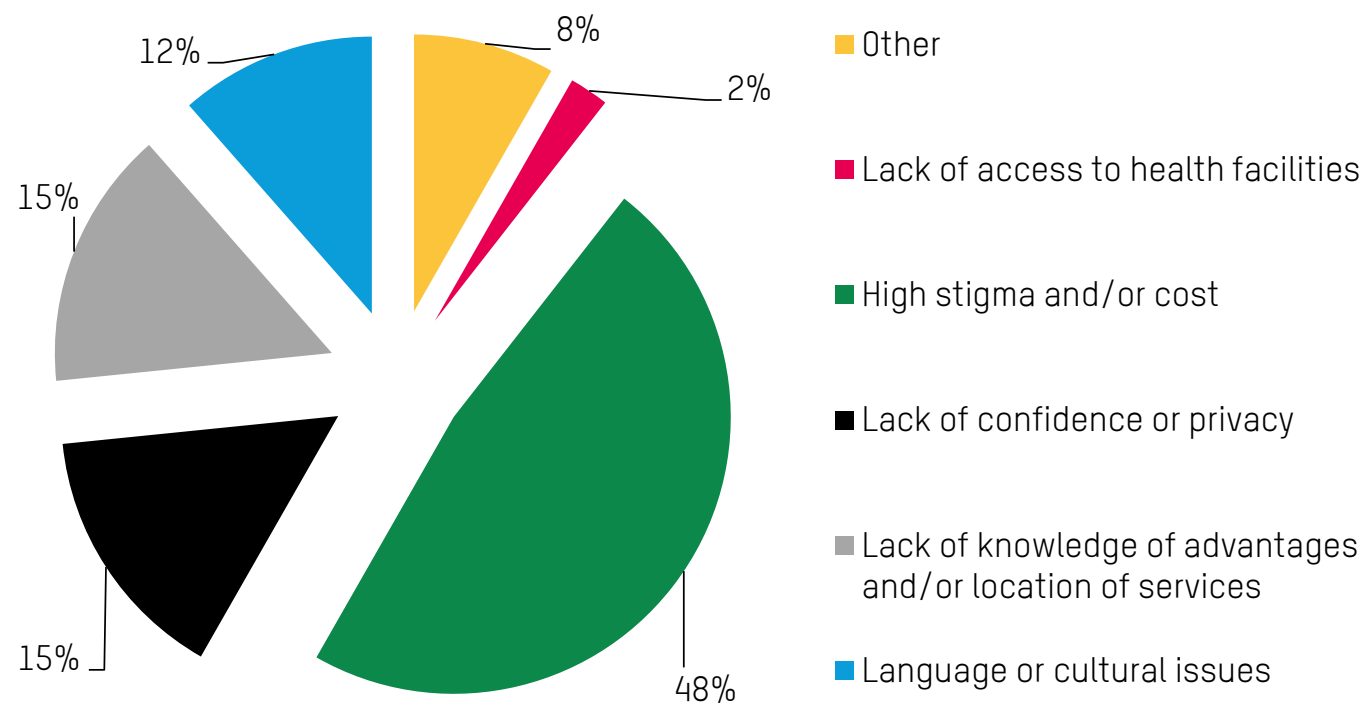

Figure 26: Obstacles faced by survivors in accessing healthcare related to sexual violence (female respondents) 


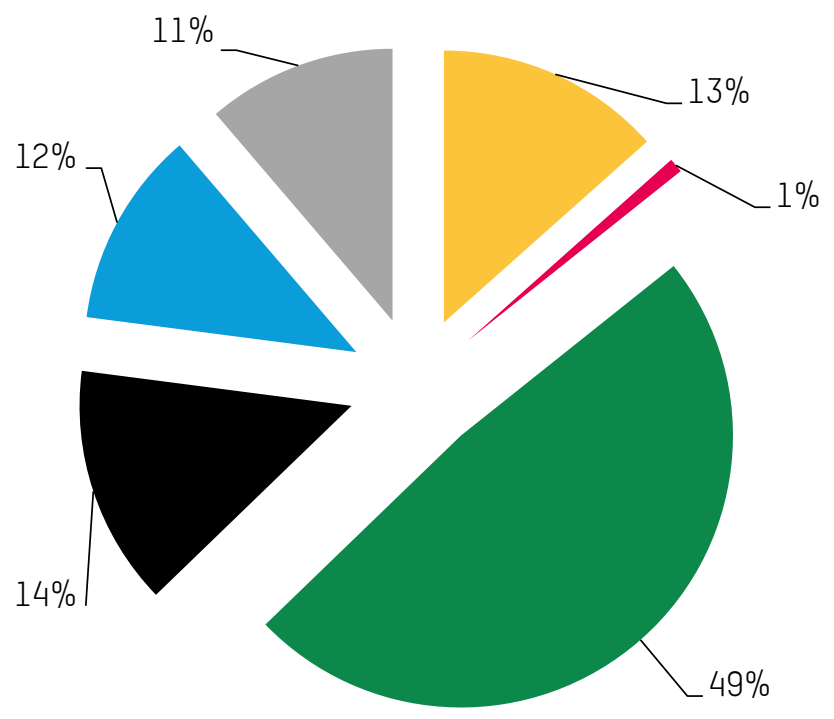

Other

- Lack of access to health facilities

- High stigma and/or cost

Lack of confidence or privacy

- Lack of knowledge of advantages and/or location of services

- Language or cultural issues

Figure 27: Obstacles faced by survivors in accessing healthcare related to sexual violence (male respondents)

DPS statistics for January-October 2017 record 39 maternal deaths for 126,992 births, and 472 cholera cases registered. However, this information was gathered only from health centres, and half the population do not have access to these centres. Almost half of respondents (47\%) said that childbirth took place in a health centre (Figure 28), but the majority of FGD participants, both adult male and female and especially those in villages, said that pregnant women gave birth at home either alone or with a midwife, due to a lack of money, lack of available health facilities or the distance to health facilities. This situation is made worse by the increased insecurity caused by the conflict, which discourages people from walking long distances. Those interviewed for the Klls - both male and female - also reported that a high number of girls in Kasai under the age of 18 were mothers, given the widespread practice of early marriage. These girls are even more vulnerable to complications from a home birth.

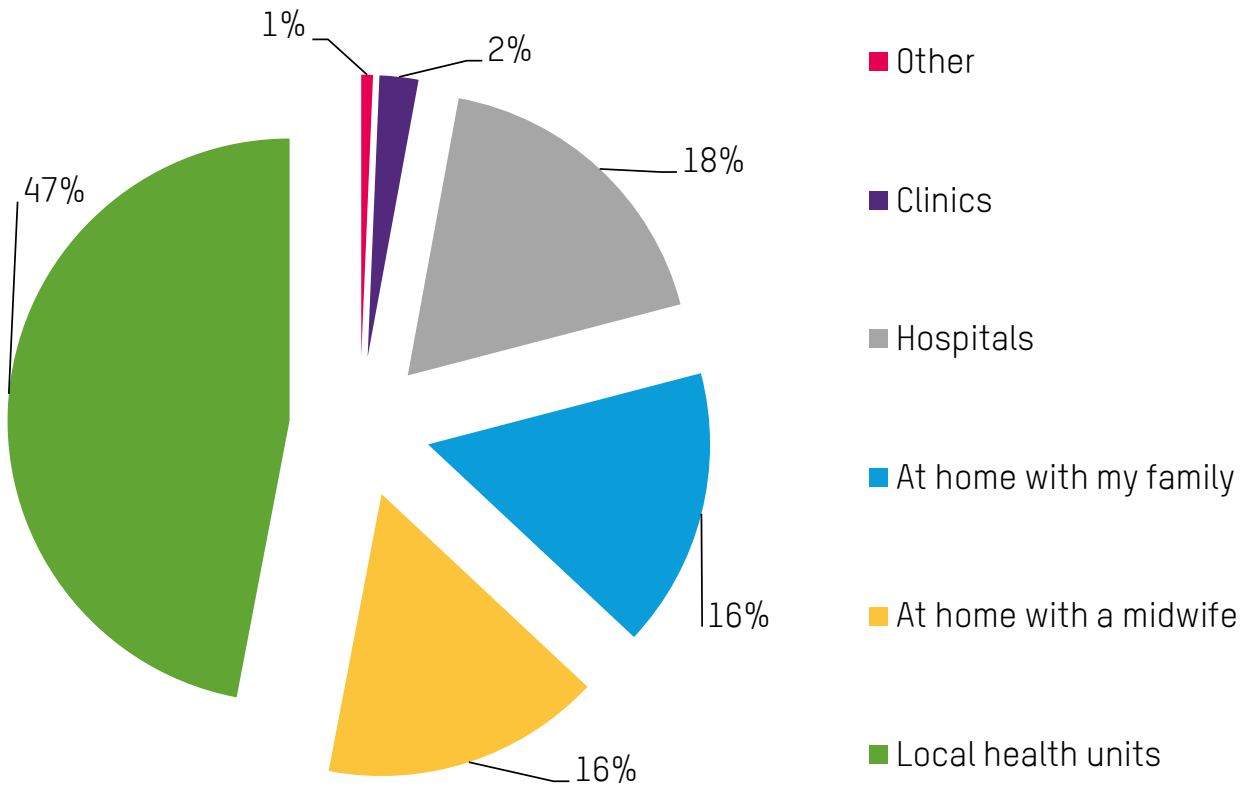

Figure 28: Locations where women give birth

Many harmful health practices were highlighted by the FGDs, with a majority of participants mentioning local practitioners and traditional medicine as the main resorts for health problems, while a few also said that people took sick people to churches or prayed for them at home due to a lack of other means. The situation has only deteriorated since the onset of the crisis. 
It is also important to note the potential psychosocial effects of the crisis. Many FGD participants, both male and female, expressed intense feelings of fear and said that they had either witnessed deaths and incidents of sexual violence directly or that they had heard of them happening. Some key informants, both male and female, said that prior to the conflict they had never heard of such forms of violence being perpetrated in Kasai. A woman from a local NGO said explicitly, 'The boys and girls who were in the militia need psychosocial support because they were kidnapped and for everything else they have seen and done, and even me too for what I have heard. ${ }^{33}$ Participants in an FGD for IDP boys aged 10-14 cited fear and stigmatization on account of what they had been through. Various key informants working in the schooling system said that IDPs faced discrimination and that there were increased tensions amongst students on account of their ethnicity, which undoubtedly puts a big strain on children. Girls and boys taking part in FGDs both said that they now felt more dependent on their parents for everything, while prior to the crisis they felt they could do more; they also expressed feelings of fear and hopelessness.

Furthermore, respondents reported that a large proportion of adult male IDPs felt that they had lost their traditional roles and authority in society due to their current inability to practise key livelihood activities, with one male FGD participant opining, 'Men have lost their power as men.'34 This could potentially have various impacts on psychosocial health as well as on social and household dynamics within the community. While this point did not emerge directly from the FGDs or KIls, it did come out indirectly in people's testimonies. Coping mechanisms were limited in general, with none noted or observed for these psychosocial effects.

\section{Access to education}

In terms of access to education, the situation in Kasai province is dire. The overall literacy rate in the province stands at around $25-30 \%$, according to local government sources, although no clear data are available. Statistics from the Division de Genre, Enfant et Famille put literacy rates at 35\% for men, 45\% for girls and highest for boys at $66 \%$, but women's literacy is currently the lowest at $22 \%$. This means that a staggering, $65 \%$ of adult males, $55 \%$ of girls and $78 \%$ of the adult female population are illiterate.

Many respondents in villages reported that the majority of schools had been destroyed, either burned or looted. Most officials have left, including teachers, and they are afraid to return due to inter-communal tensions. In the towns, most of the children interviewed lamented the shortage of school furniture and the lack of essentials such as backpacks, books, pens and stationery. Most children have to take their own chairs to school, though many schools also lacked furniture prior to the conflict, reflecting the widespread poverty of the province. In areas where schools are still functional, the main factor deterring children from attending is the lack of means to pay for tuition fees. Some children participating in FGDs, both girls and boys, also said that the long distances they had to travel to reach school and the high levels of insecurity also discourage them from going.

Statistics for Kasai province obtained from the Division Provinciale pour l'Enseignement Primaire, Secondaire et Professionnelle (the Provincial Education Department) show a decline in overall student numbers in primary school between September 2016 and September 2017, with a small increase in numbers in secondary and vocational education over the same period (Tables 2 and 3). There are fewer children pursuing secondary education compared with primary education, but the drop is bigger for girls in percentage terms, from $43 \%$ of all pupils to $36 \%$ in $2016 / 17$ and from $44 \%$ to $34 \%$ in $2017 / 18$. Numbers of female teachers are also very limited, with women accounting for just $19 \%$ of primary school teachers in both years, and falling from $9 \%$ to just $8 \%$ in secondary education. However, it is important to note that there were also very few female teachers before the crisis began, so this is not a result of the emergency.

\begin{tabular}{|l|l|l|}
\hline $\mathbf{2 0 1 6 / 1 7}$ & Primary & Secondary \\
\hline Girl students & $282,684-43 \%$ & $65,363-36 \%$ \\
\hline Boy students & $372,826-57 \%$ & $114,722-64 \%$ \\
\hline Female teachers & $4,036-19 \%$ & $1,440-9 \%$ \\
\hline Male teachers & $17,292-81 \%$ & $13,950-91 \%$ \\
\hline
\end{tabular}

Table 2: Ratio of boy/girl students and male/female teachers in primary and secondary schools in 2016/17

\begin{tabular}{|l|l|l|}
\hline $2017 / 18$ & Primary & Secondary \\
\hline Girl students & $270,867-44 \%$ & $62,260-34 \%$ \\
\hline Boy students & $346,225-56 \%$ & $122,582-66 \%$ \\
\hline Female teachers & $3,930-19 \%$ & $1,326-8 \%$ \\
\hline Male teachers & $16,622-81 \%$ & $14,561-91 \%$ \\
\hline
\end{tabular}

Table 3: Ratio of boy/girl students and male/female teachers in primary and secondary schools in 2017/18 
The data also indicate that boys are being prioritized for school attendance. Information gathered from both female and male FGDs and from KIIs indicated that girls have much less access to education than boys, largely due to stereotypes and attitudes that a girl's place is not in school, or at least not for long. As one female FGD participant noted, 'Our husbands prefer to educate our sons and not our daughters. Of all household spending, $10 \%$ goes to girls' schooling.' ${ }^{35}$ An overall lack of awareness of the rights of girls was noted, with a couple of female key informants pointing out that families prefer to marry off daughters as soon as they begin menstruating, in order to ensure their virginity and thus a higher dowry. Two respondents working in the medical sector - one female and one male - confirmed that there was a practice of parents sending teenage girls to hospital to have their virginity tested.

For many families in the area studied, early marriage is a means of escaping poverty; this is coupled with strong observance of customary laws and traditions and a lack of knowledge of constitutional law. The age at which girls are married off is often extremely young, as indicated by respondents to the household survey (Figure 29). This was unfortunately also the case before the crisis began; both male and female FGD participants expressed the view that early marriages had increased following the conflict, though not by much. Both male and female key informants also raised the issue of child mothers, both before and after the crisis.

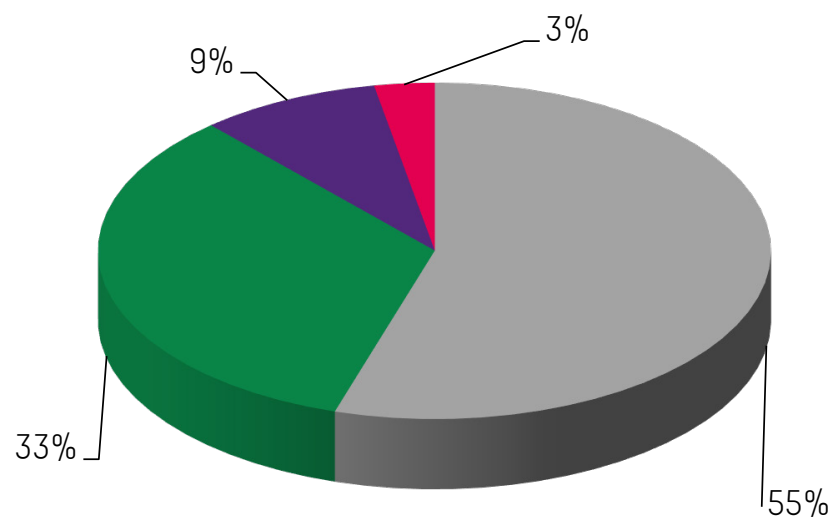

Age ranges: '15-18'

- Age ranges: '19-24'

- Under 15

Older than 25

Figure 29: Age at which girls get married

\section{Gender-based violence (GBV)}

The study's findings on GBV were similar to those of the GBV cluster evaluation carried out in Tshikapa in July 2017. ${ }^{36}$ In the present study, it is important to note that, in the FGDs, women, men, boys and girls all saw themselves as being vulnerable and facing the risk of some form of violence. A large majority cited various security risks and the presence of many checkpoints on roads, with aggressive behaviour by both armed groups and the military, and said that they were all at risk, especially when working in the fields or after dark.

An important finding was that understanding was limited of what domestic violence actually means, with the enumerators themselves having difficulty in translating the concept into local languages. In a KII, the provincial prosecutor said that cases were hardly ever reported, despite domestic violence being covered by the country's Penal Code. ${ }^{37}$ This was partly due to a lack of information on the services available and how to access them, but there are also a general lack of services and a lack of accessibility, with the majority of victims turning to family members or to community leaders to seek solutions to their problems.

Women's answers to the household survey, when they were asked what types of violence women and girls were most prone to, pointed to a variety of security risks (this was a multiple-answer question, hence several risks were repeated ${ }^{38}$ ). Overwhelmingly, women cited cases of rape, harassment, theft and domestic violence, with $56 \%$ of all respondents giving these four answers, while $13 \%$ highlighted forced marriage and domestic violence as the two main forms of violence (Figure 30). The answers were similar for all respondents, with $60 \%$ giving rape, theft, harassment and domestic violence as the main risks or forms of violence faced by women and girls (Figure 30a). 

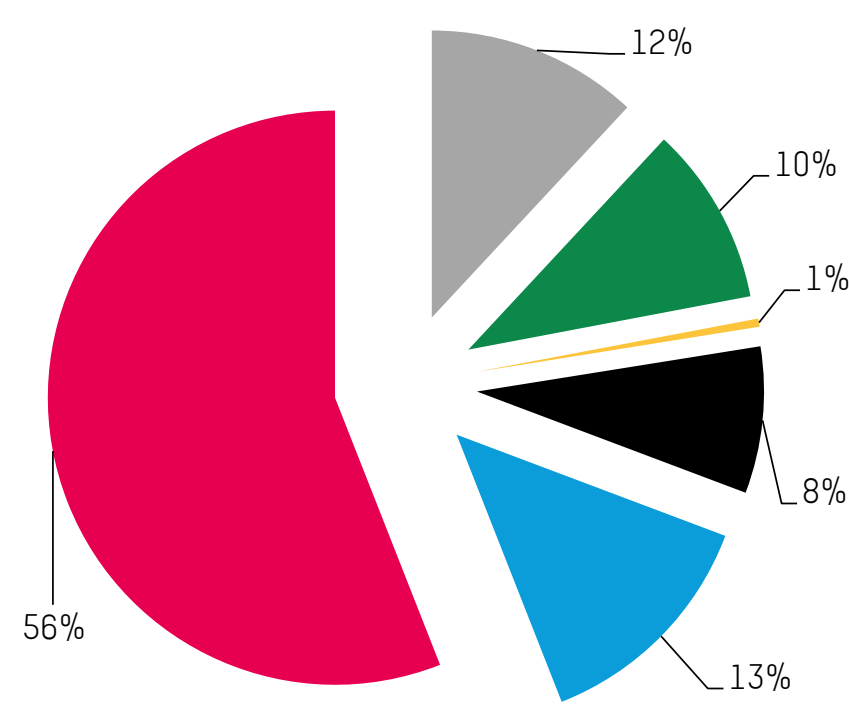

Aggression, theft and domestic violence

- Kidnapping and harassment

Extortion

Harassment and domestic violence

- Forced marriage and domestic violence

Rape, theft, harassment and domestic violence

Figure 30: Risks or other forms of violence faced by women and girls (women respondents)

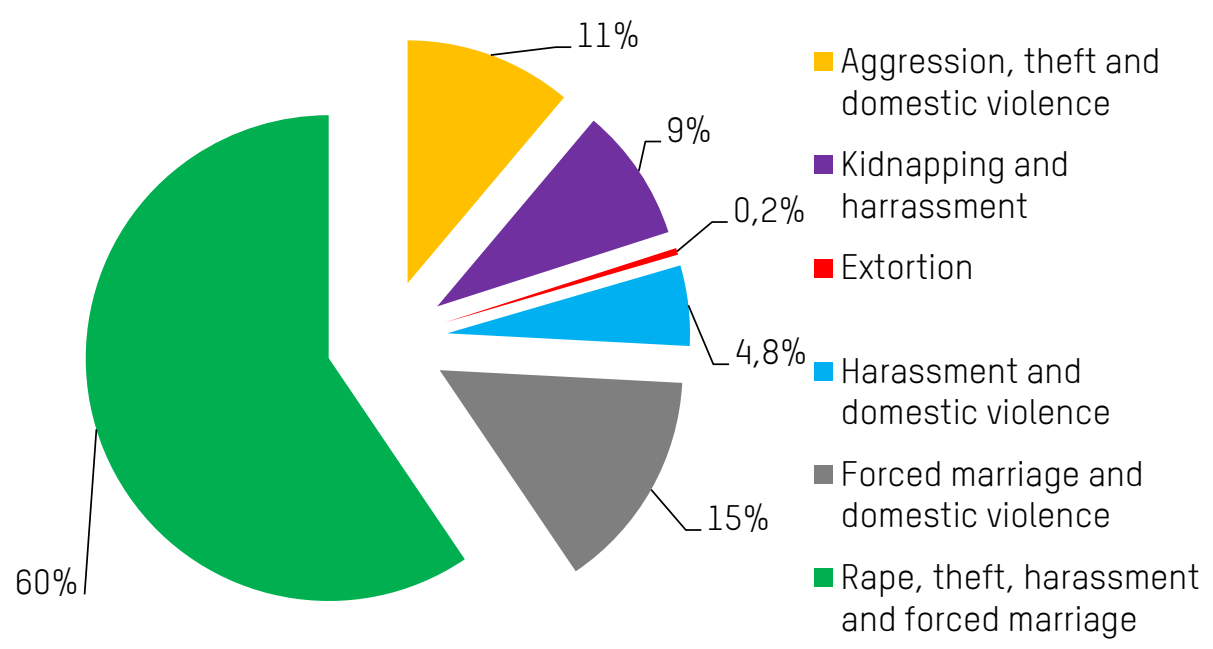

Figure 30a: Risks or other forms of violence faced by women and girls (all respondents)

When asked what type of violence or risks men and boys were most prone to, $40 \%$ of male respondents answered rape, harassment and physical violence, including injuries or death, and $28 \%$ gave their top answers as forced marriage, extortion and domestic violence (Figure 31). The results for all respondents were similar, with a large number ( $45 \%$ ) citing harassment, physical violence and rape, but $25 \%$ opting for forced marriage and domestic violence showing that boys are also vulnerable to forced marriage and men to domestic violence. 


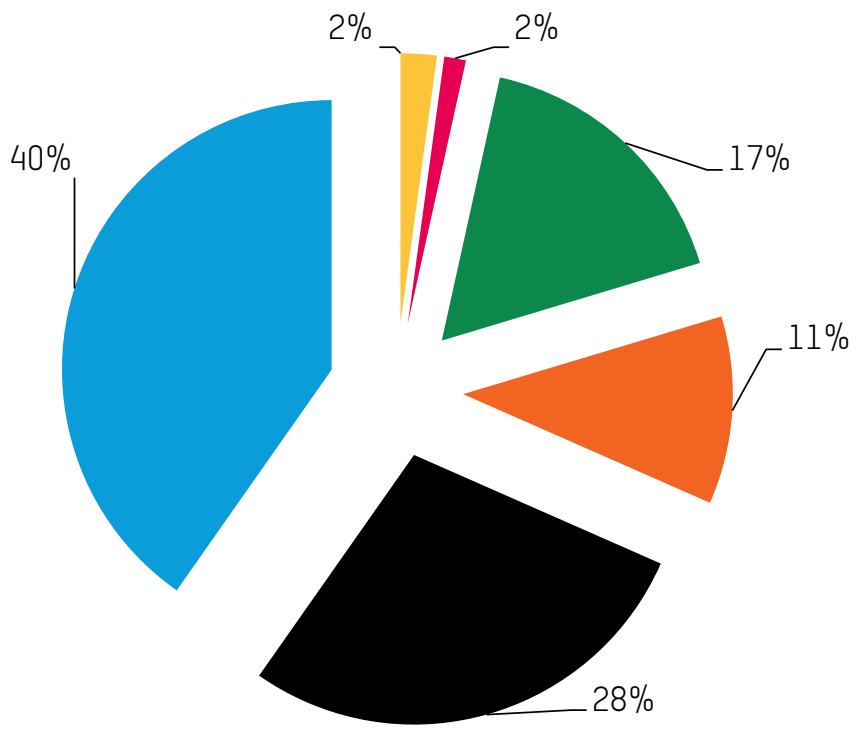

Aggression

- Other

Kidnapping, extortion and theft

- Harassment, domestic and physical violence, including injuries or death

- Forced marriage, extortion and domestic violence

- Rape, harassment and physical violence, including injuries or death

Figure 31: Risks or forms of violence faced by men and boys (male respondents)
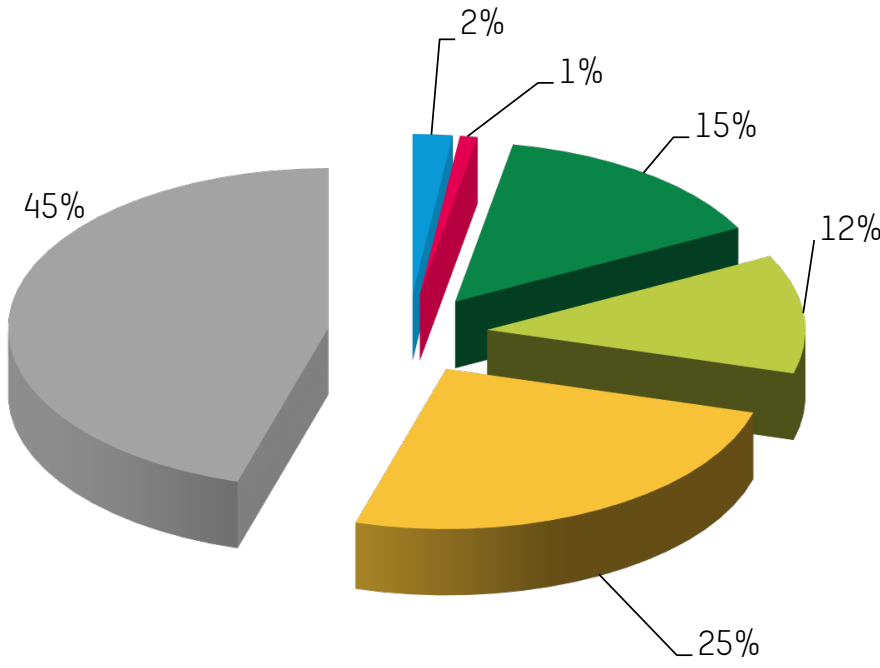

- Aggression

- Other

Kidnapping, extortion and theft

- Harassment, domestic and physical violence, including injuries or death

Forced marriage and domestic violence

Rape, harassment and physical violence, including injuries or death

Figure 3la: Risks or forms of violence faced by men and boys (all respondents)

The FGDs and data from the Division du Genre, Famille et Enfant paint a slightly different picture; women and girls were cited as being most at risk of rape, but a small number of cases of male rape were also reported (two out of 118 rape cases in July-August 2017, according to official figures). Some patterns emerged of risks and vulnerabilities to GBV arising from the crisis, with women and girls most at risk of sexual violence and men and boys most at risk of death and injury. In most KIls, both male and female respondents believed that men and boys were at risk of physical violence and of being injured or murdered during the conflict. The majority also said that there had been an overall increase in the number of GBV cases, but this was a perceived increase and there are no clear figures for the prevalence of GBV either before or after the conflict.

Types of GBV and activities that often involve security threats and were brought up in the FGDs are summarized for all four groups - women, men, boys and girls - in Tables 4 and 5. In the tables, ' $x$ ' signifies that the issue was raised in at least five different FGDs, 'xx' signifies 10 different FGDs and 'xxx' 15 different FGDs. 


\begin{tabular}{|c|c|c|c|c|}
\hline Type of GBV & Women & Men & Boys & Girls \\
\hline $\begin{array}{l}\text { Sexual violence: } \\
\text { rape, } \\
\text { sexual harassment, } \\
\text { forced prostitution }\end{array}$ & $x x$ & & & $x x x$ \\
\hline Robbery & $x$ & $x$ & $x$ & $x$ \\
\hline $\begin{array}{l}\text { Extortion; aggression } \\
\text { on roads and at } \\
\text { checkpoints }\end{array}$ & $x x$ & $x x$ & $x x$ & $x x$ \\
\hline $\begin{array}{l}\text { Early and forced } \\
\text { marriage }\end{array}$ & $\begin{array}{l}\mathrm{xx} \text { (forced } \\
\text { marriage) }\end{array}$ & & $\begin{array}{l}x \text { (early } \\
\text { marriage) }\end{array}$ & $\begin{array}{l}\text { xxx (early } \\
\text { marriage) }\end{array}$ \\
\hline $\begin{array}{l}\text { Physical violence, } \\
\text { including injury or } \\
\text { death }\end{array}$ & $x$ & $x x$ & $x x$ & $x$ \\
\hline Kidnapping & $x$ & & $x$ & $x$ \\
\hline
\end{tabular}

Table 4: Types of GBV

\begin{tabular}{|c|c|c|c|c|}
\hline $\begin{array}{l}\text { Activities when } \\
\text { security threats } \\
\text { occur }{ }^{39}\end{array}$ & Women & Men & Boys & Girls \\
\hline Collecting firewood & $x x$ & $x$ & $x$ & $x x$ \\
\hline Fetching water & $x$ & & & $\mathrm{x}$ \\
\hline Going to school & & & $x$ & $x$ \\
\hline While in the toilets & $x$ & & & $x$ \\
\hline $\begin{array}{l}\text { Carrying out income- } \\
\text { generating activities } \\
\text { or other livelihood } \\
\text { activities }\end{array}$ & $x x$ & $x$ & $x$ & $x$ \\
\hline Going to the market & $x x$ & $x$ & $x$ & $x x$ \\
\hline Going to the fields & $x x$ & $x$ & $x$ & $x x$ \\
\hline At checkpoints & $x$ & $x$ & $x$ & $x$ \\
\hline
\end{tabular}

Table 5: Activities when security threats occur

An IDP woman taking part in an FGD said that rape was now committed 'without shame or worry'. ${ }^{40} \mathrm{It}$ is important to note that the majority of rape cases, and especially those involving girls, are addressed along customary lines through a transaction between the families of the victim and the perpetrator, either in cash or in kind, with very few involving legal proceedings. This means that rape is only mildly condemned by social norms, but that reparation is needed and when reparation is provided the rape is accepted. Before the crisis, the majority of perpetrators were men or boys from the local community. The crisis has brought two new groups of perpetrators, armed groups and the military; FGD participants and key informants, both male and female, overwhelmingly confirmed that no customary arrangements apply to these groups.

In addition, most girls are at risk of early marriage and both girls and women are at risk of forced marriage. Early marriage was an issue in the community before the crisis erupted; as mentioned earlier, its practice is reinforced by customary laws and tradition and it is often seen by families as a means of escaping poverty. However, with the crisis some respondents argued that the incidence of early marriage had increased, possibly due to increased poverty and vulnerability. Forced marriage has also increased sharply since the crisis began. The term 'forced marriage' was used by respondents, when the victim was a girl, in the context of a dowry not being paid to her parents. For adult women, being forced into marriage was generally in the context of being abducted by armed forces. One female respondent from a local NGO said, 'With the crisis, [armed] men remove the girl by force and bring her home for marriage, including women already married with their children.' 41 Cases of girls and women being held captive for several days and cases of kidnapping were also reported by both male and female FGD participants and key informants, with the perpetrators always being armed militiamen or soldiers. One female key informant said of such cases, 'This is sexual slavery.' ${ }^{42}$ 


\section{Access to information}

A clear reflection of the high rate of illiteracy in the region is the lack of information available. Some $63 \%$ of respondents (both women and men) did not know what to do in the event of falling victim to GBV, including sexual exploitation and abuse (SEA). When data are disaggregated, they show a much higher number of women than men not knowing what to do, with $72 \%$ of women respondents and $56 \%$ of men saying that they had not received any information (Figures 32 and 33).

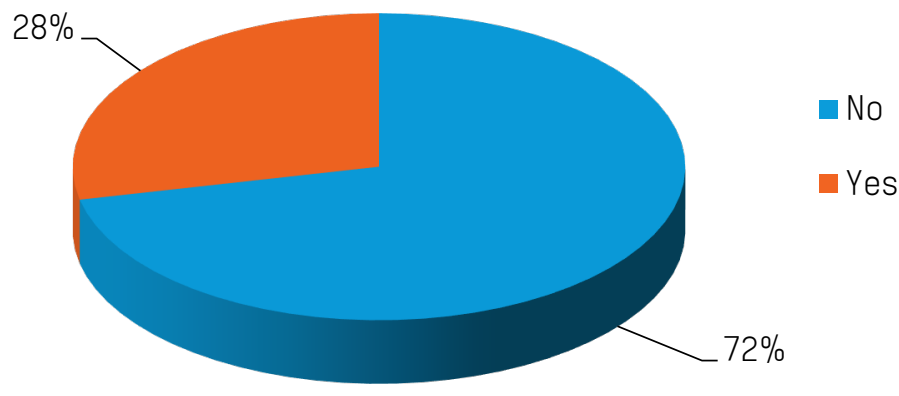

Figure 32: Information received on the procedure to follow if you are a victim of GBV, including SEA (women)

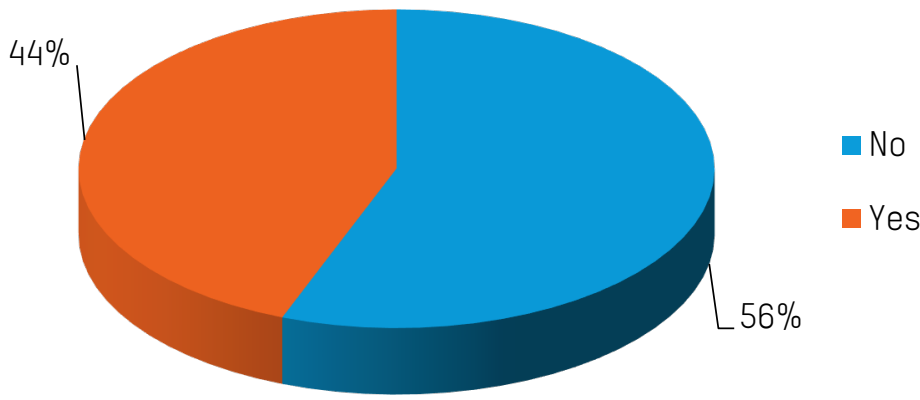

Figure 33: Information received on the procedure to follow if you are a victim of GBV, including SEA (men)

The FGDs showed that respondents living in the town of Tshikapa were more familiar with the services available for legal assistance, medical care and social reintegration; in some villages, however, such information was entirely lacking. This could be due to factors such as levels of education, access to technology and the concentration of services in the towns. In the FGDs held in villages, no coping mechanisms were noted for dealing with this lack of information. It is important to note that the Luba ethnic group is dominant in the area studied, and they have higher status in Kasai society and better access to education (Oxfam staff confirmed that the Luba generally have the most education]. It can therefore safely be assumed that the Pende and Tchowke communities have even less access to information.

\section{Patterns of power and household decision making, including control over assets and resources}

Feedback from both female and male FGDs and from KIls indicated that women in Kasai are marginalized and that it is mostly men who make decisions in the household. Men decide how to spend money earned or how to utilize food aid received. Some male FGD participants said that it was 'only the man, and never the woman' who decided on children's education or access to health services, and when children got married. One commented, 'Even other problems, always him, not the woman' - though the survey results showed a greater degree of shared decision making. ${ }^{43}$ Other male FGD participants underlined that a women's role was to take care of her household in general, and that in that role and those activities she was able to make decisions.

As shown in Figure 34, 74\% of all survey respondents said that it was the man in the household who made decisions on spending. Disaggregated by gender, $82 \%$ of male respondents said that they made such decisions, though only $65 \%$ of women said that it was men who decided (Figures $34 a$ and $34 \mathrm{~b}$ ). This indicates that some 
decisions may be quietly managed by women; this is supported by the fact that some female FGD participants said that they also took decisions in the household, or that they shared them with their husbands.

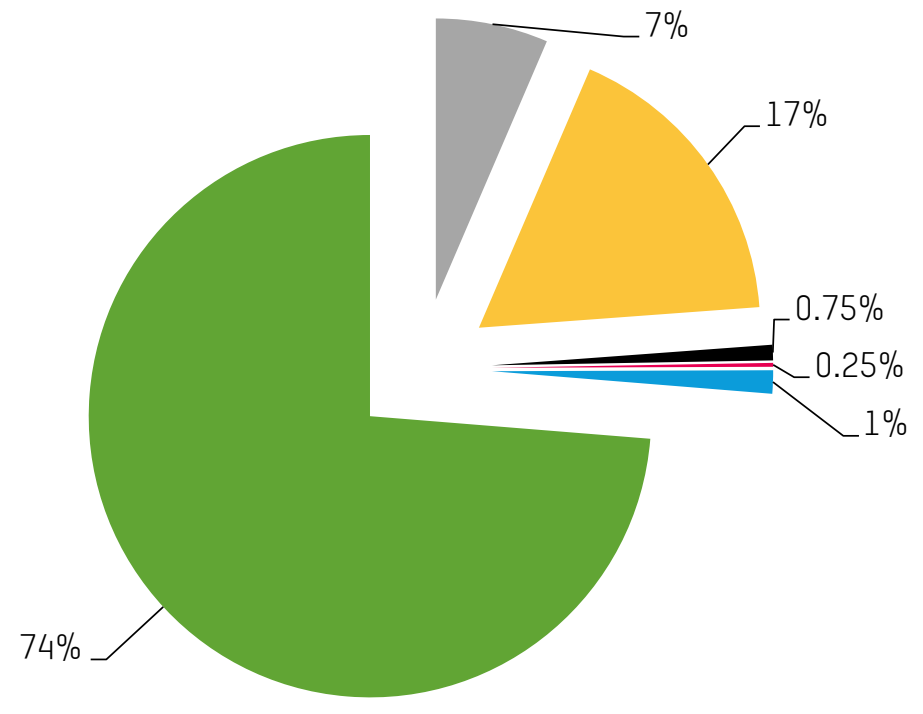

\author{
- Other \\ Women \\ - Elderly women \\ - Girls \\ Boys \\ - Men
}

Figure 34: Family member who decides on spending within the household (all respondents)

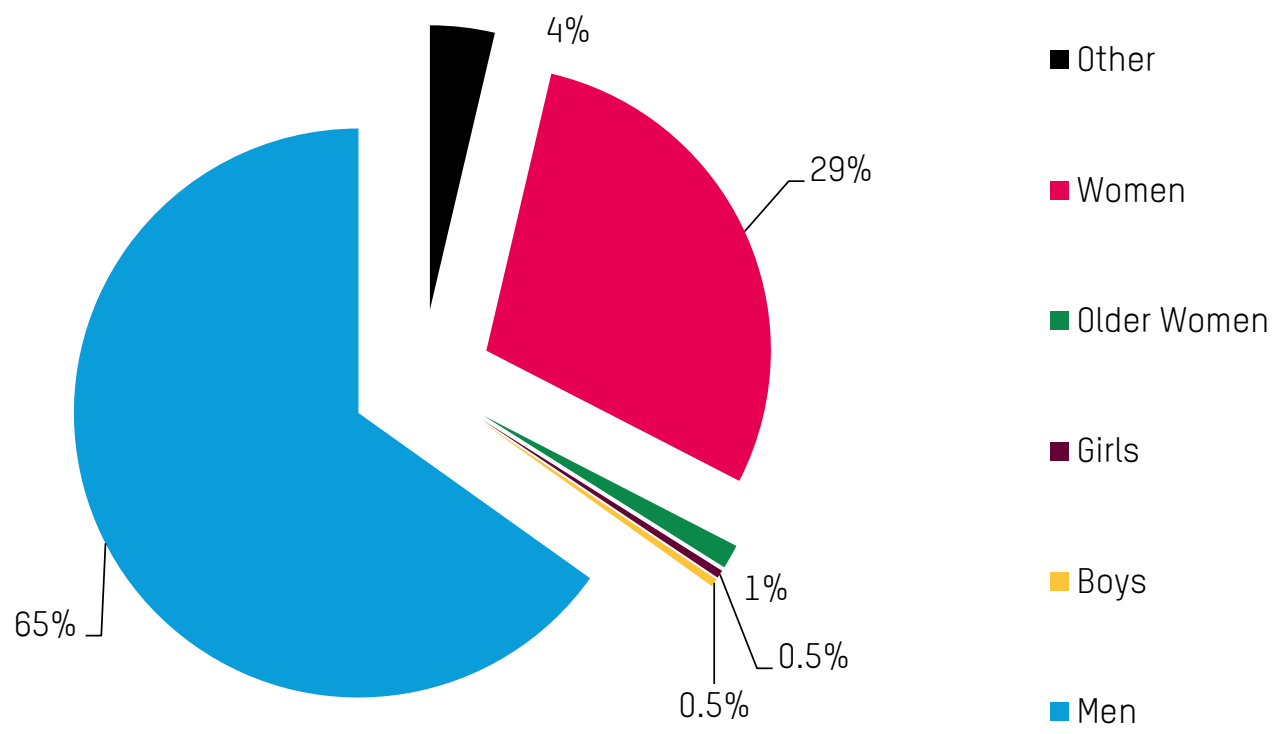

Figure 34a: Family member who decides on spending within the household (women respondents) 


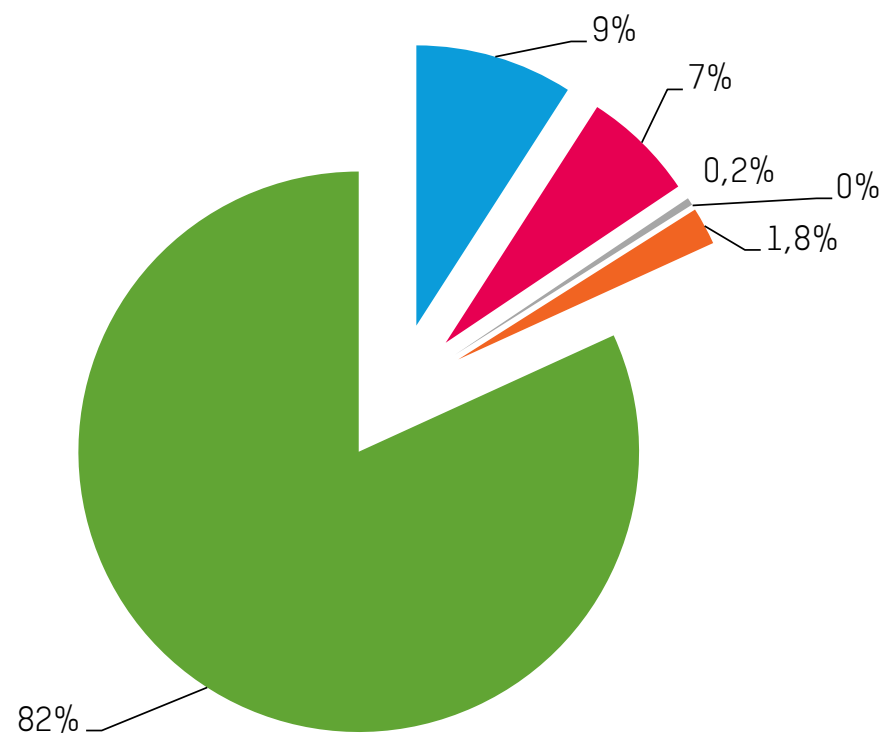

Other

Women

- Older Women

Girls

Boys

- Men

\section{Figure 34b: Family member who decides on spending within the household (men respondents)}

While women are mostly targeted for food distributions, it is ultimately men who decide how to use food aid, and men are also prioritized when it comes to food consumption within the household (as seen in Figure 24 above).
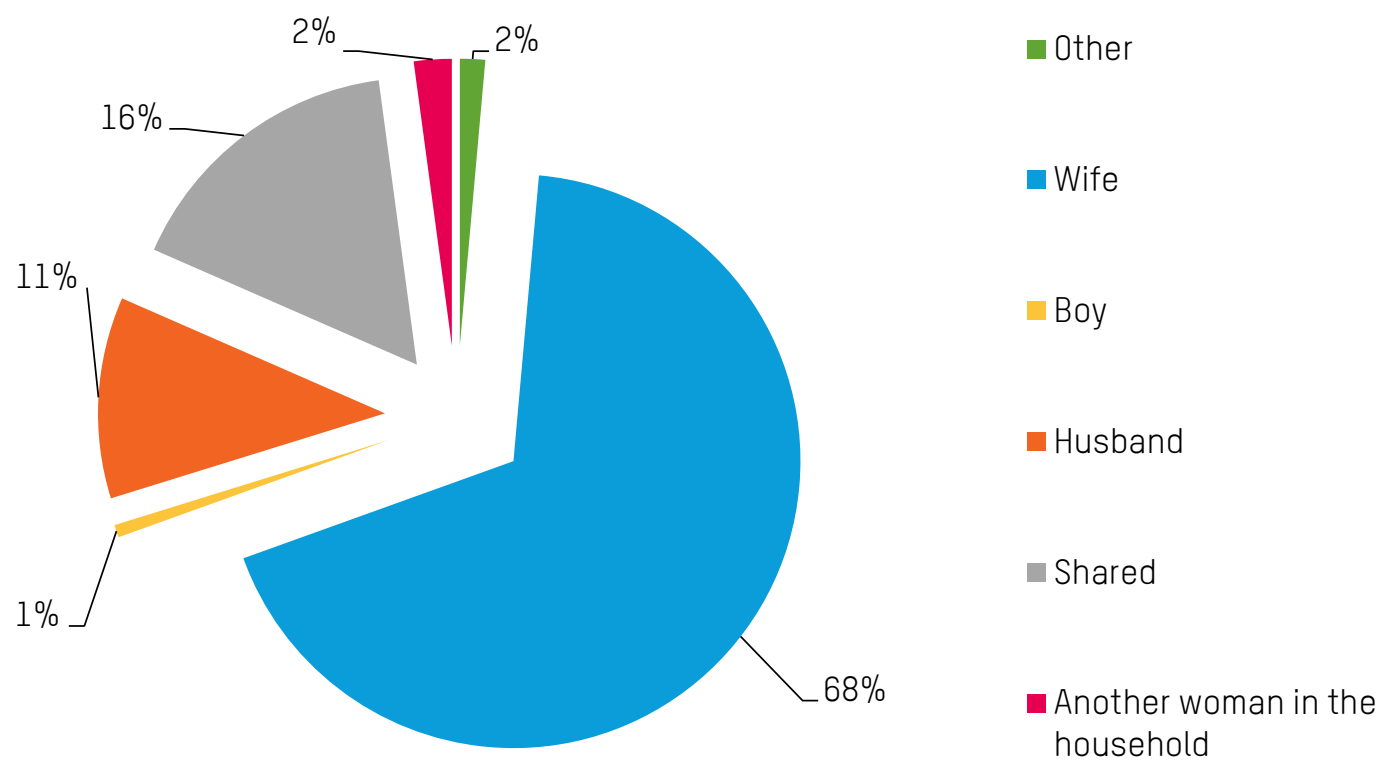

Figure 35: Family member who receives food aid on behalf of the household

While $53 \%$ of respondents said that men were responsible for managing food distribution, $41 \%$ said that it was women who made decisions about food distribution within the household. 


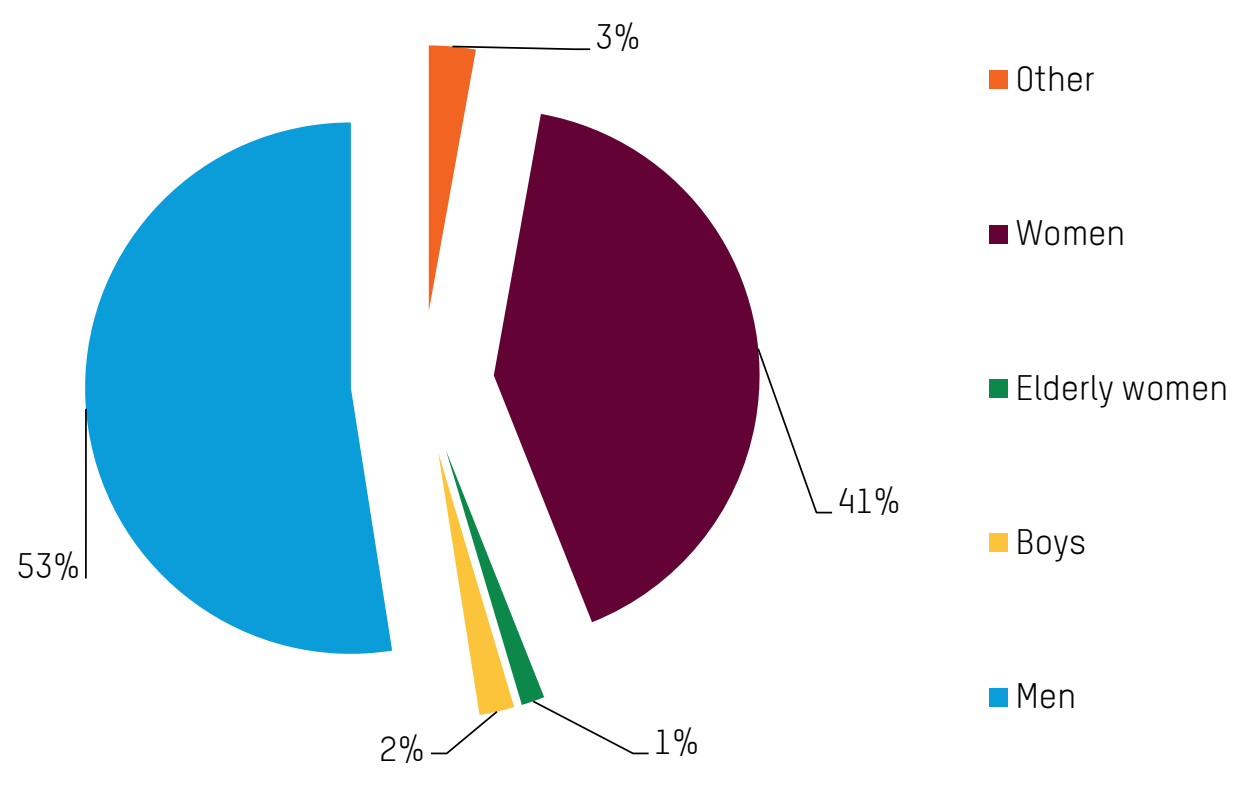

Figure 36: Family member responsible for managing food distribution within the household

The results of the survey also suggested some shared decision making: for example, both women and men can manage household assets and woman are also involved is some household decision making, particularly regarding children's education and the marriage of children.

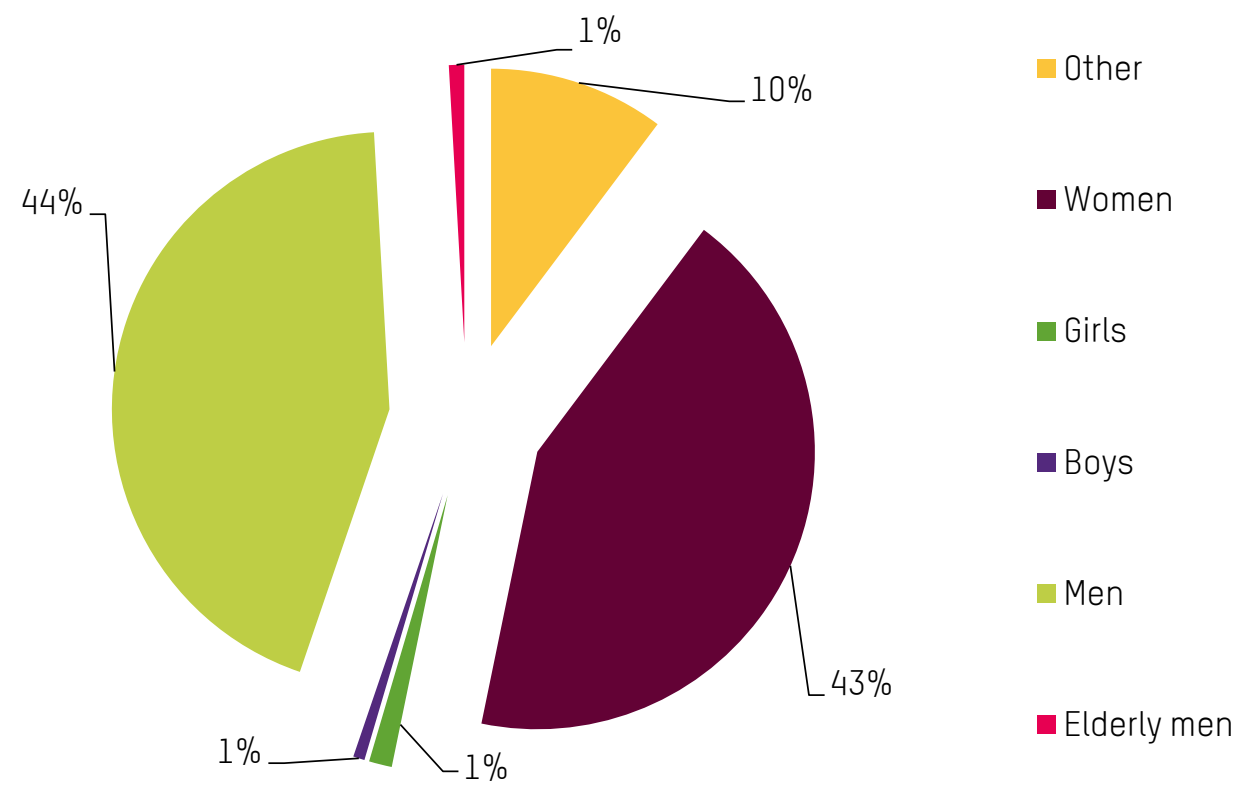

Figure 37: Family member who controls/owns/manages household assets (tools, fields, property) 

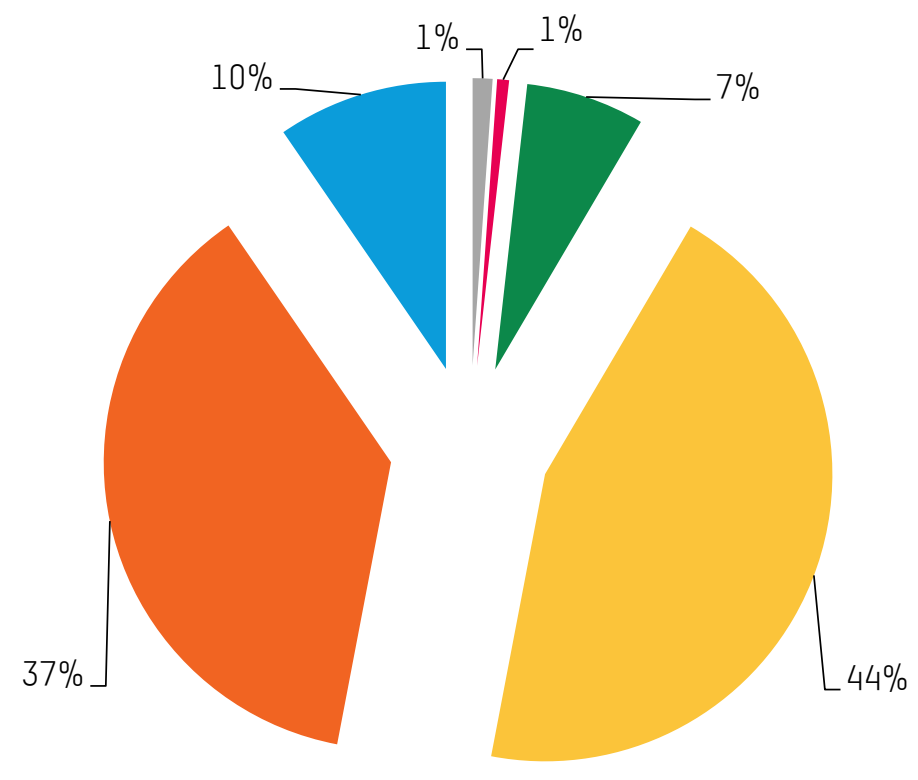

Another woman within

the family

- Another man within

the family

- Wives / mothers

Wife and husband

together

- Husbands / fathers

- Shared

Figure 38: Person responsible for deciding whether children should attend school

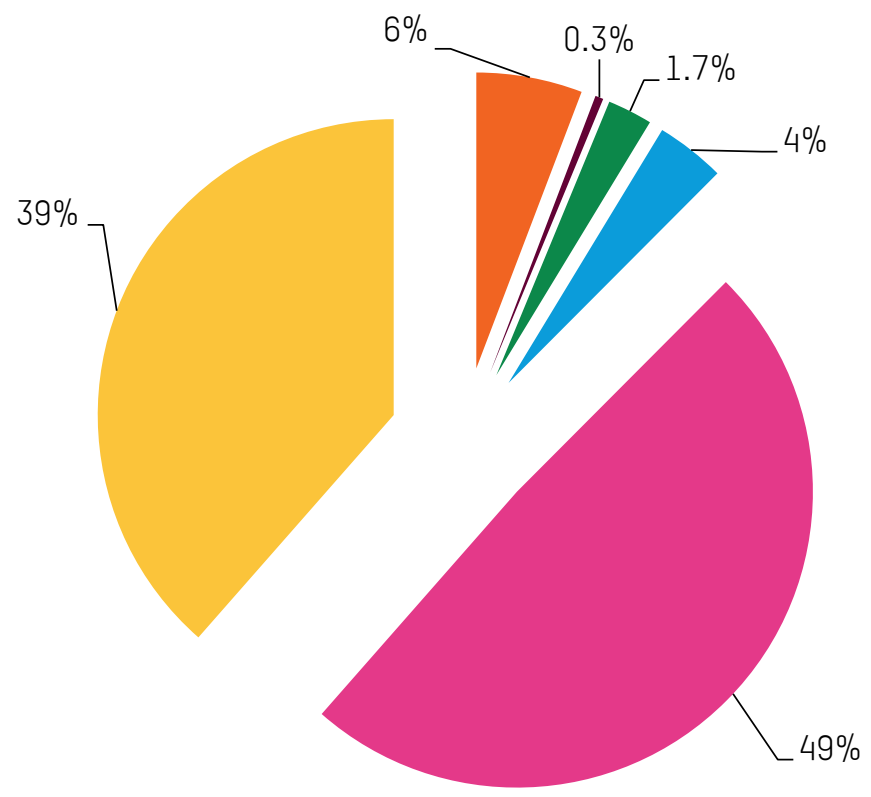
Another woman in the family

Another man in the family

- Children

Wives / mothers

- Husband and wife

together

- Husbands / fathers

\section{Figure 39: Person responsible for deciding on the marriage of children within the family}

Both male and female key informants and men taking part in FGDs reported that women's level of participation in household decision making was generally low, with all important decisions being taken by men, maintaining their status as the head of the household. One male FGD participant said, 'The man is the authority in his house'; 44 and another, 'Women have no decision-making power in our culture.' 45 Many of the key informants interviewed said that women were subordinated to men, and that they did not know their rights and therefore did not demand them. According to one female key informant, overall in Kasai men remain superior, ${ }^{46}$ due largely to strong customary laws.

However, since the crisis began women have taken economic charge of the family, and a very large number of women in the areas studied have taken up petty trading to make up for the loss of income. In households where women have taken charge of economic needs, they reported that they were involved in decisions on household expenses, schooling and marriage together with their husbands. One female FGD participant said that in households where both the husband and wife were educated they would decide together, while others also said that they participated in household decision making - 'At the moment, we are the ones deciding. ${ }^{47}$ This could 
indicate that household roles are dependent, or at least are influenced, by the levels of education and incomegenerating abilities of the women and men in the household.

\section{Participation in public decision making}

In general, women in the study areas are marginalized from decision making in both the public and private spheres, and they do not play a leading role in community decision making. Few female respondents were consulted on community decisions: answers disaggregated by sex indicated that only $26 \%$ of women were consulted on community decisions compared with $43 \%$ of men (Figures 40 and 41 ).

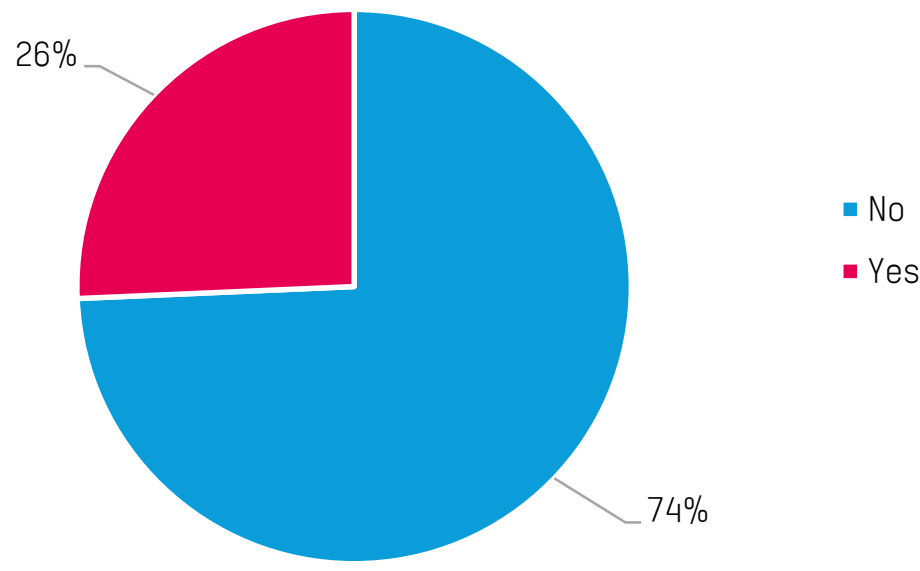

Figure 40: Consulted on community decisions (women respondents)

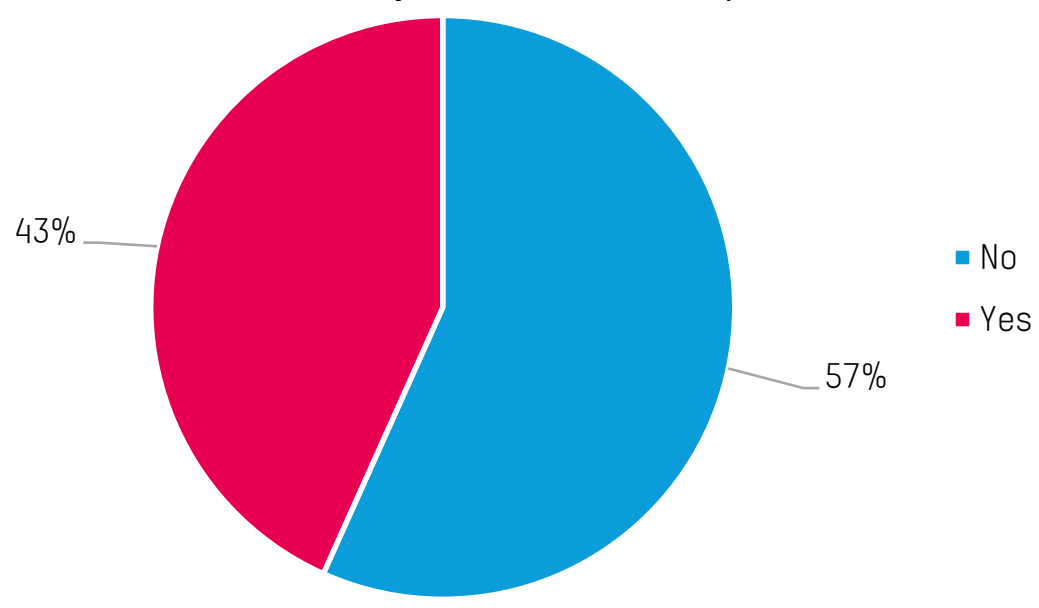

Figure 41: Consulted on community decisions (men respondents)

The FGDs confirmed that all public decision making was done by community leaders, the vast majority of whom are men, or by government leaders (also men), both before and after the crisis. The Division du Genre, Famille et Enfant provided no information on community leaders, but data collected through the FGDs and KIls indicated that it was the exception for a woman to be a community leader, with just one or two such cases reported, and usually in smaller communities. The Division du Genre, Famille et Enfant did provide data on leadership in government roles, which similarly are dominated by men. In Kasai province there are only three women directors in public government roles out of 65 such positions in total, one woman in the Bureau Urbain out of 46 such positions and one female director of government departments out of 10 such positions, and there are no women at all in leadership positions in the private sector.

The analysis identified various organizations, groups and committees, but only $37 \%$ of the survey respondents were part of such groups. Of those who were members, most were members of religious organizations (32\%) or community mutual aid groups (29\%). For respondents who were part of a group, $56 \%$ said that groups had continued to meet since the crisis began (Figure 42). This could be because, as mentioned by some male key informants, no meetings were allowed in the immediate aftermath of the crisis, as it was suspected that participants in such meetings could be colluding against the government. 


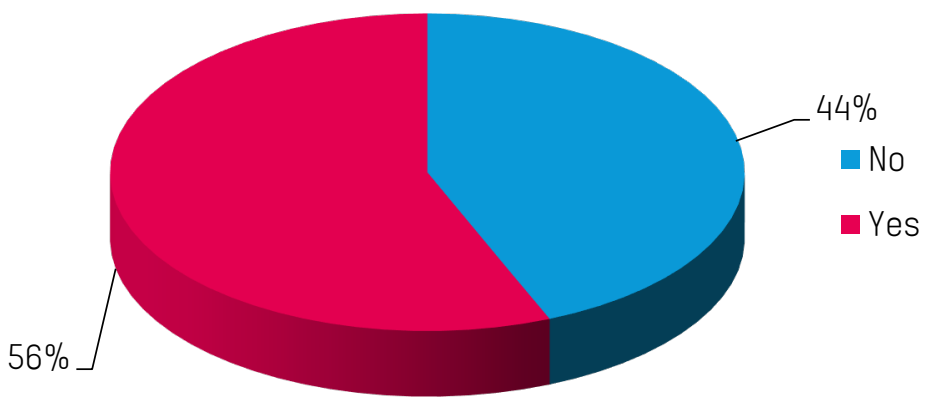

Figure 42: Group meetings organized since the beginning of the crisis

Significant challenges remain even for women who do participate in these meetings, with some FGD participants arguing that men do not want to work in meetings with intelligent women. A female key informant from a local NGO said that there were even some customs and some small religious groups that do not allow women to speak in front of men. Most key informants - both male and female - said that a large proportion of women do not know their rights and that there is a great need for sensitization on women's rights. Participants in an FGD for IDP boys aged 15-19 said that the crisis had resulted in the loss of women's groups and leaders as everyone had been displaced to different locations.

\section{Women's leadership}

Although women are marginalized, the analysis also identified female leaders. Some women's groups exist, such as an association for small traders working in the local market in Tshikapa, which is run by a female president and which organizes mutual aid support in cash. In addition, there are informal women's associations such as savings groups that help women in the community to start small businesses outside of the main markets, and these are similarly run by female presidents. Women's groups are also present within the larger religious groups Protestant, Catholic and Muslim - and they also have mutual cash support systems and organized leadership systems with presidents and treasurers.

Some of these women's groups have assisted IDPs with food, clothing or shelter and have worked hard to help other women in their communities, proving to be an effective mechanism in supporting vulnerable families. However, whether they are presidents of women's associations, religious groups or mutual aid groups, these female leaders with influencing abilities are confined to women-only groups. This indicates that female decision making is present and successful through women's groups, but it has yet to move into male-dominated spaces.

Most female leaders are educated women, and FGD participants gave examples such as female teachers or nurses as leaders in their communities. Most of them are likely to be from the Luba ethnic group, given their level of education, and likely already in leadership positions. Ordinary women members of informal or formal groups have few years of schooling in general. The president of the small traders' association, for example, said that most women in her group were illiterate.

\section{$6 \quad$ CHANGING GENDER DYNAMICS AND COPING STRATEGIES}

\section{Productive work and reproductive care activities}

Before the crisis, the majority of men and boys aged 15-19 worked in diamond-related activities, whether diamond extraction or in the many shops buying diamonds in the towns. As a result of the recent insecurity, men who were previously employed in the diamond sector are now unemployed and have found themselves badly affected by the crisis. In addition, much of their livestock has been killed, sold or stolen, leaving many men with no activity with which to occupy themselves. While women, men, boys and girls have all tried to find extra daily work to help their families, it appears that it has been easier for women to cope by starting up small trading activities. This could be because they are members of the many women's associations that offer a mutual aid system. Hence women have largely taken over economic responsibility for the family, especially in families most affected by the crisis, including IDPs and those in local village and town communities.

However, while women are now generating revenue for the family, it appears that men have retained their traditional role as the main decision makers on how income is utilized (as seen in Figure 34). One adult male 
participant in an FGD, however, argued that men felt that women were not sharing their income and that this created further tensions within the family. Although not noted directly in the FGDs, it is possible that men's perceived role as decision makers could come into conflict with the fact that women are now earning the family's income and this could potentially lead to domestic violence.

IDP men felt that they had lost their traditional role of head of household since they are no longer engaging in income-generating activities, they no longer have access to land or livestock and they can no longer support their children's education or health costs. In one FGD for male IDPs, participants said that, since they were no longer heads of household and women were bringing in the needed resources, they now spent their time at home, taking care of small children while women were out generating income.

As one male key informant put it, since there are limited jobs in Tshikapa, women are now 'the engine of the local economy' 48 and that 'without the women, men know they cannot do anything'. ${ }^{9}$ Women dominate all forms of petty trading in the province, and it is only women who sell food and non-food items in the markets, both formal and informal, large and small. However, women taking part in the FGDs felt that the crisis was overloading them; in addition to their petty trading activities, women also said that they bore most of the burden of housework.

\section{Coping strategies}

A number of coping strategies emerged from the data collected. In terms of protection, communities now avoid contact with the military and armed groups and always travel and work in the fields in a group. In terms of incomegenerating activities, they have taken to selling water and construction sand. They have also asked for support and assistance from members of their extended families in other areas of Kasai or DRC who are better off. In terms of health practices, a coping mechanism worth noting was mentioned in a number of both male and female FGD groups, whose members indicated that the community would pool resources and contribute money in order to send those who were sick to the health centre. However, participants in some FGDs, both male and female, also said that they were unable to cope with the difficulties caused by the current crisis in any way and that they were extremely vulnerable as a result. This indicates that these people have not managed to adopt any sustainable or positive coping strategies.

Negative coping strategies were also observed, with high rates of people begging, reducing their food intake or selling livestock for ready cash, thus depleting their resources further. Some of the worst coping strategies noted, in at least one each of the FGDs for men, women and adolescent boys and girls, as well as by some female key informants, were the prostitution of women and girls and minor girls being married off early. A few participants in FGDs for IDP boys aged 10-14 said that they had started stealing small items or food in order to survive.

\section{$7 \quad$ NEEDS}

Requests emerging from the household survey were overwhelmingly focused on income-generating activities, access to toilets and access to potable water. Again, the way that data were collected allowed for multiple responses to each question; $87 \%$ of all respondents chose the same three answers i.e. $87 \%$ wanted incomegenerating activities but also wanted access to toilets and potable water. 


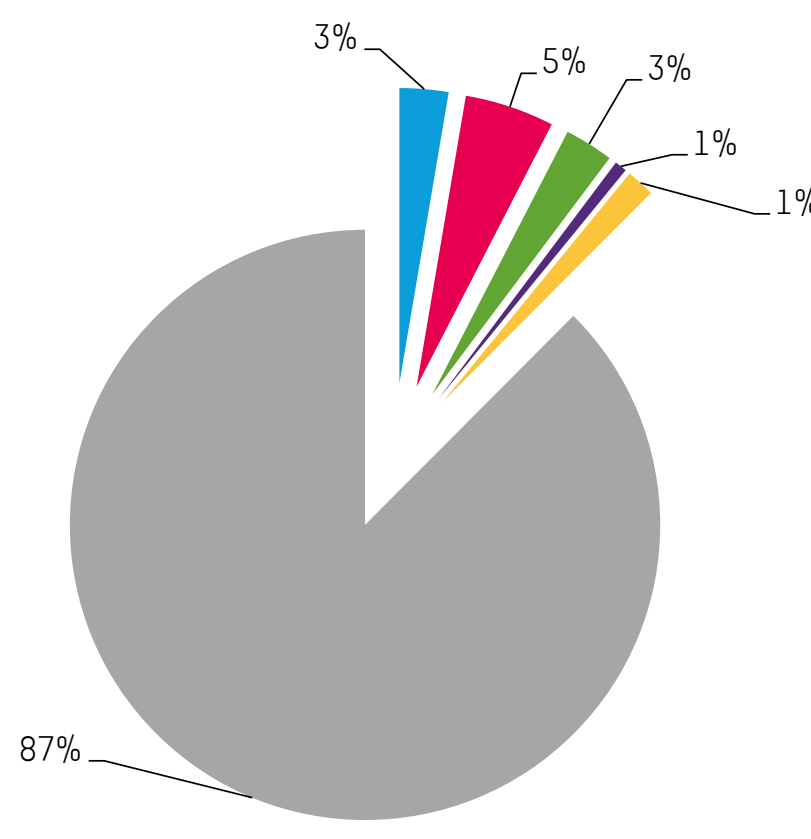

Access to health centres, livelihood opportunities and access to education

Livestock purchase and more access to markets

Livestock purchase, restoring community cohesion through awareness and more access to markets

Feminine hygiene items, more access to markets and education

Other

- Support income-generating activities, access to toilets and access to drinking water

\section{Figure 43: The type of support that you and your family need the most}

There were many different requests from the different FGDs in terms of population needs. In addition to access to food, water and free health services, participants requested the construction of homes (adult FGDs) and schools (children). Children also asked for their education to be free, and for clothing, school furniture and school essentials such as backpacks, books, pens and stationery. Requests were also voiced by both teenagers and adults for more vocational schools and for income-generating activities. Most adults also requested agricultural tools and seeds, in addition to food distributions. Peace, security and an end to aggression on the roads were among the most common requests made by groups of women, men, boys and girls alike. In terms of NFIs, the items most in demand were clothing, jerrycans, buckets and kitchen utensils.

\section{HUMANITARIAN RESPONSE}

International NGOs and the UN have had to scale up operations in DRC without sufficient funding for aid, which has meant a very delayed response. Most INGOs and UN agencies present in Kasai province arrived between June and September 2017; this left the community without adequate response for almost a year after the emergency started. Within the greater Kasai region, Kasai province is the least capable of responding to the crisis, with little interest shown in it by the government in Kinshasa and very few local NGOs. Furthermore, organizations that are working there and are familiar with the context of instability have no capacity when it comes to large-scale humanitarian interventions.

Coordination systems have been set up, but in October 2017 not all clusters were meeting regularly. Coordination between the many different humanitarian actors could be improved across the board, but particularly in terms of gender programming. The two local organizations working on women's rights ${ }^{50}$ need to be supported and engaged with more. They were the first responders, together with other local NGOs, and have been working on sensitization and supporting women survivors of GBV since well before the crisis began. However, like other local NGOs, they have massive funding gaps and limited capacity.

An important need observed during the analysis was support for the GBV working group, led by the Division Genre, Enfant et Famille and involving only local organizations at the time of the analysis. Most organizations are falling behind on integrating GBV prevention and risk mitigation into humanitarian response. There are very few organizations working directly on GBV, and local NGOs have limited capacity. Overall, interventions are inadequate 
for the overwhelming needs in the province and insufficient attention has been paid to the differing needs of women, men, boys and girls.

\section{$9 \quad$ CONCLUSION}

The gender analysis conducted in the five health zones of Kasai province shows that the crisis has exacerbated vulnerabilities in an already very poor province, leading to increased food insecurity and health risks and having further impacts on already poor livelihoods opportunities, WASH facilities and education levels. As in other crises, this has affected men, women, boys and girls in different ways. The gender analysis provides a clearer picture of these different needs and the roles of different groups, along with their access to and control of resources. Although the conflict has subsided for now, there are ongoing security risks for women, men, boys and girls, and the first conflict in decades to hit this area has created a very strong fear factor. There is a great need for humanitarian assistance, but the response is currently insufficient. Duty bearers will need to improve their responses to ensure that they target the different needs of all four groups. It is hoped that the recommendations set out below will inform the humanitarian programmes of Oxfam, its partners and other organizations, as well as the wider humanitarian response, on how to better take these needs into account.

\section{RECOMMENDATIONS}

\section{GENERAL RECOMMENDATIONS}

\section{For donors}

- Allocate financial resources for gender mainstreaming, GBV prevention and gendered response interventions, including integrated gender considerations and GBV and SEA prevention, into all humanitarian programmes.

- Allocate more funding overall for the response, particularly for emergency food security and livelihoods (EFSL).

\section{For INGOs}

- Ensure a coordinated approach between the government, the UN system and local, national and international NGOs to address food and water needs.

- Strengthen coordination, advocacy, sensitization and collaboration on gender, GBV and women's empowerment.

- $\quad$ Provide capacity building by relevant UN agencies for local NGOs and for the government in gender mainstreaming, gender-focused actions and GBV considerations.

- Prioritize gender-responsive actions, prevention of GBV and promotion of women's leadership.

- Support more women's rights organizations and women's groups as agents of change in communities and as leaders in establishing mechanisms for women's protection, participation and leadership, including province-wide sensitization on women's rights.

- Focus on both short-term and long-term needs to improve resilience and reduce dependency on aid.

\section{For INGOs and NGOs}

- $\quad$ Integrate gender considerations and GBV and SEA prevention into all humanitarian interventions.

- Implement initiatives that increase women's voice and participation in any humanitarian programming through training and capacity building targeted at women, sensitization for men and boys, building on existing women's groups, etc.

- Extend targeting practices to host communities and to female- and child-headed households.

- Introduce information, sensitization and awareness-raising initiatives on women's and girls' rights.

- $\quad$ Support and scale up women's mutual aid groups.

\section{Sector-specific recommendations in the immediate, medium and long terms}

\section{WASH response recommendations for all WASH actors}

- Engage women, girls, men and boys separately in the design of latrines and bathing spaces, including on locations and distance from dwellings.

- $\quad$ Ensure that the design of latrines includes safety measures such as locks on doors and sufficient distance for privacy. 
- Ensure that both women and men participate in the identification of safe and accessible sites for water pumps and sanitation facilities.

- Train women and men on the use and maintenance of facilities.

- Distribute female dignity kits to women and girls (these can include menstrual cloths, underwear, soap, flashlights).

- Involve boys and men in hygiene education and promotion programmes to relieve the burden on women and girls, and involve them in household activities through sensitization and by creating programmes targeted specifically at them.

- Increase the number of female community health volunteers and encourage equal male/female membership of all committees and the active participation of women. Ensure that committee meetings are held at convenient times and locations and that targeted support is provided to women, while men are engaged in order to sensitize them on women's needs.

- Ensure women's active participation and leadership in water committees and monitor their participation continuously.

- Distribute NFIs including jerrycans, clothes and kitchen utensils to all households, especially IDPs and host family households.

\section{EFSL response recommendations for all EFSL actors}

- Provide blanket distribution of food and seeds in all villages.

- Ensure that polygamous households receive more humanitarian assistance by targeting co-wives as heads of different households and the husband as an individual.

- Ensure registration for female-headed households, and distribute extra food items for infants, elderly people and pregnant and lactating women and girls. The selection of women beneficiaries must be justified and explained to men in order to reduce the threat of domestic violence for women.

- Ensure that food distribution sites are secure and accessible to everyone, and that distributions take place at an appropriate time and location.

- Provide targeted support for women's mutual aid groups, including access to grants for small businesses, and engage men and youth as direct participants in parallel livelihoods programmes and as supportive partners.

- Implement cash-for-food interventions, including for informal women's groups, and relieve the burden of women's reproductive responsibilities by incentivising men to undertake care work in return for cash..

- Create income-generating opportunities for men and youth (both girls and boys) to compensate for the loss of livelihoods and to prevent them from joining armed groups, taking criminal pathways or adopting negative coping mechanisms, as well as preventing any increase in domestic violence.

- Promote garden farming on household plots and provide tools and seeds, prioritizing female-headed and other most vulnerable households.

- Increase access to fields, either by advocating for improved security or supporting communities to find alternative fields in safer areas, and provide them with tools and seeds.

\section{Education response recommendations for all education actors}

- Improve existing schools in terms of infrastructure and by providing food distributions at school, along with school furniture and kits for students containing backpacks, books, pens and stationery.

- Create and build emergency primary and secondary schools in villages where schools have been burned or destroyed and include WASH facilities for boys and girls, proportionate to their numbers.

- Enhance school enrolment rates for girls by providing cash for education and other targeted interventions.

- Increase the number of trained female teachers in schools.

- Support the provision of literacy courses for women and girls.

- Offer vocational training courses to adolescent mothers.

- Child protection actors should offer empowerment programmes to help girls avoid early marriage by informing them of their basic rights and providing educational programmes on health and sex education.

- Child protection actors should also support young girls who have already married, providing them with a chance to complete or continue their education.

- Educate families to challenge stereotypes and attitudes that result in early marriage, emphasizing the contribution that educated girls can make to their families.

- Raise awareness among religious leaders and community leaders of the negative impacts of early marriage and polygamous relationships. 


\section{Health response recommendations for all health actors}

- $\quad$ Ensure free access to primary health services for the most vulnerable people, including IDPs and femaleheaded and single-parent households, and provide information in local languages to women and men about the health services available and their locations.

- Train traditional midwives.

- $\quad$ Regularly distribute dignity kits to girls and women and health kits containing medicines to treat preventable life-threatening diseases to households that are unable to access healthcare.

- Improve the sexual and reproductive health of girls and women through access to gynaecological treatment, and educate women, men, girls and boys on the prevention of pregnancy and culturally acceptable methods of contraception.

\section{Protection response recommendation for all protection actors}

- Ensure sensitization for all three ethnic groups - Luba, Tchokwe and Pende - on peaceful cohabitation.

\section{GBV}

- Advocate for free access to services, provide information to survivors about the intervention services available and direct them to appropriate services.

- $\quad$ Scale up existing GBV prevention and response structures, including psychosocial support, legal assistance and safe shelter for GBV survivors, and provide training for health and community-based service providers to listen and provide emotional support.

- Ensure that GBV interventions are mainstreamed throughout humanitarian actions.

- Protection actors should strengthen referral systems to support women, girls, boys and men who have been affected by GBV or who require psychosocial support, and ensure collaboration with other sectors to strengthen GBV prevention and risk mitigation across sectors, in alignment with the 2015 IASC Guidelines on GBV. ${ }^{51}$

- $\quad$ Provide training for all humanitarian staff on GBV/SEA.

- Ensure the sensitization of communities on GBV/SEA, using local languages.

- Adopt strategies for targeting, recruiting and organizing men and boys as champions for combating GBV and promoting women's rights.

- Advocate for better law enforcement in relation to polygamy and early marriage.

- Educate communities on constitutional rather than customary law.

\section{Women's leadership: recommendations for all actors}

- Ensure capacity building on gender equality and women's rights by engaging women, men, girls and boys.

- Ensure that spaces are created for women's leadership and representation at community level.

- Ensure that attention is paid to not overloading women, as they are already involved in both productive and care work, by engaging men and boys or providing cash for care work.

- Ensure capacity development on women's rights.

\section{References}

Agence Française de Développement (2016). Profil Genre République Démocratique du Congo.

Downloaded from https://www.afd.fr/fr/profil-genre-afrique

Al Jazeera (2017). US threatens sanctions on anyone delaying DR Congo vote. http://www.aljazeera.com/news/2017/07/threatens-sanctions-delaying-dr-congo-vote-170711214545803.html

Berwouts, K. (2017). Trench war: The factions that make up DR Congo's fragmented landscape. African Arguments. http://africanarguments.org/2017/06/15/the-factions-that-make-up-the-dr-congo-fragmented-politicalmosaic/

Clowes, W. (2017). Briefing: The conflict in Kasai, DRC. IRIN News. https://www.irinnews.org/analysis/2017/07/31/briefing-conflict-kasai-drc

Davis, L., P. Fabbri and I.M. Alphonse (2014). Profil du pays en matière d'égalité de genre RDC. https://www.lauradavis.eu/wp-content/uploads/2014/07/Profil-genre-2014-RDC.pdf 
de Freytas-Tamura, K. (2017). Who's in Congo's Mass Graves? And Why Are Soldiers Guarding Them? The New York Times, 28 July 2017. https://www.nytimes.com/2017/07/28/world/africa/congo-kasai-kabila-militia-graves.html

European Commission Directorate-General for European Civil Protection and Humanitarian Aid Operations (DG ECHO) (2017). Democratic Republic of Congo - Tanganyika province - IDPs (DG ECHO, UN OCHA) (ECHO Daily Flash of 7 June 2017). http://erccportal.jrc.ec.europa.eu/ECHO-Flash/ECHO-Flash-List/yy/2017/mm/6

FocusEconomics (2017). DR Congo Economic Outlook. https://www.focus-economics.com/countries/dr-congo Food and Agriculture Organization of the United Nations (FAO) (2016). The State of Food and Agriculture: Climate Change, Agriculture and Food Security. http://www.fao.org/publications/sofa/2016/en/

Food Security Cluster (2017). DR Congo: crisis in the provinces of Kasai, Central Kasaï, Eastern Kasaï, $n^{\circ}$ 1, May 2017. http://reliefweb.int/sites/reliefweb.int/files/resources/wfp292097.pdf

Global Protection Cluster, GBV Sub-Cluster (2017). Gender Based Violence Situation And Response In The Democratic Republic Of Congo (DRC): The Kasai Crisis.

http://www.globalprotectioncluster.org/ assets/files/field protection clusters/Democratic Republic Congo/fil es/gbvsc -update-on-kasai.en.pdf

Global Protection Cluster, GBV Sub-Cluster (2017). RD Congo: Evaluation de la situation et de la réponse aux violences basées sur le genre dans la crise du Kasaï (Kasaï Central, Kasaï Oriental et Kasaï). Mai--Août 2017 https://www.humanitarianresponse.info/system/files/documents/files/rapport_evaluation_sc_vbg_-_grandkasai vf.pdf

Human Rights Watch (2017). Democratic Republic of Congo in Crisis. https://www.hrw.org/blog-feed/democraticrepublic-congo-crisis

Human Rights Watch (2017). DR Congo: EU, US Sanction Top Officials. UN, AU Should Expand Action Against Rights Abusers, Press for Credible Elections. https://www.hrw.org/news/2017/06/01/dr-congo-eu-us-sanction-topofficials

Institut National de la Statistique (INS) et UNICEF (2011). Enquête par grappes à indicateurs multiples - RDC (2010): Résultats préliminaires. https://www.unicef.org/drcongo/french/MICS RDC 2010.pdf

Organisation for Economic Co-operation and Development (OECD) Development Centre, Social Institutions and Gender Index (SIGI) (2017). What is S/GI?http:/ /www.genderindex.org/

Oxfam (2017). Tshikapa Rapid Evaluation Report. June 2017.

Rolley, S. (2017). RDC: Violences au Kasai. Chapitre 3: Les Nations-Unies face à la crise. http://webdoc.rfi.fr/rdckasai-violences-crimes-kamuina-nsapu/chap-03/index.html

Schlein, L. (2017). UN: Destruction, Human Suffering Acute in DRC's Kasai Region. VOA News. https://www.voanews.com/a/democratic-republic-of-congo-kasai-region/4020788.html

UNICEF (2017). Education in the Greater Kasai: 150,000 children need emergency support. https://www.unicef.org/media/media_96397.html

UN News Centre (2017). DR Congo: UN report indicates Government participation in ethnic massacres in Kasai. http://www.un.org/apps/news/story.asp?NewsID=57309\#.WbfuS7KGPIU

UN News Centre (2017). DRC's Kasai region one of world's 'largest displacement crises' for children - UNICEF. http://www.un.org/apps/news/story.asp?NewsID=57281\#.Wbe177KGPIU

UN Office of the High Commissioner for Human Rights (OHCHR) (2017). DRC: Zeid calls for international investigation into massive human rights violations in Kasais.

http://ohchr.org/EN/NewsEvents/Pages/DisplayNews.aspx?NewsID=21714\&LangID=E\#sthash.BF2HTPUZ.dpuf

UN Office of the High Commissioner for Human Rights (OHCHR) (2017). DRC: Victims' harrowing accounts indicate Government complicity in ethnic-based massacres in Kasai - UN report.

http://www.ohchr.org/EN/NewsEvents/Pages/DisplayNews.aspx?NewsID=219378LangID=E

United Nations Development Programme (UNDP) (2016). Human Development Report 2016. Human Development for Everyone. Briefing note for countries on the 2016 Human Development Report: Congo (Democratic Republic of the). http://hdr.undp.org/sites/all/themes/hdr theme/country-notes/COD.pdf

United Nations Office for the Coordination of Humanitarian Affairs (UN OCHA) (2017). Flash Appeal.

https://reliefweb.int/sites/reliefweb.int/files/resources/2017_Flash_Appeal_DRC_fr_final26042017.pdf 
UN OCHA (2017). Complex Emergency in the Kasai region - DR Congo Situation Report No.7, 31 May 2017. https://reliefweb.int/report/democratic-republic-congo/complex-emergency-kasai-region-dr-congo-situationreport-no-7-31

UN OCHA (2017). West and Central Africa: Weekly Regional Humanitarian Snapshot (23-29 May 2017). http://reliefweb.int/sites/reliefweb.int/files/resources/External\%20Weekly\%2023\%20\%2029\%20May\%202017.pdf

UN OCHA (2017). DR Congo - Situation Report N'12: Complex Emergency in the Kasai Region (25 August 2017). https://www.humanitarianresponse.info/en/operations/democratic-republic-congo/document/dr-congosituation-report-n\%C2\%B012-complex-emergency-kasai

UN OCHA (2017). Urgence complexe dans la région du Kasaï, R.D. Congo. Rapport de situation No.14 len date du 23 octobre 2017). https://reliefweb.int/report/democratic-republic-congo/urgence-complexe-dans-la-r-gion-deskasa-rd-congo-rapport-de-7

UN OCHA (2017). Level 3 Response in the DRC Priority Requirements OCHA. source supplied direct by UN OCHA

UN OCHA (2015). Aperçu des besoins humanitaires 2016 - République démocratique du Congo. https://www.humanitarianresponse.info/fr/operations/democratic-republic-congo/document/rdcaper\%C3\%A7u-des-besoins-humanitaires-2016

UN OCHA (2016). Aperçu des besoins humanitaires 2017 - République démocratique du Congo. https://www.humanitarianresponse.info/en/operations/democratic-republic-congo/document/rdcaper\%C3\%A7u-des-besoins-humanitaires-2017

World Food Programme (2017). Kasai (DRC) emergency. http://www1.wfp.org/emergencies/kasai-emergency 


\section{Appendix 1: Key informant interviews}

\begin{tabular}{|c|c|c|}
\hline & Affiliation & Informant \\
\hline \multirow{9}{*}{ Local organizations } & $\begin{array}{l}\text { ADEDEFO (Association pour la Défense des } \\
\text { Droits des Enfants, des Femmes et des } \\
\text { Opprimés) }\end{array}$ & Philomène Muamba \\
\hline & DINAFET (Dynamique Femmes Travail) & Christine Mbalo \\
\hline & $\begin{array}{l}\text { CADEFA (Centre d'Appui au Développement } \\
\text { de la Femme en Action) }\end{array}$ & $\begin{array}{l}\text { Julienne Lombe (secretary- } \\
\text { accountant) } \\
\text { Martin Mbamba Njimbo lexecutive } \\
\text { secretaryl }\end{array}$ \\
\hline & $\begin{array}{l}\text { COPROMOR (Centre Oecuménique pour la } \\
\text { Promotion du Monde Rural) }\end{array}$ & Dieudonné Lovua Mujito \\
\hline & CARITAS Luebo & Dady Llunga \\
\hline & $\begin{array}{l}\text { AJID (Association des Jeunes Islamique pour } \\
\text { le Developpement) }\end{array}$ & Ismaël Mudada \\
\hline & AMOR (Association des Amis du Monde Rural) & Jean Ingomba \\
\hline & $\begin{array}{l}\text { CEMEA (Centre d'Entraide Médicale pour les } \\
\text { Enfants Abandonnés) }\end{array}$ & Louis Mbelapay Mondjoko \\
\hline & $\begin{array}{l}\text { CAJEM (Centre d'assistance judiciaire et } \\
\text { psychosociale mère et enfants) }\end{array}$ & $\begin{array}{l}\text { Kabedi Mbula Adele et Natalie } \\
\text { Elamenji (psychosocial } \\
\text { assistants) }\end{array}$ \\
\hline \multirow{2}{*}{$\begin{array}{l}\text { International } \\
\text { organizations }\end{array}$} & Médecins Sans Frontières (MSF) & Mario Lopez (therapist) \\
\hline & Handicap International & $\begin{array}{l}\text { Alice Repesse et Gaby Kasereka } \\
\text { (during a meeting on protection) }\end{array}$ \\
\hline \multirow{9}{*}{ Local leaders } & $\begin{array}{l}\text { Les mamans musulmanes (Muslim women's } \\
\text { group) }\end{array}$ & $\begin{array}{l}\text { Bangoula Sauda (president) } \\
\text { Chabu Alima (secretary) }\end{array}$ \\
\hline & $\begin{array}{l}\text { Fédération des Mamans Mennonites } \\
\text { (Menonite women's group) }\end{array}$ & Adolphine Tshiama (president) \\
\hline & $\begin{array}{l}\text { Leaders des associations de femmes } \\
\text { Shimbi Ja Pwo = La parole de la femme }\end{array}$ & $\begin{array}{l}\text { Damienne Musenu Ngalula } \\
\text { (president) }\end{array}$ \\
\hline & $\begin{array}{l}\text { AMACO (Association mamans commerçantes } \\
\text { du Congo) - local women's commerce group }\end{array}$ & $\begin{array}{l}\text { Valeriane Mutata Buloba } \\
\text { (president) }\end{array}$ \\
\hline & $\begin{array}{l}\text { Ecole Technique Industrielle et Profesionelle } \\
\text { Maman Olive - Lembe }\end{array}$ & Nkanku Remys (CEO) \\
\hline & High School for Girls of Tshikapa & Prefect/Sister Elizabeth Mbuyi \\
\hline & St Antoine Catholic Church & $\begin{array}{l}\text { Abeleon Kalambayi Nsumbu } \\
\text { (priest) }\end{array}$ \\
\hline & Kanzala Hospital & Marie Jose Muema (nurse) \\
\hline & Tshikapa Hospital & Josephine Mubanda Kileza (nurse) \\
\hline Government & $\begin{array}{l}\text { Ministère des Affaires Humanitaires et } \\
\text { Ministère de Genre, Famille et Enfant }\end{array}$ & Tchoko Kwete (minister) \\
\hline
\end{tabular}




\begin{tabular}{|c|c|c|}
\hline & $\begin{array}{l}\text { (Ministry of Humanitarian Affairs and Ministry } \\
\text { of Gender, Family and Children) }\end{array}$ & \\
\hline & Prosecutor & Yanyi Ya Mukanga Francois \\
\hline & $\begin{array}{l}\text { Division des Affaires Sociales (Social Affairs } \\
\text { Division) }\end{array}$ & Martin Kabongo (head of office) \\
\hline & $\begin{array}{l}\text { Division du Genre, Enfant et Famille (Ministry } \\
\text { of Gender, Family Affairs and Children) }\end{array}$ & Davidson Kayembe (head of office) \\
\hline & $\begin{array}{l}\text { Division d'Enseignement Primaire, } \\
\text { Secondaire et Professionnelle (Division of } \\
\text { Primary, Secondary and Professional } \\
\text { Education) }\end{array}$ & $\begin{array}{l}\text { Wivine Mudenkoko Yimbu (head of } \\
\text { office) (during a meeting on data } \\
\text { on education) }\end{array}$ \\
\hline \multirow{3}{*}{ United Nations } & UNHCR & $\begin{array}{l}\text { Denis Oulai (Protection Cluster } \\
\text { coordinator) }\end{array}$ \\
\hline & $\overline{\mathrm{OCHA}}$ & $\begin{array}{l}\text { Watts Munang James (head of } \\
\text { office) }\end{array}$ \\
\hline & UNICEF & $\begin{array}{l}\text { Ibrahima Diarra (child protection } \\
\text { specialist) } \\
\text { Paul Luyinu (education officer and } \\
\text { lead for Education Cluster) }\end{array}$ \\
\hline \multirow{6}{*}{ Oxfam } & \multicolumn{2}{|c|}{ Ingrid Kamikazi (Humanitarian Support Personnel - Capacity Development) } \\
\hline & \multicolumn{2}{|l|}{ Morris Kolubah (Programme Manager) } \\
\hline & \multicolumn{2}{|l|}{ Constant Mboka Ngele (EFSL Specialist) } \\
\hline & \multicolumn{2}{|l|}{ Evariste Mulumba (HR and Admin Officer) } \\
\hline & \multicolumn{2}{|c|}{ Modeste Mirindi (Humanitarian Support Personnel - WASH Coordinator) } \\
\hline & \multicolumn{2}{|l|}{ Evariste Kimba (Protection Officer) } \\
\hline
\end{tabular}

\section{Endnotes}

1 While OXFAM does not work on this issue, the breadth of information gathered and analysed must be shared and the recommendations will hopefully be useful for education actors.

2 While OXFAM does not work on this issue, the breadth of information gathered and analysed must be shared and the recommendations will hopefully be useful for health actors.

3 IASC (2015). Guidelines for Integrating Gender-Based Violence Interventions in Humanitarian Action: Reducing risk, promoting resilience and aiding recovery. https://gbvguidelines.org/wp/wp-content/uploads/2015/09/2015-IASCGender-based-Violence-Guidelines lo-res.pdf

4 UN OCHA (2017). Democratic Republic of the Congo: Key figures. Humanitarian Update 2018 and Priority Requirements $L 3$. http://www.unocha.org/drc

5 http://www.wipo.int/edocs/lexdocs/laws/fr/cd/cd00lfr.pdf

6 Mo Ibrahim Foundation (2017). 2017 Ibrahim Index of African Governance: Index Report. http://s.mo.ibrahim.foundation/u/2017/11/21165610/2017-IIAGReport.pdf? ga=2.34450337.1882450301.1511331614-1858539648.1511155962

7 Inter-Parliamentary Union (IPU) (2017). Women in national parliaments. http://archive.ipu.org/wmn-e/classif.htm 
8 Government of DRC, US Agency for International Development (2014). Democratic Republic of Congo Demographic and Health Survey 2013-14: Key findings. https://dhsprogram.com/pubs/pdf/SR218/SR218.e.pdf

9 United Nations Development Programme (UNDP). Human Development Reports. Democratic Republic of the Congo: Human Development Indicators (consulted 28 September 2017). http://hdr.undp.org/en/countries/profiles/COD

10 Agence Congolaise de Presse (2016). La féminisation de la pauvreté en RDC s'explique par la montée de la discrimination. http://acpcongo.com/acp/la-feminisation-de-la-pauvrete-en-rdc-sexplique-par-la-montee-de-ladiscrimination/

11 Government of DRC, USAID (2014). Deuxième enquête démographique et de santé (EDS-RDC // 20132014).http://reliefweb.int/sites/reliefweb.int/files/resources/FR300 0.pdf

12 World Bank. Ratio filles/garcons des inscriptions au secondaire (\%). https://donnees.banquemondiale.org/indicator/SE.ENR.SECO.FM.ZS?locations=CD\&view=chart; https://data.worldbank.org/indicator/SE.ENR.PRSC.FM.ZS

13 Radio Okapi (2014). RDC: les multiples affectations des frais scolaires. https:// www.radiookapi.net/actualite/2014/09/09/rdc-les-multiples-destinations-prennent-les-frais-scolaires

14 Government of DRC, USAID (2014). Deuxième enquête démographique et de santé (EDS-RDC // 2013-2014), op. cit.

15 Both are as quoted in Aperçu des besoins humanitaires 2017 - République démocratique du Congo. United Nations Office for the Coordination of Humanitarian Affairs (OCHA), December 2016. https://www.humanitarianresponse.info/system/files/documents/files/drc hno 2017 1.pdf

16 Albutt, K., J. Kabanga, and M. VanRooyen. Stigmatisation and rejection of survivors of sexual violence in eastern Democratic Republic of the Congo. Disasters, 30 May 2016.

17 International Men and Gender Equality Survey (2014). Gender Relations, Sexual and Gender-Based Violence and the Effects of Conflict on Women and Men in North Kivu, Eastern Democratic Republic of the Congo. https://promundoglobal.org/wp-content/uploads/2014/12/Gender-Relations-Sexual-and-Gender-Based-Violenceand-the-Effects-of-Conflict-on-Women-and-Men-in-North-Kivu-Eastern-DRC-Results-from-IMAGES.pdf; W. Storr (2011). The rape of men: the darkest secret of war. The Guardian/Observer. https:// www.theguardian.com/society/2011/jul/17/the-rape-of-men; BBC News (2017). 'We need to talk about male rape': DR Congo survivor speaks out. http://www.bbc.co.uk/news/world-africa-40801782

18 OHCHR (2017). Report of a Mission of the United Nations High Commissioner for Human Rights - accounts of Congolese fleeing the crisis in the Kasai region, in the Democratic Republic of the Congo. http://www.ohchr.org/EN/Countries/AfricaRegion/Pages/CDReports.aspx

19 OCHA (2017). Urgence complexe dans la région des Kasaï, R.D. Congo. Rapport de situation no.14. https://reliefweb.int/report/democratic-republic-congo/urgence-complexe-dans-la-r-gion-des-kasa-rd-congorapport-de-7

20 Agriculture provides 75\% of Kasai region's food income, according to Oxfam's needs assessment (May 2017).

21 Government of DRC (2014). Democratic Republic of Congo Demographic and Health Survey 2013-14: Key findings, op. cit.

22 Demographic information and estimates of IDP numbers were provided directly to the field team by local government representatives

23 The other 9\% were not categorized by the enumerators, as they spoke either French or Lingala.

24 UN OCHA (2017). Democratic Republic of the Congo: Key figures, first page of http://www.unocha.org/drc

25 World Food Programme (2017). Kasai (DRC) emergency. http://www1.wfp.org/emergencies/kasai-emergency

26 'Une adaptation sauvage, par exemple deux mangues par jour.'

27 With the answer options being: al wife/woman; b) husband/man.

28 'L'homme ne donne pas l'argent a toutes les familles également, pour la plupart des cas c'est que la dernière femme.'

29 'Les hommes au Kasaï utilise la polygamie pour utiliser les femmes comme unité de production.'

30 'll n'y a que des menaces.'

31 'Les femmes et les filles sont plus exposées au risque pour la sécurité associe à la distance, beaucoup des risques à cause de la distance.'

32 'Tout est limité à cause de la destruction et la crainte d'être violé en route seule.'

33 'Les enfants qui était dans des milices (filles et garçons) ont besoin d'un appui psychosocial à cause de l'enlèvement par force, et toutes les autre choses qu'ils ont vu ou fait, et même moi pour ce que j'ai entendu.'

34 'Les hommes ont perdu leur pouvoir en tant que hommes.' 
35 'Oui, nos maries préfère éduquer les garçons que les filles, sur 100\% d’un ménage la scolarisation des filles représente $10 \%$ '.

36 GBV Sub-Cluster (2017). Rapport d'evaluations sur les violences basées sur le genre (VBG) dans le crise de la region de Kasaï. https://www.humanitarianresponse.info/system/files/documents/files/rapport evaluation sc vbg grand-kasai vf.pdf

37 Project Femme au Fone (2014). Un Silence Coupable: Les violences domestiques à l'égard des femmes en République Démocratique du Congo. http://deboutcongolaises.org/wpcontent/uploads/2017/04/violences domestiques rdc -Rapport-FemmAuFone.pdf

38 Data collection for this study allowed multiple-choice answers to some questions, giving respondents the option to choose several different answers (for this question, the top perceived risks). This meant that some risks were repeated - with, for example, harassment and domestic violence appearing in two different areas of the pie chart.

39 The FGDs did not yield details of what type of security threats occurred.

40 'Actuellement ils se font sans pudeur, sans être inquiète.'

41 'Avec la crise, les hommes enlèvent la fille de force et on l'ammene a la maison pour le mariage, inclus les femmes déjà mariées avec ses enfants.'

42 'Ca c'est l'esclavage sexuel.'

43 'L'homme décide sur les fréquentations des enfants à l'école, sur le mariage des enfants; seulement l'homme, pas la femme. Meme d'autres problèmes toujours lui, pas la femme.'

44 'L'homme est l'autorité dans sa maison.'

45 'Les femmes n'ont aucun pouvoir de décision dans notre culture.'

46 'Dans le Kasai - l'homme reste supérieur.'

47 'Actuellement c'est nous qui décidons.'

48 'll n'y a pas d'emploi à Tshikapa, les femmes sont le moteur de l'économie.'

49 'Sur le plan économique les hommes savent que sans la femme, ils (ne) peuvent rien.'

50 CAJEM and ADEDEFO.

51 IASC (2015). Guidelines for Integrating Gender-Based Violence Interventions in Humanitarian Action, op. cit. 
